Marcos Antonio de Andrade

\title{
Propriedades Elásticas de Nanotubos de Carbono Utilizando Métodos Clássicos
}

\author{
Brasília
}


Marcos Antonio de Andrade

\title{
Propriedades Elásticas de Nanotubos de Carbono Utilizando Métodos Clássicos
}

\begin{abstract}
Dissertação apresentada como requisito parcial para obtenção do grau de Mestre em Ciência de Materiais pelo Programa de Pós-Graduação em Ciência de Materiais da Faculdade UnB Planaltina da Universidade de Brasília.
\end{abstract}

Universidade de Brasília

Faculdade UnB Planaltina

Programa de Pós-Graduação em Ciência de Materiais

Orientador: Prof. Dr. David Lima Azevedo

Brasília

30 de agosto de 2016 
Ficha catalográfica elaborada automaticamente, com os dados fornecidos pelo(a) autor(a)

\section{ANTONIO DE ANDRADE, MARCOS}

AD282p PROPRIEDADES ELÁSTICAS DE NANOTUBOS DE CARBONO UTILIZANDO MÉTODOS CLÁSSICOS / MARCOS ANTONIO DE ANDRADE; orientador DAVID LIMA AZEVEDo. -- Brasilia, 2016. $89 \mathrm{p}$.

Dissertaçāo (Mestrado - Mestrado em Ciencia de Materiais) -- Universidade de Brasilia, 2016.

1. O CARBONO. 2. FUlerenos. 3. NanOtubos DE CARBONO. 4. ENCAPSULAMENTO DE NANOTUBOS DE CARBONO. 5. ENCAPSULAMENTO DE FULERENOS EM NANOTUBOS DE CARBONO. I. LIMA AZEVEDO, DAVID, orient. II. Título. 
Marcos Antonio de Andrade

\section{Propriedades Elásticas de Nanotubos de Carbono Utilizando Métodos Clássicos}

Dissertação apresentada como requisito parcial para obtenção do grau de Mestre em Ciência de Materiais pelo Programa de Pós-Graduação em Ciência de Materiais da Faculdade UnB Planaltina da Universidade de Brasília.

Trabalho aprovado. Brasília, 30 de agosto de 2016:

Prof. Dr. David Lima Azevedo

Orientador

Professor

Convidado 1

Professor

Convidado 2

Brasília

30 de agosto de 2016 
Dedico este trabalho a minha esposa, aos meus filhos e a meus pais 


\section{Agradecimentos}

Gostaria de agradecer a minha esposa por estar sempre me incentivando ao estudos; aos meus filhos por compreenderem a minha falta de presença quando tive que estudar e não estar ao lado deles; aos meus pais por ter-me dado uma boa educação; ao meu amigo Wilson Miranda por me orientar na confecção do texto e ao meu professor orientador David L. Azevedo por ter me ajudado com tanta paciência. 
"Eu tentei 99 vezes e falhei, mas na centésima tentativa eu consegui, nunca desista dos seus objetivos mesmo que esses pareçam impossíveis, a próxima tentativa pode ser a vitoriosa."

Albert Einsten (1879-1955) 


\section{Resumo}

Neste trabalho, a fim de encontrar condições de encapsulamento em nanotubos, realizamos várias simulações utilizando o programa Materials Studio, com nanotubos de carbono tipo amchair e zig-zag, com ênfase no primeiro tipo, com vistas a ocorrência de encapsulamento destes nanotubos uns dentro dos outros. Conseguimos encontrar alguns parâmetros que levam ao encapsulamento dos nanotubos. E para obtenção de propriedades elásticas de nanotubos de parede simples, nanotubos simples com fulerenos, utilizamos dinâmica clássica. Quando possível comparamos os resultados obtidos pelo presente trabalho com os publicados em artigos da área, tanto experimentais quanto teóricos. Dentre as diversas metodologias clássicas e quânticas levantadas pela pesquisa, selecionamos duas que possibilitaram a obtenção do módulo de elasticidade de forma simples e rápida com a vantagem de apresentar um bom acordo com resultados experimentais. Além disso, com base na confiabilidade dos resultados obtidos para nanotubos de paredes simples, nós fizemos ensaios de obtenção do módulo de elasticidade para casos ainda não publicados, que sejam, nanotubos preenchidos com fulerenos. Os módulos de elasticidades destes sistemas para o caso de fulerenos encapsulados em nanotubos de parede simples, pelo método da segunda derivada da strain energy, se manteve constante, enquanto que utilizando dinâmica clássica, houve uma diminuição do módulo de elasticidade.

Palavras-chaves: nanotubos de carbono, encapsulamento e módulos de elasticidade. 


\section{Abstract}

In this project, in order to study the conditions of nanotubes encapsulation, we realized some simulations using the Materials Studio software, with type armchair and zig zag carbon nanotubes, giving emphasys in the first type, we tried to find conditions for the encapsulation of those nanotubes with each other to happen. We could find some parameters wich cause this encapsulation. For the analisys of elastic properties of simple and double wall nanotubes, simple nanotubes with fullerenes and double wall nanotubes with fullerenes, we utilized classic dynamics. When possible, we compared the results registereds in the project with those published in articles on the area of study, both experimental and theorical. Among several classic and quantic methodologies, we selected two that made possible the obtainment of the elasticity module in a simple and fast way, with the advantage of showing good experimental results. In addition, based on the reliability of the results obtained for simple walls nanotubes, we made rehearsals for the obtainment of the elasticity module for cases not yet published, in that case, nanotbues filled with fullerenes and double wall nanotubes. The elasticity modules of these systems for the fullerenes encapsulated in simple wall nanotubes case, by the method of second derivative of the "strain energy" was constant, while using classic dynamics, there was a decrease in the elasticity module.

Keywords: Carbon nanotubes, encapsulation, elasticity modules. 


\section{Lista de ilustrações}

Figura 1 - Forma alotrópica do carbono: folha de grafeno. . . . . . . . . . . 21

Figura 2 - Formas alotrópicas do carbono: a)diamante b)grafite c)londasleite d-f)fulerenos $\left(C_{6} 0, C_{5} 40, C_{7} 0\right)$ g)carbono amorfo h)nonotubos . . . . 22

Figura 3 - a) Fulereno $C_{60}$ b) Comparação com a bola de futebol . . . . . . 24

Figura 4 - (a) Fulereno $C_{60}$ encapsulado no nanotubo $(10,10)$, (b) Fulerenos $C_{70}$ (superior) e $C_{78}$ (em baixo) encapsulados em nanotubos $(10,10)$, (c) fulerenos $C_{70}$ (superior) e $C_{78}$ (em baixo) encapsulados em nanotubos $(11,11) \cdot d_{C_{60}}$ representa a distância intermolecular centro-a-centro do fulerenos $C_{60}$-fonte Karla at al. . . . . . . . . . . . . . . . .

Figura 5 - Construção do Fulereno $C_{60}$. À esquerda: parte da folha de grafeno com pentágonos e hexágonos; à direita: fulereno já formado . . . . . 26

Figura 6 - Estrutura do nanotubo de carbono antes de enrolar . . . . . . . 28

Figura 7 - Folha de grafeno do nanotubo tipo misto . . . . . . . . . . . 29

Figura 8 - Classificação dos nanotubos de acordo com o seu enrolamento, (a) armchair, (b) zig-zag e (c) misto . . . . . . . . . . . . . . . . . . 29

Figura 9 - (a) Representação da estrutura de banda de energia eletrônica para um material sólido; (b) A energia eletrônica para um agregado de átomos. . . . . . . . . . . . . . . . . . . 30

Figura 10 - (a) Rede hexagonal da folha de grafeno. A célula unitária está definida por $a_{1}$ e $a_{2}$. (b) Rede reciproca (pontilhada) com os vetores $b_{1}$ e $b_{2}$ em correspondência à rede real definida por $a_{1}$ e $a_{2}$.A primeira zona de Brillouin se encontra desenhada em cinza escuro e a segunda em cinza claro. Entre dois pontos K's existem os pontos M.

Figura 11 - Painel esquerdo: Relação de dispersão de energia do grafeno 2D através de toda a zona de Brillouin; Painel Direito: dispersão da energia ao longo das direção de alta simetria do triângulo $\Gamma M K$. . .

Figura 12 - (Acima) estrutura de banda de ligação forte do grafeno (um único plano basal grafite). (Inferior) estimação dos vetores $k$ dos $\operatorname{SWNT}(7,1)$ e SWNT $(8,0)$ (linhas sólidas) mapeada na zona de Brillouin do grafite. 32

Figura 13 - Estrutura de bandas para nanotubos de carbono do tipo: (a) armchair

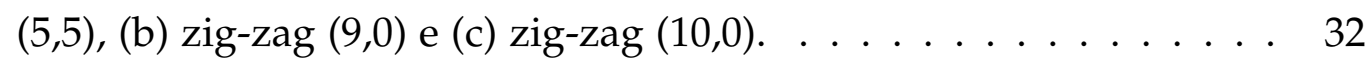

Figura 14 - Obtenção de nanotubos de carbono pelo método CVD . . . . . . . . 35

Figura 15 - À esquerda o material está sendo alongado e à direita está sendo comprimido. As linhas pontilhadas mostram o material antes da deformação- fonte Callister . . . . . . . . . . . . . . . . 36 
Figura 16 - Representação esquemática do aparelho usado para conduzir testes elásticos de tensão-deformação. A amostra de material é alongada pela cruzeta em movimento; uma célula de carga mede força $F$ aplicada e o extensômetro mede o alongamento da amostra- fonte Callister. . . . . . . . . . . . . . . . . .

Figura 17 - À esquerda o material está sob deformação de cisalhamento e à direita está sob torção quando é aplicado um torque T. E $\phi$ é o ângulo de torção. As linhas pontilhadas mostram o material antes da deformação- fonte Callister. . . . . . . . . . . . . . . . . .

Figura 18 - Alongamento axial(z) (deformação positiva) e contrações laterais (x e y) (deformação negativa) na direção $\mathrm{z}$ em resposta a uma tensão de tração imposta. As linhas contínuas representam dimensões depois da aplicação tensão; as linhas tracejadas representam as dimensões antes da aplicação da tensão- fonte: Callister. . . . . . . . . . . . . . .

Figura 19 - Energia de deformação (eV por átomo de carbono) vs uniforme esforço de tensão na direção do eixo tubular para o tubo $[5,5]$ usando potenciais empíricos EP1 (círculos abertos), EP2 (losangos abertos), e o método LDF (quadrados a cheio) calculados por Robertson et al . 40

Figura 20 - Segunda derivadas numéricas de energia por carbono no que diz respeito à deformação uniforme ao longo da direção do eixo do tubo para potenciais EP1 e EP2 calculados por Robertson et al . . . . . . .

Figura 21 - Energia de deformação de curvatura em função do diâmetro do tubo de equilíbrio, tal como obtida a partir de cálculos tight-binding para nanotubos, para $\mathrm{C}$, $\mathrm{BN}$ e $B C_{3}$-E. Hernández et al. . . . . . . . . . 44

Figura 22 - Micrografias de vibração de nanotubos simples no campo de vibração TEM . Inserido em cada micrografia é a imagem simulada que corresponde aos melhores mínimos quadrados após o ajuste para o comprimento $\mathrm{L}$ nanotubo livre $\mathrm{L}$ e ponta amplitude de vibração $\sigma$. As marcas em cada micrografia indicar a secção da haste nanotubo que foi montado-A. Krishnan et al. . . . . . . . . . . . . . . 45

Figura 23 - Curva do Potencial Morse . . . . . . . . . . . . . . . . . . . . . 51

Figura 24 - Comparação da curva da Lei de Hooke com as Curvas quadrática e

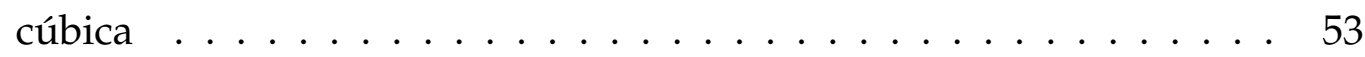

Figura 25 - Ângulos de Flexão . . . . . . . . . . . . . . . . . . . 54

Figura 26 - Potenciais torcionais mostrados para valores diferentes de $V_{n}$, n e $\gamma .55$

Figura 27 - Ângulos de Torção . . . . . . . . . . . . . . . . . . 56

Figura 28 - Termos Cruzados . . . . . . . . . . . . . . . . . . 57

Figura 29 - Interação energética e a força entre dois átomos . . . . . . . . . . . 59

Figura 30 - O potencial de Lennard Jones . . . . . . . . . . . . . . . . . . . 59 
Figura 31 - Encapsulamento do SWNT(8,8) no SWNT(13,13)-quadro $01 \ldots 65$

Figura 32 - Encapsulamento do $\operatorname{SWNT}(8,8)$ no $\operatorname{SWNT}(13,13)$-quadro $84 \ldots 65$

Figura 33 - Encapsulamento do SWNT(8,8) no SWNT(13,13)-quadro 113 . . . . 65

Figura 34 - Encapsulamento de fulereno $C_{60}$ em SWNT-quadro $01 \ldots$. . . . . . 66

Figura 35 - Encapsulamento de fulereno $C_{60}$ em SWNT-quadro 320 . . . . . . . 67

Figura 36 - Encapsulamento de fulereno $C_{60}$ em SWNT-quadro 495 . . . . . . . 67

Figura $37-4$ fulereno $C_{60}$ encapsulados em $\operatorname{SWNT}(10,10)$, distanciados $3.5 \AA$ um do outro . . . . . . . . . . . . . . . . 67 67

Figura 38 - a) Gráfico do Potencial da borda da parede percebido pelo fulereno $C_{60}$ à distância de aproximadamente $2 \AA$ da extremidade de um $\operatorname{DWNT}(10,10) @(30,30)$. Os picos correspondem às extremidades das paredes dos nanotubos onde há expulsão dos fulerenos $C_{60}$. Os vales correspondem regiões propícias ao encapsulamento. b) Fulereno $C_{60}$ em trajetória horizontal passando pela extremidade do DWNT. . .

Figura 39 - Fulereno $C_{60}$ em trajetória vertical, no qual passará à $2 \AA ̊$ da ponta de um DWNT(10,10)@(30,30) . . . . . . . . . . . . . . . . . . . 70

Figura 40 - a) Gráfico do Potencial da borda da parede percebido pelo fulereno $C_{60}$ à distância de aproximadamente $2 \AA$ da ponta de um DWNT $(10,10) @(20,20))$. Os picos correspondem às extremidades das paredes dos nanotubos. Os vales correspondem regiões onde não ocorrem o encapsulamento devido à largura ser menor que $14 \AA$. b) Fulereno $C_{60}$ em trajetória horizontal passando pela extremidade da parede do DWNT. . . . . . . . . . . . . . . . . 71

Figura 41 - Emcapsulamento de fulerenos em DWNT- Disposição quase paralela. 71 Figura 42 - Fulerenos $C_{60}$ no interior $\operatorname{SWNT}(18,18)$ (Camada de três molécula) e fulerenos $C_{70}$ e $C_{78}$ dentro SWNT $(21,21)$ (quatro cadeias de simples hélices) obtidas por simulações de dinâmica molecular-fonte Karla et al ............................ 72

Figura 43 - Emcapsulamento de fulerenos em DWNT- Disposição quase paralela, sem o nanotubo exterior. . . . . . . . . . . . . . 72

Figura 44 - Parâmetros utilizados pelo programa Materials para realização da dinâmica para o cálculo do módulo de elasticidade em nanotubos curtos e longos. . . . . . . . . . . . . . . . . . 74

Figura 45 - Gráfico da energia de deformação/átomo pela deformação $(\epsilon)$ do nanotubo(10,10). . . . . . . . . . . . . 76

Figura 46 - Gráfico da energia de deformação pela deformação( $\epsilon)$ do nanotubo(10,10). . . . . . . . . . . . . . . 76

Figura 47 - Gráfico do módulo de Young dos nanotubos de carbono descritos na Tabela14. Os pontos em vermelho descrevem a curva $y=\frac{a}{x^{2}} . \quad . \quad 80$ 
Figura 48 - Gráfico do módulo de Young dos nanotubos de carbono descritos na Tabela1. Módulo de Young decrescente em função do raio. Os números ao lado dos pontos representam os tamanhos dos nanotubos,

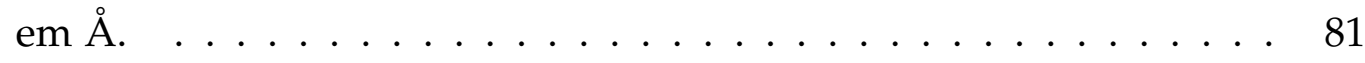

Figura 49 - Nanotubo de parede múltipla. . . . . . . . . . . . . 83 


\section{Lista de tabelas}

Tabela 1 - Valores do módulo de Young obtidos por Treacy et al. . . . . . . . . 42

Tabela 2 - Módulos de Young e cisalhamento de nanotubos de parede simples. 42

Tabela 3 - Módulos de Young e Coeficiente de Poisson de SWNT obtidos por Hernándes et al. . . . . . . . . . . . . . . . 43 43

Tabela 4 - Cálculo da $\frac{\partial^{2} E}{\partial \epsilon^{2}}$ para diferentes SWNT e folhas de grafeno com diferentes células. . . . . . . . . . . . . . . 46

Tabela 5 - Tabela de nanotubos de carbono armchair e zig-zag com respectivos diâmetros . . . . . . . . . . . . . . . . . . . . 64

Tabela 6 - Valores da energia de deformação por átomo e Módulo de Young 74

Tabela 7 - Comparação entre os nossos resultados e os de Jim Ping Lu. . . . . . 75

Tabela 8 - Comparação entre os nossos resultados e os de E. Hernándes et al. . 75

Tabela 9 - Comparação entre os nossos resultados e os de Sánches Portal. . . . 75

Tabela 10 - Módulos de Young calculados pela metodologia do desvio padrão das amplitudes de vibrações nas direções x,y e z. . . . . . . . . . . 77

Tabela 11 - Módulos de Young calculados pela metodologia do desvio padrão das amplitudes de vibrações na direções z. . . . . . . . . . . . 78

Tabela 12 - Comparações entre os Módulos de Young calculados pelo programa Materials e o calculado por A.Krishnan et al nas direções x,y e z . . 78

Tabela 13 - Módulos de Young calculados pela metodologia do desvio padrão das amplitudes de vibrações na direção z em SWNT(n,n) de 100 células. . . . . . . . . . . . . . . . . . 79

Tabela 14 - Módulos de Young calculados pela metodologia do desvio padrão das amplitudes de vibrações nas direções x,y e z em SWNT(n,n) de 100 células. . . . . . . . . . . . . . . . . 79

Tabela 15 - Comparações entre os valores dos Módulos de Young dos nanotubos armchair com e sem fulerenos na direção z. . . . . . . . . . . . . . 82 


\section{Lista de abreviaturas e siglas}

SWNT Nanotubo de Carbono de Parede Simples

DWNT Nanotubo de Carbono de Parede Dupla

$C_{60} @ S W N T \quad$ Nanotubo de Carbono de Parede Simples encapsulado com fulereno

MWNT Nanotubo de Carbono de Múltiplas Paredes

SEP Superfície de Energia Potencial

MM Mecânica Molecular

DM Dinâmica Molecular 


\section{Lista de símbolos}

$\begin{array}{ll}\Gamma & \text { Letra grega maiúscula gama } \\ \sigma & \text { Letra grega minúscula sigma } \\ \epsilon & \text { Letra grega minúscula epsilon } \\ \theta & \text { Letra grega minúscula theta } \\ \omega & \text { Letra grega minúscula ômega } \\ \gamma & \text { Letra grega minúscula gama } \\ \pi & \text { Letra grega minúscula pi } \\ \mu & \text { Letra grega minúscula mu } \\ \geq & \text { Maior ou igual } \\ \cong & \text { Aproximadamente } \\ \Delta & \text { Letra grega maiúscula delta } \\ \partial & \text { Derivada parcial } \\ \sum & \text { Somatório }\end{array}$




\section{Sumário}

Introdução $\ldots \ldots \ldots \ldots \ldots$

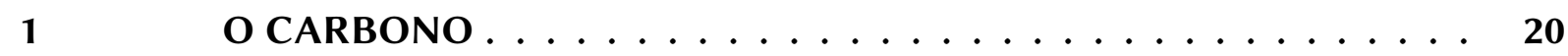

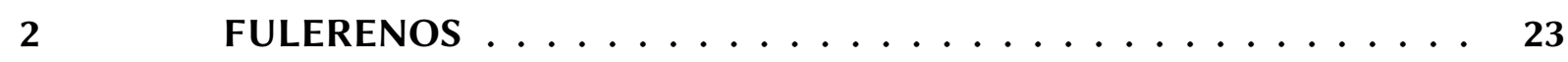

2.0.1 PROPRIEDADES E CARACTERÍSTICAS DOS FULERENOS $C_{60} \ldots \ldots$

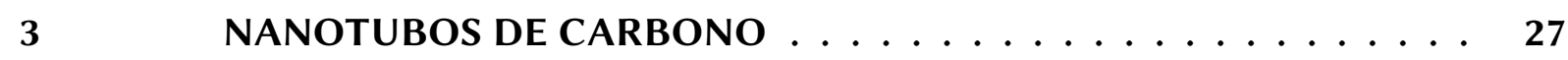

3.0.1 MÉTODOS DE OBTENÇÃO DE NANOTUBOS DE CARBONO . . . . . . 33

3.0.2 O MÓDULO DE YOUNG EM MATERIAIS MACROSCÓPICOS . . . . . . 34

3.0.3 O MÓDULO DE YOUNG EM NANOTUBOS DE CARBONO . . . . . . . 39

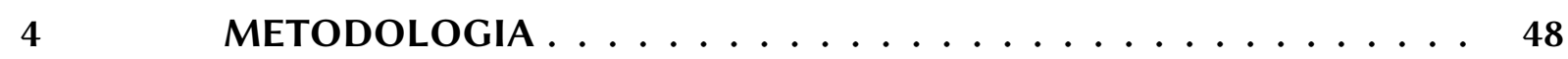

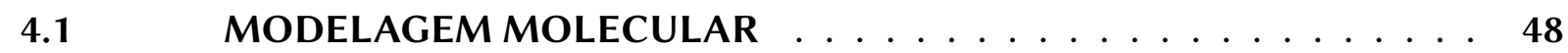

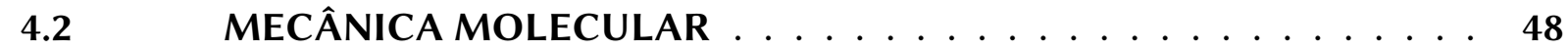

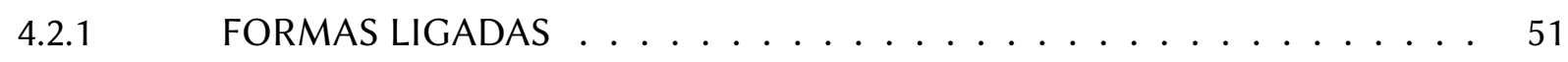

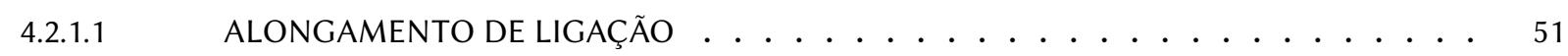

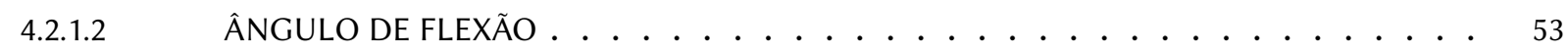

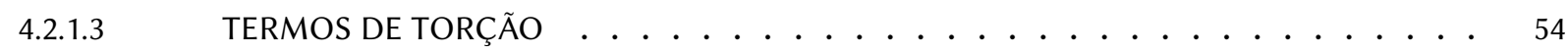

4.2.1.4 TORÇÕES IMPRÓPRIAS E MOVIMENTOS DE LIGAÇÕES FORA DO PLANO . . . . . 55

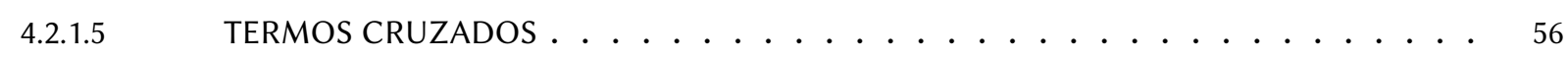

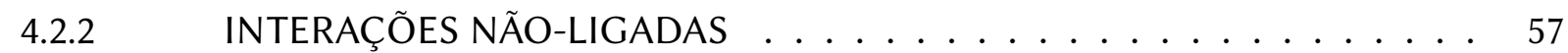

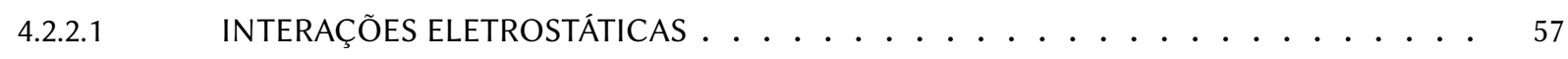

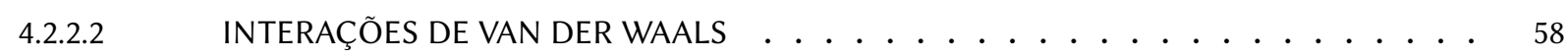

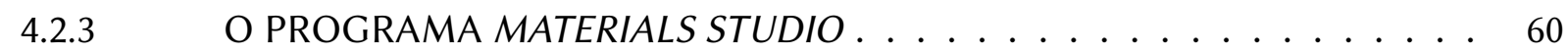

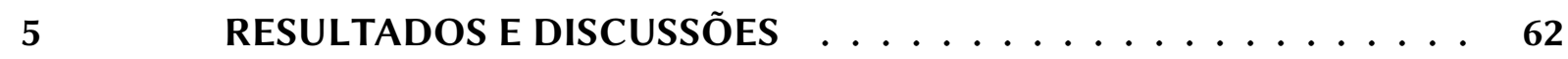

5.1 ENCAPSULAMENTO DE NANOTUBOS DE CARBONO . . . . . . . 62

5.2 ENCAPSULAMENTO DE FULERENOS EM NANOTUBOS DE CARBONO DE PAREDE SIMPLES-SWNT . . . . . . . . . . . . . 65

5.3 ENCAPSULAMENTO DE FULERENOS EM NANOTUBOS DE CARBONO DE PAREDE DUPLA-DWNT . . . . . . . . . . . . . . . 67

5.4 OBTENÇÃO DO MÓDULO DE YOUNG EM NANOTUBOS DE CARBONO POR METODOLOGIAS CLÁSSICAS . . . . . . . . . . . 70

5.5 O MÓDULO DE ELASTICIDADE EM NANOTUBOS DE CARBONO PREENCHIDOS COM FULERENOS . . . . . . . . . . . . . . 81 
REFERÊNCIAS . 


\section{Introdução}

O advento da nanotecnologia é o grande acontecimento que povoa os dias modernos (1). É cada vez menor o tamanho de equipamentos eletrônicos que são usados pela população, com uma eficiência cada vez maior. Pesquisas nas diversas áreas buscam soluções para problemas que antes não poderiam ser resolvidos, mas que hoje, com o avanço tecnológico é possível. Poderíamos citar como exemplo os grandes avanços na biologia e medicina com manipulações em medicamentos que ocasionam cura e tratamento para uma variedades de doenças (2). É a nanotecnologia que possibilita a manipulação de átomos e moléculas, melhorando o entendimento do que ocorre ao nosso redor com o auxílio de computadores que possuem microprocessadores com partes nanométricas, possibilitando o aumento na velocidade de computação e menores consumos de energia (3).

Paralelo a isto é crescente o estudo de novos materiais que serão utilizados nessa revolução tecnológica. São materiais novos, com características diferentes, leves, fortes e duradouros. Dentro destes materiais, encontramos os que são feitos de átomos de carbono (4), ou melhor dizendo, das formas alotrópicas dos carbonos: grafite, diamante, nanotubos de carbono, fulerenos etc.

O nosso trabalho se restringe ao estudo de duas classes de nanomateriais: nanotubos de carbono e fulerenos (5). E apesar de vários pesquisadores já terem estudado estes materiais, ainda há uma quantidade considerável de produtos que poderemos desenvolver utilizando esta base de carbono. Procuramos encontrar algumas regras que definissem quando um nanotubo de parede simples (single-wall carbon nanotubesSWNT) é encapsulado em outro nanotubo, produzindo o nanotubo de parede dupla (double-wall carbon nanotubes-DWNT). Estudamos com detalhes estes encapsulamentos, com suas dinâmicas, mínimas distâncias exigidas e quais os diâmetros destes nanotubos que permitissem que o fato ocorresse.Tentamos entender todo este mecanismo para que uma simples regra pudesse nos mostrar se um nanotubo encapsula ou não no outro.

Fizemos uma pesquisa detalhada, analisando as técnicas utilizadas por vários autores, tentando desenvolver uma nova abordagem que possibilitasse o cálculo do módulo de Young em nanotubos de carbono de uma maneira inteiramente clássica, evitando com isso a demora nos cálculos.

Após o encapsulamento de SWNT, investigamos o encapsulamento dos fulerenos dentro dos SWNT, energias potenciais na borda dos nanotubos, o fator de empacotamento, amplitudes de vibrações dos nanotubos e os cálculos dos módu- 
los de Young tanto de nanotubos simples (SWNT) quanto dos nanotubos simples encapsulados com fulerenos $C_{60}$.

Para o cálculo das propriedades mecânicas, energias potenciais e dinâmicas utilizamos o programa Materials Studio 6.1, com Campo de Força Compass-Modules Forcite. 


\section{O CARBONO}

O carbono (do latim carbo, carvão) é um elemento químico, símbolo $C$, número atômico 6 (6 prótons e 6 elétrons), massa atómica $12 u$, sólido à temperatura ambiente. Pertence ao grupo 14 da tabela periódica, ele é um não metal e é tetravalente. Existindo quatro elétrons disponíveis na forma de ligações covalentes. Sua configuração eletrônica é denotado como $1 s^{2} 2 s^{2} 2 p^{2}$. É um sólido, e sublima a $3642^{\circ} \mathrm{C}$. O carbono tem a capacidade de formar cadeias muito longas de natureza forte e estável, interligando $C-C$, permitindo formar um número quase infinito de compostos. Portanto, existem compostos conhecidos contendo mais carbono do que todos os compostos de outros elementos químicos combinados, excetuando os compostos de hidrogênio (6). É o elemento químico mais numeroso de compostos químicos, mais do que os outros elementos químicos, com quase dez milhões de compostos.

O carbono é o 15 elemento químico mais abundante na crosta terrestre e o 4 elemento mais abundante no universo depois do hidrogênio, hélio e o oxigênio. Ele está presente em todas as formas de vida, e no corpo humano é o segundo elemento mais abundante em massa (cerca de 18,5\%) depois do oxigênio (7). Esta abundância, em conjunto com a exclusiva diversidade e sua incomum capacidade de formar polímeros sob as diversas condições de temperatura na Terra, tornando-o este elemento básico para todas as formas de vidas conhecidas.

Os compostos à base de carbono formam toda a vida conhecida na Terra, isto acontece devido ao ciclo do carbono-nitrogênio que fornece parte da energia produzida pelo sol e outras estrelas . O carbono tem uma afinidade para se ligar com outros átomos, incluindo outros átomos de carbono através da formação de ligações covalentes estáveis. Apresenta uma grande afinidade para combinar-se quimicamente com outros átomos pequenos, incluindo átomos de carbono que podem formar longas cadeias. O seu pequeno raio atômico permite-lhe formar cadeias múltiplas; assim, como o oxigênio forma o dióxido de carbono, essencial para o crescimento das plantas; com o hidrogênio forma numerosos compostos, os hidrocarbonetos, essenciais para a indústria e o transporte na forma de combustíveis derivados de petróleo e gás natural. Forma os ácidos graxos, essenciais para a vida, e os ésteres que dão sabor às frutas.

O carbono tem vários alótropos, ou diferentes formas em que ele se apresenta na natureza. A alotropia do carbono abrange uma ampla gama de propriedades físicas, tendo o diamante que é extremamente duro, abrasivo, podendo ter características elétricas, isolantes, condutoras e ser uma das substâncias que mais difícil ocorrem na natureza; enquanto o grafite é uma substância macia, opaco, bom lubrificante, condutor 
de eletricidade e um isolante térmico.

Além do diamantes e grafites, existem outros alótropos do carbono como os buckyballs (fulerenos), carbono amorfo, carbono vítreo, e nanotubos etc, como podemos visualizar na figura 2.

Sob condições ambientais normais, o diamante, os nanotubos de carbono e o grafeno têm uma elevada condutividade térmica entre todos os materiais conhecidos.

Todos os alótropos de carbono são sólidos em temperatura ambiente, com o grafite sendo o mais estável termodinâmico. A maior disponibilidade de compostos inorgânicos com carbono está no calcário, na dolomita e o dióxido de carbono, porém quantidades significativas são encontradas nas minas de carvão, nas turfas, no petróleo e nas fontes de hidrato de carbono (8).

À pressão normal, o carbono adota a forma de grafite estando cada átomo unido a outros três em um plano composto de células hexagonais; neste estado, 3 elétrons se encontram em orbitais híbridos planos $\mathrm{sp}^{2}$ e o quarto em um orbital $\mathrm{p}$. Devido ao deslocamento dos elétrons do orbital $\pi$, o grafite é condutor de eletricidade. O material é frágil e as camadas se encontram unidas por forças de Van der Waals. Sob pressões elevadas, o carbono adota a forma de diamante, na qual cada átomo está unido a outros quatro átomos de carbono, encontrando-se os 4 elétrons em orbitais $\mathrm{sp}^{3}$, se tornando um dos materiais mais duros da natureza. Sob certas condições, o carbono cristaliza como lonsdaleíta, uma forma similar ao diamante, porém hexagonal, encontrado nos meteoros.

O grafeno (ver Figura 1) é uma das formas cristalinas do carbono. É muito forte, leve, quase transparente, um excelente condutor de calor e eletricidade. Tem a forma de uma folha plana de átomos de carbono, em ligações $s p^{2}$, densamente compactados e com espessura de apenas um átomo (8).

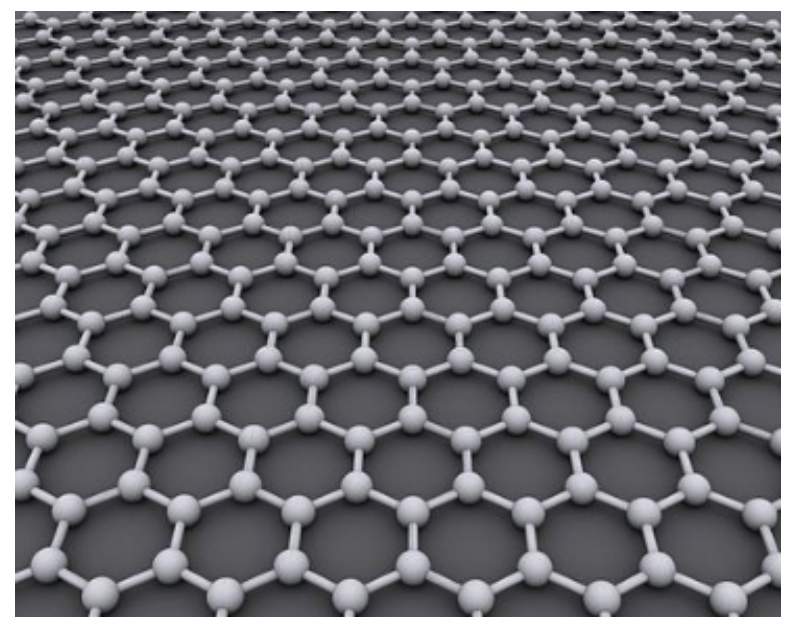

Figura 1 - Forma alotrópica do carbono: folha de grafeno. 
Os fulerenos têm uma estrutura similar à do grafite, porém o empacotamento hexagonal, curvando os planos e transformando sua estrutura em forma esférica, elipsoidal e cilíndrica. São constituídos por 20, 60, 70, 78 100, 180, 240 e até 540 átomos de carbono apresentando uma estrutura tridimensional similar a uma bola de futebol (9).

E por último, temos os nanotubos de carbono, de forma cilíndrica, que podem apresenta-se com semi-esferas nos seus extremos (semi-fulerenos) ou abertos em suas extremidades. Sendo um dos produtos principais na industria da nanotecnologia. Investiga-se sua aplicabilidade em fios de nanocircuitos e em eletrônica molecular, já que, por ser derivado do grafite, conduz eletricidade em toda sua extensão, não havendo perdas de energia. Possui ainda, grande aplicabilidade em compostos dinâmicos (8).

Como o nossa trabalho é em nanotubos de carbono e fulerenos, daremos uma maior atenção nestas estrutura
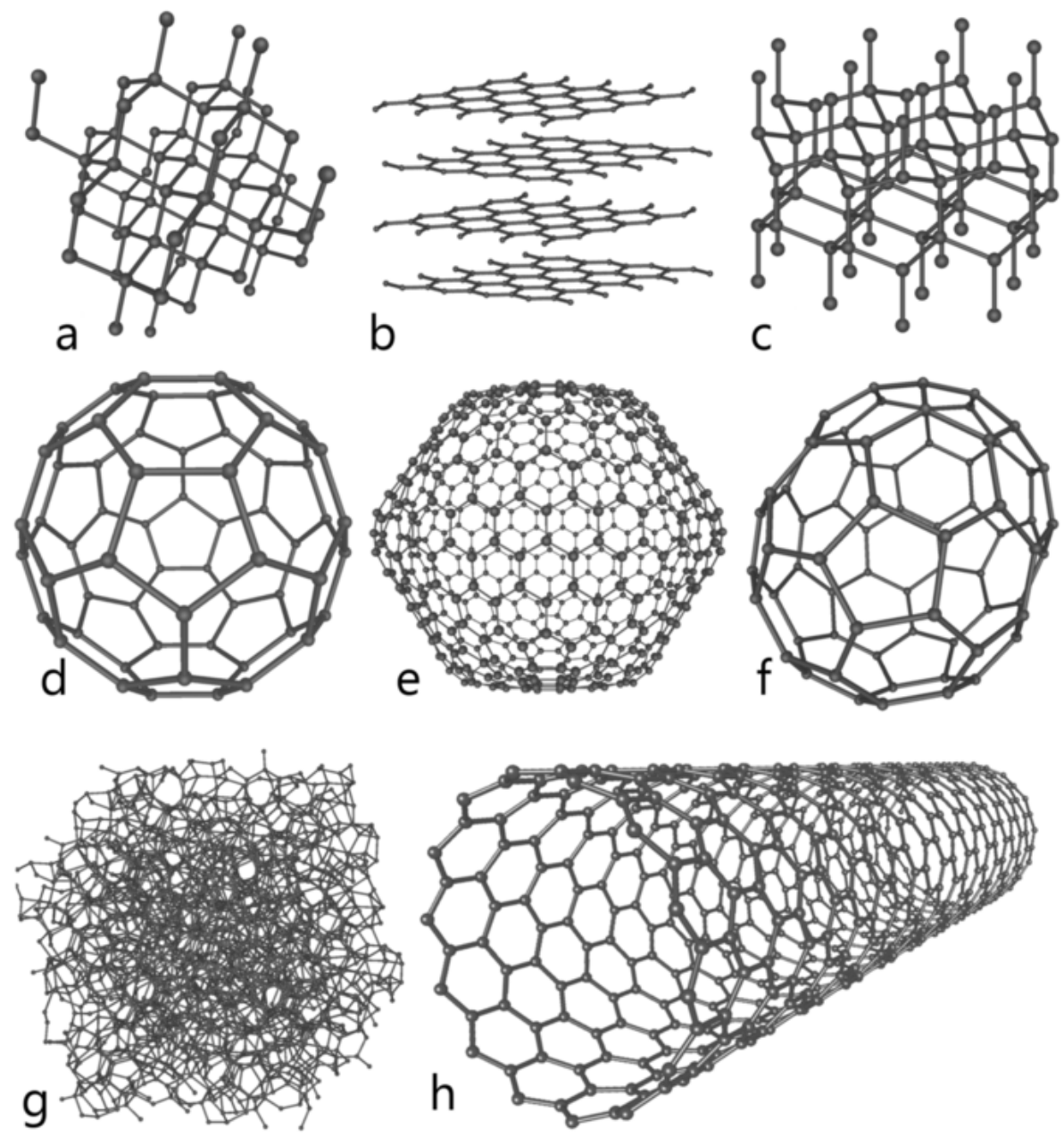

Figura 2 - Formas alotrópicas do carbono: a)diamante b)grafite c)londasleite df)fulerenos $\left.\left(C_{6} 0, C_{5} 40, C_{7} 0\right) \mathrm{g}\right)$ carbono amorfo h)nonotubos 


\section{FULERENOS}

A descoberta dos fulerenos (buckyballs) $C_{60}$ começou com a investigação de certas linhas de absorção interstelares que se desconfiavam serem devidas a moléculas de carbono $C_{n}$. O cientista interessado neste trabalho era o professor inglês H.Kroto (10) que, em 1985, teve a colaboração do professor Smalley, da Univerdade de Rice, texas, que tinha desenvolvido uma máquina de produção de agregados atômicos de carbono por vaporização à laser. Eles descobriram que os agregados atômicos de carbono com 60 átomos eram abundantes nos espectros de massa. E procurando uma explicação para a estabilidade que possuíam, postularam a estrutura da bola de futebol, com simetria icosaédrica e na qual todos os 60 átomos ocupavam posições simetricamente equivalentes, satisfazendo as regras básicas associadas com a ligação química do carbono.

Ao fim de vários anos, Smalley e seus colaboradores conseguiram provar que se tratava de uma estrutura de gaiola, pois podiam "prender" átomos no seu interior. Mais tarde Kratschmer, Huffman e colaboradores que também estavam interessados nas linhas de absorção interstelares, produziram uma fuligem de carbono fazendo passar uma descarga elétrica entre duas barras de grafite numa atmosfera de gás inerte. Então eles observaram no espectro infravermelho dessa fuligem especial linhas que correspondiam ao que tinha sido previsto anteriormente: que o $C_{60}$ é uma molécula icosaédrica (11).

Em 1990, R. Taylor (12), um especialista em cromatografia, foi capaz de obter pela primeira vez amostras puras de $C_{60}$ e $C_{70}$ em quantidades mínimas, mas suficiente para começar a exploração de suas propriedades químicas e espectroscópicas. No mesmo ano, Kratschmer, W. e Huffman, N. e outros pesquisadores descreveram a primeira síntese e o isolamento do $C_{60}$, ao conseguirem produzir macroscopicamente $o$ fulereno ao evaporarem o grafite em aquecimento resistivo sob uma atmosfera de hélio, com a adição de benzeno e após a evaporação deste, formou-se a primeira amostra de fulereno (13). Isto representou uma etapa decisiva para as áreas das ciências.

Os fulerenos compõem-se de uma vasta família de nanomoléculas superaromáticas, compostas de dezenas de átomos de carbono $s p^{2}$-hibridizados, em ligações simples com outros átomos de carbono. Suas moléculas são unidas pelas ligações de Van der Waals, tidas como "ligações fracas", o que favorece o aparecimento de várias fases de transição, quando submetidos a altas pressões e temperaturas (14).

Desde então, esse composto vêm atraindo um grande interesse na comunidade de pesquisadores teóricos devido a suas ótimas propriedades magnéticas, estruturais, 
eletrônicas e ópticas (15). Sendo que pesquisa sobre fulerenos tem resultado na síntese de mais de mil novos compostos. A descoberta de fulerenos também levou a pesquisa em nanotubos de carbono, o cilíndrico primos de buckballs. Hoje, há estudos em áreas da nanotecnologia, em busca de aplicações em áreas como energia, armadura corporal, antibióticos, supercondutores, e óptica. Além de fornecerem oportunidades de pesquisa abundantes em química pura, física e ciência de materiais (16).

Bing-She (17), em 2008, apresentou um levantamento de estudos sobre o desenvolvimento das pesquisas de preparação, mecanismos de crescimento, purificação, modificação e potenciais aplicações dos nanoonion-like fullerene (NOLF), devido às propriedades especiais desses compostos, tais como ser capaz de acumular energia, ter alta resistência ao desgaste, ter comportamento de semicondutor e mesmo como biomaterial.

Um dos compostos mais conhecidos da família dos fulerenos é o de 60 átomos de carbono $\left(C_{60}\right)$ organizados na forma de um icosaedro truncado(bola de futebol), como mostra a Figura 3.
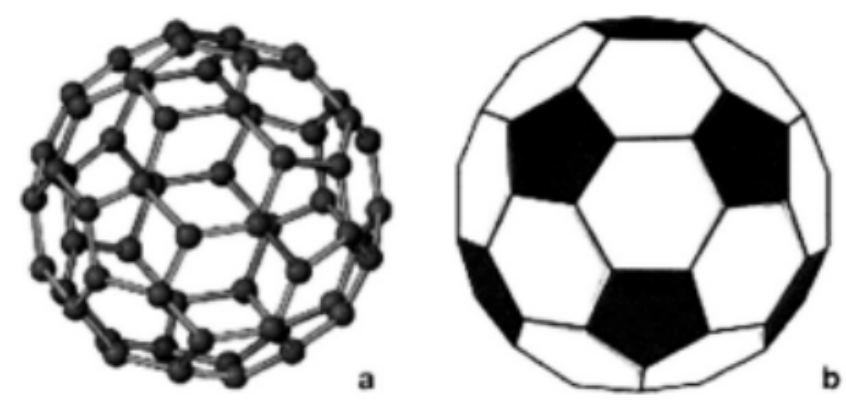

Figura 3 - a) Fulereno $C_{60}$ b) Comparação com a bola de futebol

Atualmente a dopagem endoédrica com fulerenos no interior dos nanotubos, tais como o $C_{20}$ e o $C_{60}$, denominados peapods têm chamado a atenção de muitos pesquisadores pelo fato de muitas propriedades dos nanotubos ocos conseguirem ser modificadas por esse motivo (18). Entre eles temos Chadli et al (19), que em 2005, estabeleceu que os peapods são novos materiais e que representam uma nova classe híbrida entre o $C_{60}$ e o SWNT, em que as ligações entre as moléculas do fulereno e do tubo hospedeiro ocorriam por forças de Van der Walls, que são mais fracas, o que impedia a formação de uma ligação iônica ou covalente.

Kumar et al (14), que em 2007, observando o mesmo comportamento do $C_{60}$ em nanotubos de paredes múltiplas (MWNT), pela espectropia de Raman em pressões de 20 e $25 \mathrm{GPa}$, percebeu que em $13 \mathrm{GPa}$ houve a transformação de hibridização $s p^{2}$ para $s p^{3}$ para o fulereno, já para o MWNT, isto ocorreu em torno de $16 \mathrm{GPa}$. 


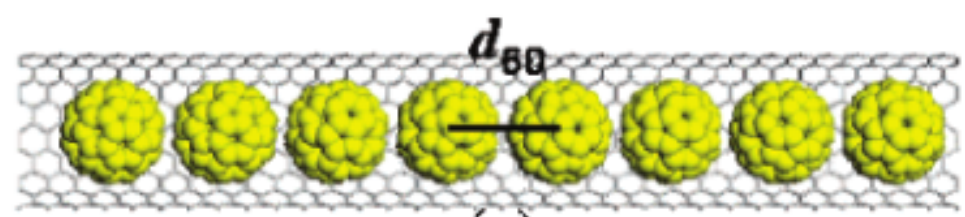

(a)

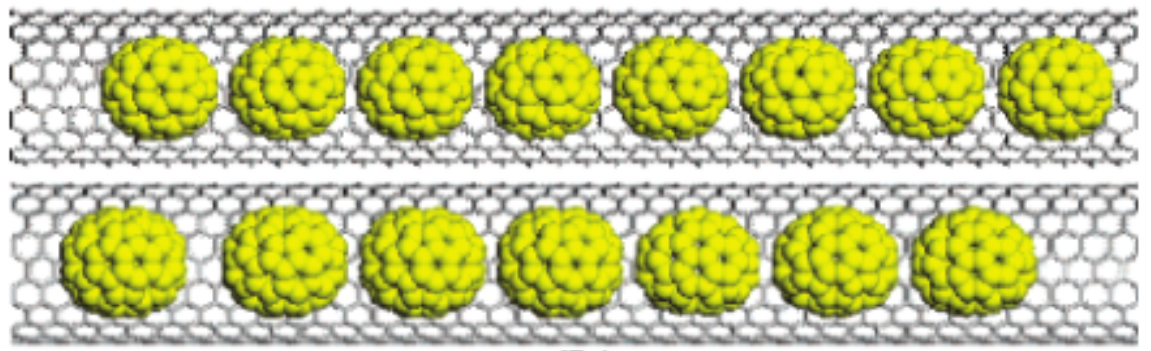

(b)

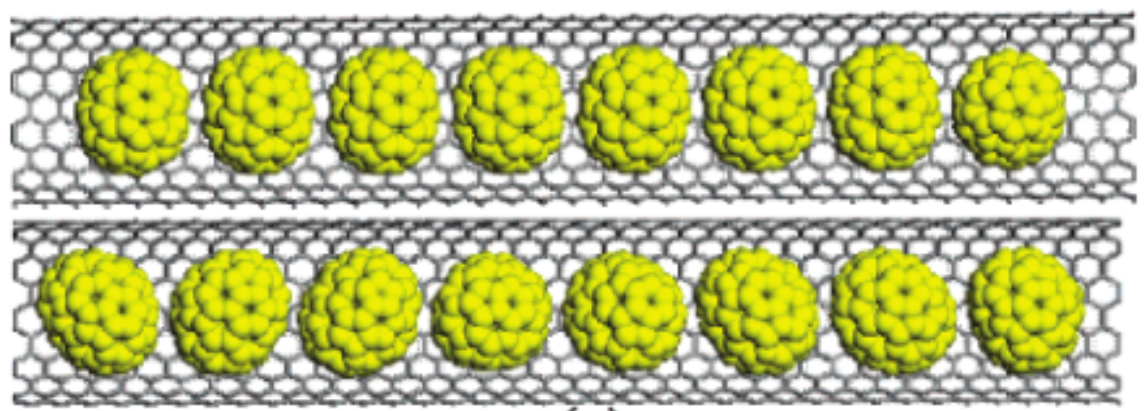

(c)

Figura 4 - (a) Fulereno $C_{60}$ encapsulado no nanotubo $(10,10)$, (b) Fulerenos $C_{70}$ (superior) e $C_{78}$ (em baixo) encapsulados em nanotubos $(10,10)$, (c) fulerenos $C_{70}$ (superior) e $C_{78}$ (em baixo) encapsulados em nanotubos $(11,11) \cdot d_{C_{60}}$ representa a distância intermolecular centro-a-centro do fulerenos $C_{60}$-fonte Karla at al.

\subsubsection{PROPRIEDADES E CARACTERÍSTICAS DOS FULERENOS $C_{60}$}

Todos os fulerenos $C_{60}$ têm um número fixo de 12 pentágonos, enquanto o número de hexágonos, $m$, varia pela equação do teorema de Euler: $m=\frac{\left(C_{n}-20\right)}{2}$. A curvatura e as propriedades especiais do $C_{60}$ tem 30 ligações carbono-carbono (6-6) situadas nos vértices das fusões entre os anéis de 6 membros e são mais curtas do que as ligações (5-6) entre os anéis de 5 e 6 membros (1.388 $\AA$ e $1.432 \AA$, respectivamente) (20). Portanto, as ligações (6-6), situadas entre os pares de carbonos que unem dois diferentes pentágonos, têm características de ligações $\pi$, em contraste com as outras (5-6) mais longas localizadas na junção dos anéis com cinco e seis membros (veja Figura 5), melhores descritas como ligações simples (21).

No $C_{60}$ observa-se um caráter eletrônico reduzido, atribuído aos orbitais moleculares Lumo não ligantes que estão num patamar de energia bastante baixo (22).Pelas medidas de voltamétria cíclica, o $C_{60}$ é reduzido, reversivelmente, por até seis elétrons 


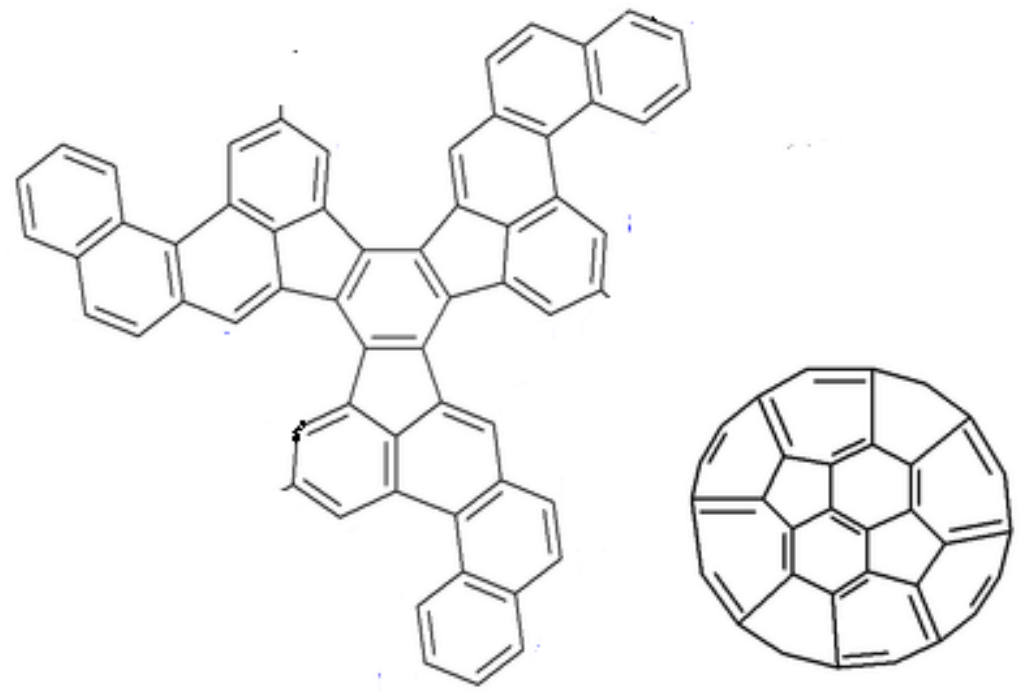

Figura 5 - Construção do Fulereno $C_{60}$. À esquerda: parte da folha de grafeno com pentágonos e hexágonos; à direita: fulereno já formado

em solução, gerando a espécie diamagnética.

Hoje, sabe-se que a molécula de $C_{60}$, embora rica em elétrons, se comporta como uma espécie eletronegativa capaz de aceitar reversivelmente de um até seis elétrons, formando os ânions correspondentes (23). Outra propriedade interessante é que a molécula de $C_{60}$ pode se tornar supercondutora em espécies do tipo $M_{3} C_{60}$ ( $\mathrm{M}=$ metal alcalino) (24), além de possuir propriedades ópticas não lineares (25) e um estado tripleto de longa duração (26).

Os fulerenos são moléculas extremamente fortes, capaz de resistirem grandes pressões e voltar à sua forma original depois de ter sido sujeito a mais de 3.000 atmosferas, isso devido a estabilidade da molécula. Teórico cálculos sugerem que uma única molécula de $C_{60}$ possui um eficaz módulo de volume de $668 \mathrm{GPa}$ quando comprimida a 0.75 do seu tamanho (27). Esta propriedade faz o fulerenos ser mais resistente do que o aço e diamante, cujos módulos de volume são 160 GPa e $442 \mathrm{GPa}$, respectivamente. 


\section{NANOTUBOS DE CARBONO}

A descoberta dos nanotubos de carbono em 1991 por Sumio Iijima (28) se deu por acaso, quando ao tentar fabricar fulerenos acabou por encontrar nanotubos de carbono em meio a uma massa de carbono amorfo. $\mathrm{O}$ trabalho de Iijima demonstrava a formação de cilindros concêntricos (dois ou mais), com espaçamento de $0.34 \mathrm{~nm}$, com diâmetro externo da ordem de 4-30 nm, diâmetro do cilindro mais interno da ordem de $2.0 \mathrm{~nm}$ e comprimentos de até $1.0 \mu$. Esses foram os primeiros nanotubos de carbono observados de paredes múltiplas (Multi-Walled Carbon Nanotubes - MWNT). Aproximadamente, dois anos depois, Iijima e Ichihashi demonstraram a síntese de nanotubos de carbono de parede simples (Single-Walled Carbon Nanotubes - SWNT) e Donald Bethune, independentemente, também apresentam resultados semelhantes na mesma época (29).

Não se pode negar, no entanto, que as expectativas em relação aos nanotubos de carbono são muito altas. Uma das principais razões para isso é a aplicação prevista de nanotubos eletrônicos, pois muitos acreditam que as técnicas atuais para miniaturizar microchips está prestes a atingir os seus limites mais baixos, e que tecnologias baseadas em nanotubos são a melhor esperança para se obter uma maior miniaturização. Os nanotubos de carbono, portanto, podem fornecer os blocos de construção para novos progressos tecnológicos, melhorando nossos padrões de vida (13).

Um nanotubo de carbono de parede simples é definido teoricamente como uma folha de grafite de duas dimensões enrolada e cortada em diferentes ângulos em relação a uma rede hexagonal qualquer definida. Ângulo este o qual foi cortada a folha de grafite, que vai determinar a quiralidade do nanotubo de carbono. A quiralidade $\mathrm{C}$ do nanotubo de carbono vai definir a sua geometria como mostra a Figura 6.

Onde $a$ é a constante da rede $(a=2,49 A)$ e $\overrightarrow{a_{1}}$ e $\overrightarrow{a_{2}}$ são vetores da rede direta, como mostra a equação

$$
\begin{gathered}
\overrightarrow{a_{1}} \cdot \overrightarrow{a_{1}}=\overrightarrow{a_{2}} \cdot \overrightarrow{a_{2}}=a \\
\overrightarrow{a_{1}} \cdot \overrightarrow{a_{2}}=\frac{a^{2}}{2}
\end{gathered}
$$

O vetor quiral é definido como:

$$
\vec{C}=n \overrightarrow{a_{1}}+m \overrightarrow{a_{2}} \equiv(n, m)
$$




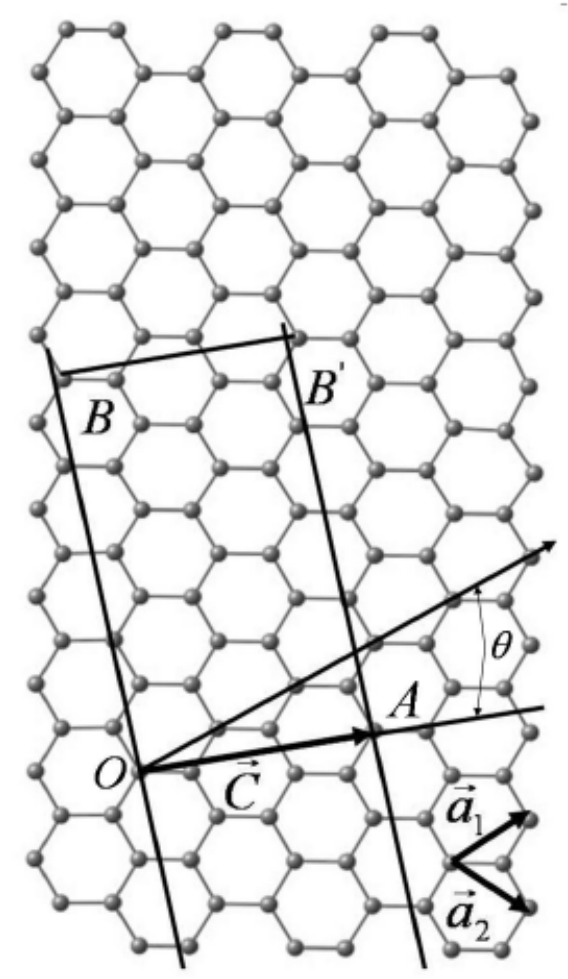

2.4 - Estrutura do nanotubo antes de enrolar.

Figura 6 - Estrutura do nanotubo de carbono antes de enrolar

Onde $0 \leq m \leq n$, sendo que $\mathrm{m}$ e $\mathrm{n}$ são números inteiros. E o diâmetro do tubo será dado por:

$$
d_{t}=\frac{L}{\pi}
$$

e L é o comprimento da circunferência do tubo e é escrito como:

$$
L=|C|=a \sqrt{n^{2}+m^{2}+n m}
$$

E o ângulo quiral é dado por:

$$
\cos (\theta)=\frac{C_{1} \cdot \overrightarrow{a_{1}}}{|C|\left|\overrightarrow{a_{1}}\right|}=\frac{2 n+m}{2 \sqrt{n^{2}+m^{2}+n m}}
$$

Os nanotubos de carbono podem ser metálicos ou semicondutores. Denominamse nanotubos do tipo zig-zag $(n, 0)$ os que apresentam características semicondutoras e, do tipo armchair $(n, n)$ com características metálicas. Ainda, existem nanotubos do tipo misto em que, com $n \neq m$ onde $n$ e m são inteiros, dependendo da sua quiralidade, 
isso ocorre devido ao confinamento quântico ao longo da circunferência do tubo, como veremos na Figura 7 (30).

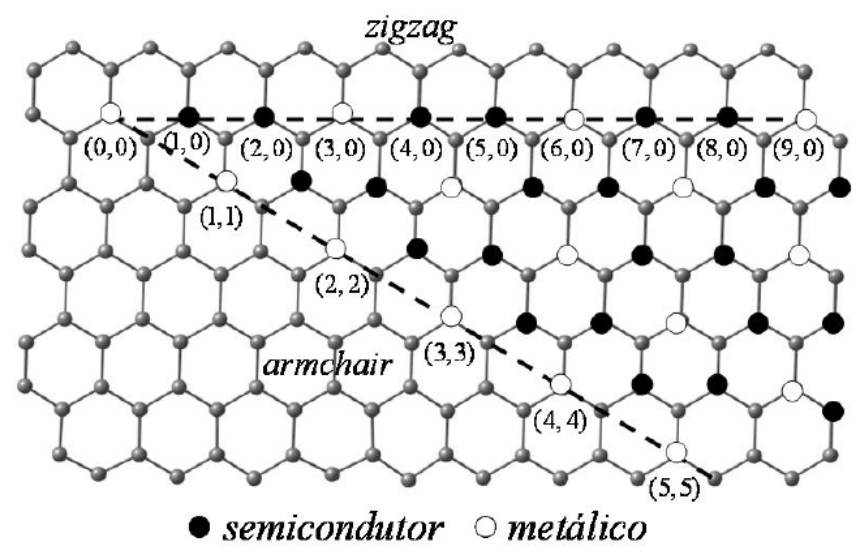

Figura 7 - Folha de grafeno do nanotubo tipo misto

Para o caso dos nanotubos mistos, se a diferença entre os índices quirais $(\mathrm{n}, \mathrm{m})$ não for um número múltiplo de 3 ou zero então o nanotubo é um semicondutor, caso seja múltiplo de três, este nanotubo será metálico (30). Na Figura 8 mostramos alguns exemplos de nanotubos de carbono, (a) armchair, (b)zig-zag e (c) misto.
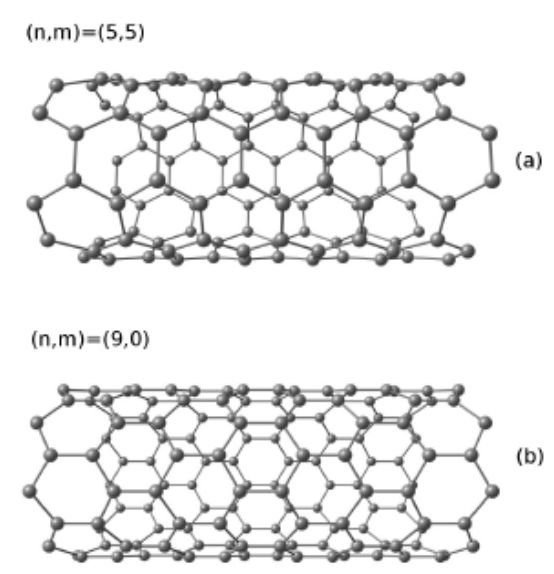

$(n, m)=(10,5)$

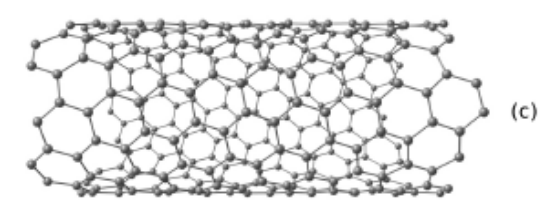

Figura 8 - Classificação dos nanotubos de acordo com o seu enrolamento, (a) armchair, (b) zig-zag e (c) misto

As propriedades eletrônicas de materiais sólidos podem ser entendidas e visualizadas a partir da estrutura de bandas do sistema, que é descrita como conjuntos de um número muito grande de níveis de energia muito pouco espaçados, limitada 
por um número de elétrons em cada banda de energia. Entre uma banda e outra, não existem níveis de energia possíveis de serem preenchidos pelos elétrons e dizemos que aí existe uma banda proibida (ver Figura 9) (31).

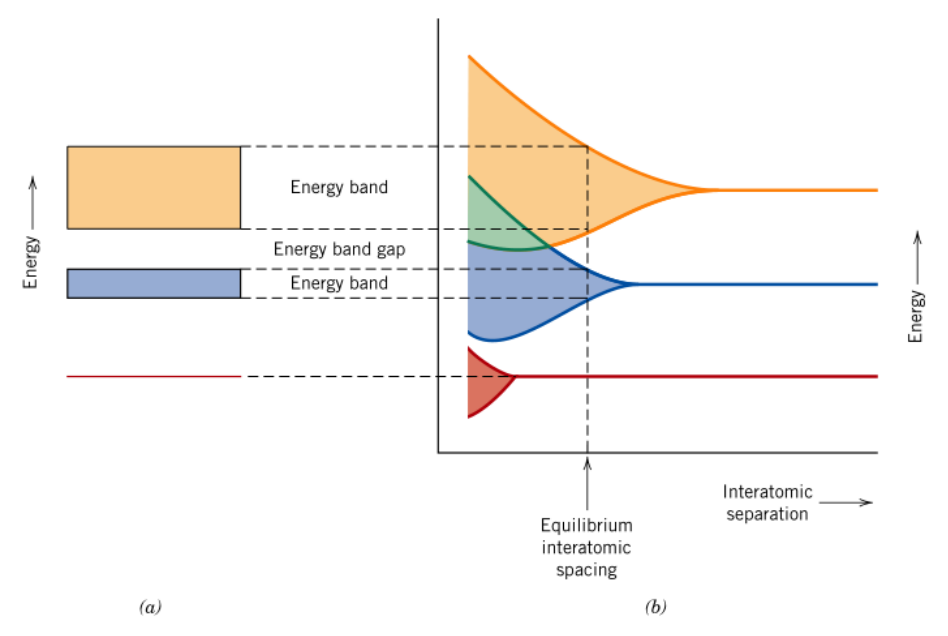

Figura 9 - (a) Representação da estrutura de banda de energia eletrônica para um material sólido; (b) A energia eletrônica para um agregado de átomos.

As propriedades eletrônicas dos nanotubos de carbono pode ser entendida dentro de um quadro da estrutura de banda a partir da primeira zona de Brillouin (ZB) de uma folha de grafeno (30), conforme as Figuras 10 e 11, que tem estados cruzando o nível de Fermi em apenas 2 pontos não equivalentes no espaço k, e à quantização do vetor de onda de elétrons ao longo da direção da circunferência do nanotubo. Uma folha isolada de grafite é um semicondutor de $g a p=0$ cuja estrutura eletrônica perto da energia do nível de Fermi é dada por uma banda $\pi$ ocupada e uma banda $\pi^{*}$ vazia. Estas duas bandas têm dispersão linear e, como mostrado na Figura 12, entram em contato com o nível de Fermi no ponto $\mathrm{K}$ na zona de Brillouin. A superfície de Fermi de um folha de grafite ideal consiste nos seis pontos de canto K. Quando se forma um tubo, devido às condições de contorno periódicas impostas na direção da circunferência, apenas um determinado conjunto de estados $\mathrm{K}$ da folha plana de grafite é permitido. O conjunto permitido de $K^{\prime}$ s, indicado pelas linhas na Figura 12, depende do diâmetro e da helicidade do tubo. Sempre $k^{\prime} s$ permitidos incluem o ponto K, o sistema é um metal com uma densidade de estados diferente de zero no nível de Fermi, resultando em um metal unidimensional com 2 bandas lineares dispersantes. Quando o ponto K não está incluído, o sistema é um semicondutor com uma energia de gap de tamanho diferentes. É importante notar que os estados perto da energia de Fermi em ambas os tubos metálicos e semicondutores são todos de estados perto do ponto $\mathrm{K}, \mathrm{e}$, portanto, o seu transporte e outras propriedades estão relacionados com as propriedades dos estados sobre as linhas permitidas (32).

No grafeno, temos três ligações fortes do tipo $\sigma$, a partir das configurações 

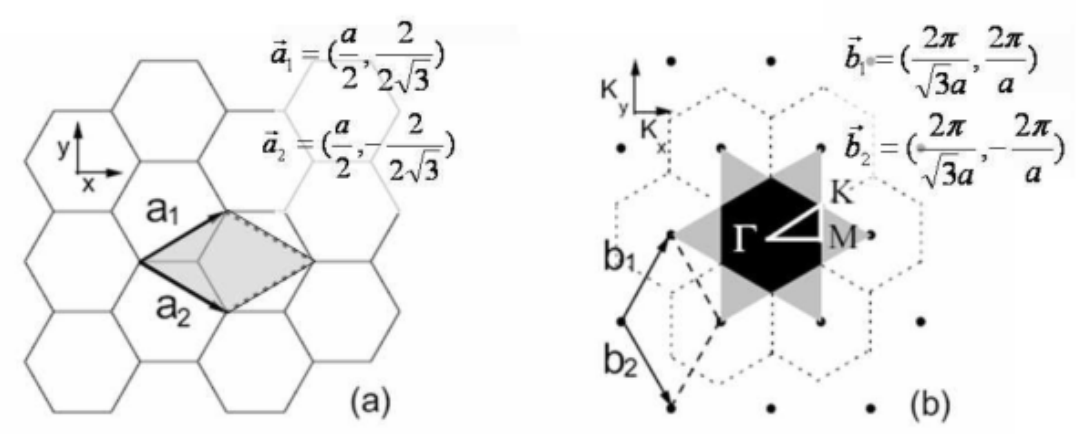

Figura 10 - (a) Rede hexagonal da folha de grafeno. A célula unitária está definida por $a_{1}$ e $a_{2}$. (b) Rede reciproca (pontilhada) com os vetores $b_{1}$ e $b_{2}$ em correspondência à rede real definida por $a_{1}$ e $a_{2}$.A primeira zona de Brillouin se encontra desenhada em cinza escuro e a segunda em cinza claro. Entre dois pontos K's existem os pontos M.
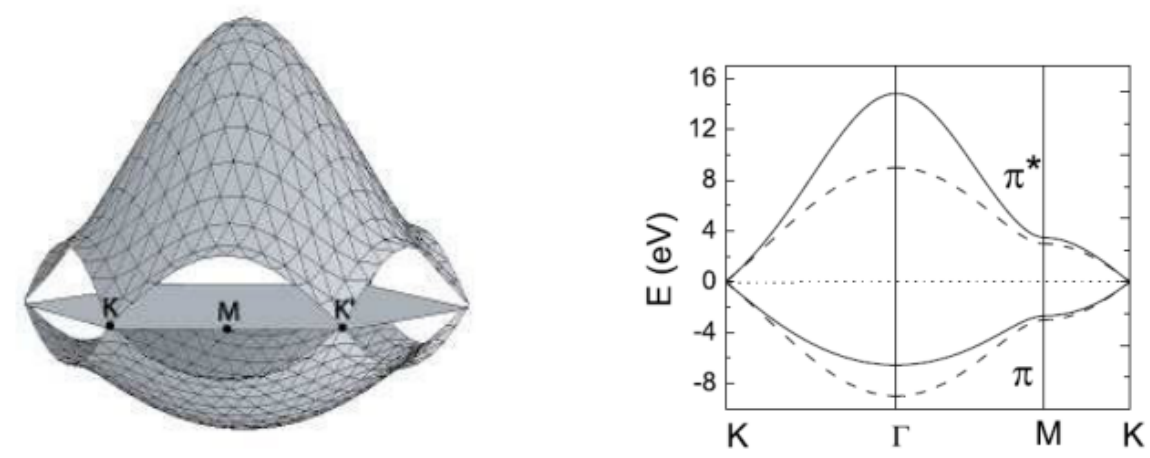

Figura 11 - Painel esquerdo: Relação de dispersão de energia do grafeno 2D através de toda a zona de Brillouin; Painel Direito: dispersão da energia ao longo das direção de alta simetria do triângulo $\Gamma M K$.

hibridizadas $s p^{2}$, e uma ligação fraca do tipo $\pi$, que associamos ao orbital $2 \mathrm{pz}$, perpendicular ao plano, isso ocorre para os carbonos tetravalentes do grafeno. Os elétrons de valência $\pi$ são os mais importantes para a definição das propriedades físicas e químicas da grande maioria dos materiais de carbono, logo, para uma primeira aproximação é válido analisar as bandas de energia $\pi$ para a determinação das propriedades do grafeno.

Como ilustrado na Figura 13(a), na estrutura de banda do nanotubo armchair $(5,5)$ verificamos que a banda de valência e a banda de condução encontram-se (gap nulo) em uma posição que está alocada a dois terços do ponto $\Gamma$ para o contorno da zona de Brilloin em $k=\frac{\pi}{a}$, para este caso temos então um nanotubo de carbono do tipo metálico. 


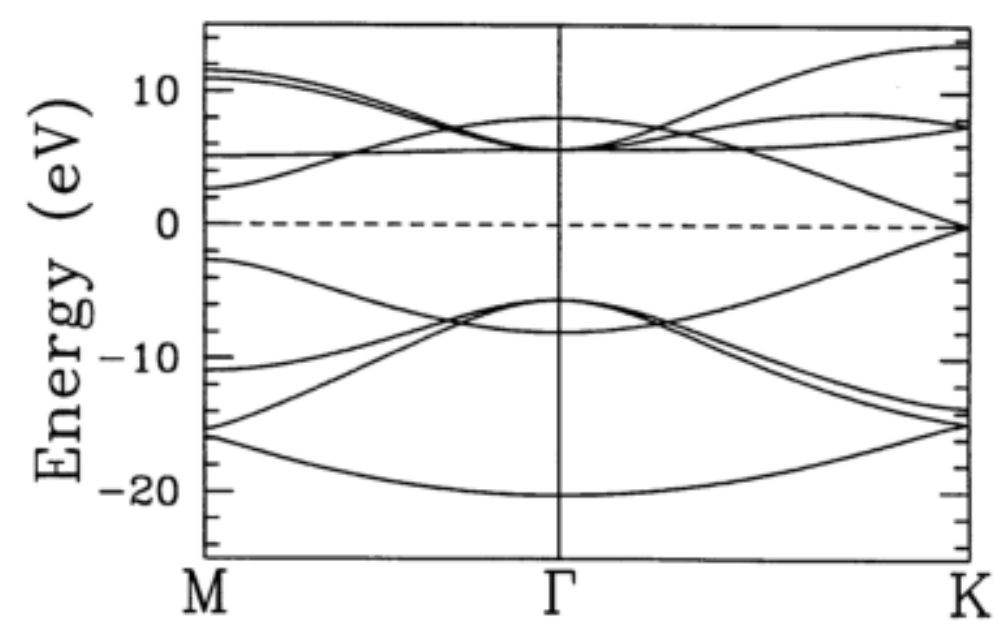

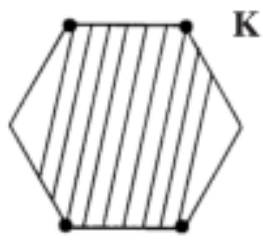

$(7,1)$

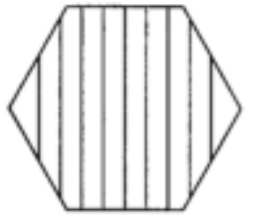

$(8,0)$

Figura 12 - (Acima) estrutura de banda de ligação forte do grafeno (um único plano basal grafite). (Inferior) estimação dos vetores k dos $\operatorname{SWNT}(7,1)$ e $\operatorname{SWNT}(8,0)$ (linhas sólidas) mapeada na zona de Brillouin do grafite.
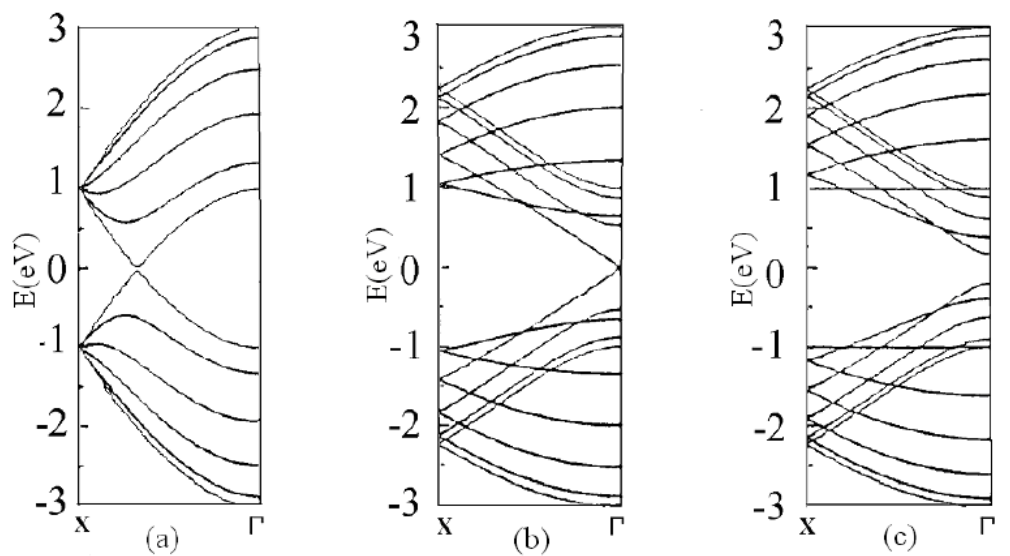

Figura 13 - Estrutura de bandas para nanotubos de carbono do tipo: (a) armchair $(5,5)$, (b) zig-zag $(9,0)$ e (c) zig-zag $(10,0)$.

Já para a estrutura de banda do nanotubo zig-zag do tipo $(9,0)$ que esta representada na Figura 13, observou-se que os níveis de energia acima do nível de Fermi $\mathrm{E}(\mathrm{eV})=0$ no ponto $\Gamma$ são os níveis antiligantes $\pi^{*}$. Portanto, a partir da Figura 13, 
observamos que apenas diferenciando o modo de enrolamento dos nanotubos temos uma grande diferença entre eles, pois, causa uma variação no gap de energia (observe a Figura 12, na parte inferior). Os nanotubos quirais, eles podem ser tanto semicondutores como metálicos, isso dependendo da sua quiralidade e do seu diâmetro. Para um nanotubo zig-zag quando o valor de n é múltiplo de 3, o gap de energia em $\mathbf{k}$ torna-se zero, caso contrário n não múltiplo de 3 abre-se um gap de energia em k.

Os nanotubos de carbono puros são formados por ligações do tipo $\sigma$ e essas ligações são as mais fortes que existem na natureza, o que os torna uma das fibras mais resistentes.

Experimentos revelam que os nanotubos de carbono são mais duros que o diamante, com maior resistência à tensão e maior módulo de elasticidade. Este módulo de elasticidade ou módulo de Young é um parâmetro que proporciona uma medida de rigidez de um material sólido, alguns autores dizem que o módulo de Young independe da quiralidade do tubo, mas decresce com o aumento do diâmetro (33). Embora outros como Sánches Portal et al (34) e Yakobson et al (35) discordem, afirmando que o módulo de Young pouco varia em virtude do raio e da quiralidade.

Outra característica importante dos nanotubos de carbono é a resposta elástica a deformações, os nanotubos são extremamente flexíveis na direção normal à superfície, podendo ser torcidos em grandes ângulos sem a ocorrência de rupturas em sua estrutura. Os nanotubos também possuem uma elevada resistência elástica para diversos tipos de deformações, como tensão de stress compressão e torção, tudo isso se deve ao fato dos nanotubos possuírem hibridizações $s p^{2}$ (36) (30).

\subsubsection{MÉTOdOS DE OBTENÇÃO DE NANOTUBOS DE CARBONO}

Saito, Y. et al. (37), em 1993, desenvolveu a Descarga por Arco (Arc Discharge), que é baseado em uma descarga por arcos elétricos, gerados por dois eletrodos cilíndricos de grafite com diâmetro de 6 a 10 mm, em uma câmara de aço, geralmente contendo gás inerte (38). Os dois eletrodos são mantidos a uma distância menor do que $1 \mathrm{~mm}$, acarretando uma temperatura de plasma na faixa de $3000^{\circ} \mathrm{C}$ a $4000^{\circ} \mathrm{C}$. Um deles pode ser preenchido com partículas metálicas (metais de transição: geralmente Fe, $\mathrm{Ni}$, Co e suas combinações) e catalisadores, que sofrendo a descarga elétrica, aparece alta temperatura entre eles, que permite a sublimação do carbono para a formação de nanotubos (39). Este método produz nanotubos de alta qualidade em relação à estrutura dos nanotubos, porém com uma alta taxa de impurezas nas amostras.

A Ablação a Laser (Laser Ablation) é um outro método que assemelha-se em alguns aspectos ao método de descarga por arco, gerando fulerenos na fase gasosa, mas com menor teor de impurezas. O carbono, geralmente grafite de alta pureza 
(40), é vaporizado através de um laser de NdYAG pulsado ou de $\mathrm{CO}_{2}$, irradiado e focalizado, a partir de uma superfície de disco de grafite, com quantidades pequenas de metais de transição (podendo utilizar esses metais) com a finalidade de condensar o carbono na forma de SWNTS, em um forno de alta temperatura (até $1500{ }^{\circ} \mathrm{C}$ ) em atmosferas de gases inertes ( $\mathrm{Ne}, \mathrm{Ar}, \mathrm{He})$, que é inserido no meio de um tubo de quartzo, sob temperatura de cerca de $1200{ }^{\circ} \mathrm{C}$, acarretando a formação de nanotubos, condensados numa superfície refrigerada de cobre. Assim, a variação dos diâmetros dos SWNTs pode ser conseguida simplesmente mudando a temperatura do forno, o gás transportador, a taxa do fluxo de gás, etc., levando, desse modo, o sistema a uma evaporação mais uniforme (41).

No método de deposição química de vapor (CVD), o processo envolve a reação de decomposição de um vapor ou gás precursor contendo átomos de carbono, geralmente hidrocarboneto, na presença de um catalisador metálico em atmosfera inerte. Geralmente, esta decomposição é realizada em temperaturas abaixo de $1000^{\circ} \mathrm{C}$. Os nanotubos de carbono são criados pelos átomos de carbono advindos da decomposição do precursor, sendo possível obter nanotubos de paredes simples ou múltiplas utilizando um catalisador suportado em sílica, alumina, zeólitos, entre outros (42). Neste último processo o catalisador é fundamental para a obtenção dos nanotubos de carbono de paredes simples ou duplas (43).

A microestrutura dos nanotubos de carbono produzidos por CVD são dependentes dos parâmetros do processo, como por exemplo, temperatura, pressão, quantidade do precursor, forma e diâmetro das partículas do catalisador. E é importante considerar que o interesse por esse método vem crescendo e sendo largamente utilizado para a produção de nanotubos à base de fulerenos em grande quantidade, de modo simples, em grande escala e com custo reduzido, pois oferece parâmetros facilmente controlados e possibilidade de crescimento contínuo. A figura 14 mostra um conjunto de nanotubos de carbono formados pelo método CVD.

No processo de Pirólise de Spray os nanotubos são fabricados pelo processo de introdução das moléculas de carbono em solução e sendo arrastados por um fluxo contínuo, denominado floating catalysts. Tem como dinâmica básica a introdução de partículas catalíticas em um reator, por intermédio de um fluido transportador, envolvendo a atomização de uma solução previamente contida em recipiente de vidro com a ajuda de fluxo de ar para dentro de um tubo de quartzo pré-aquecido até a temperatura ideal para a síntese de nanotubos (44).

\subsubsection{O MÓDULO DE YOUNG EM MATERIAIS MACROSCÓPICOS}

Quando algum novo material é produzido ou descoberto, como por exemplo uma nova liga de alumínio, uma maneira de se conhecer a suas propriedades é realizar 


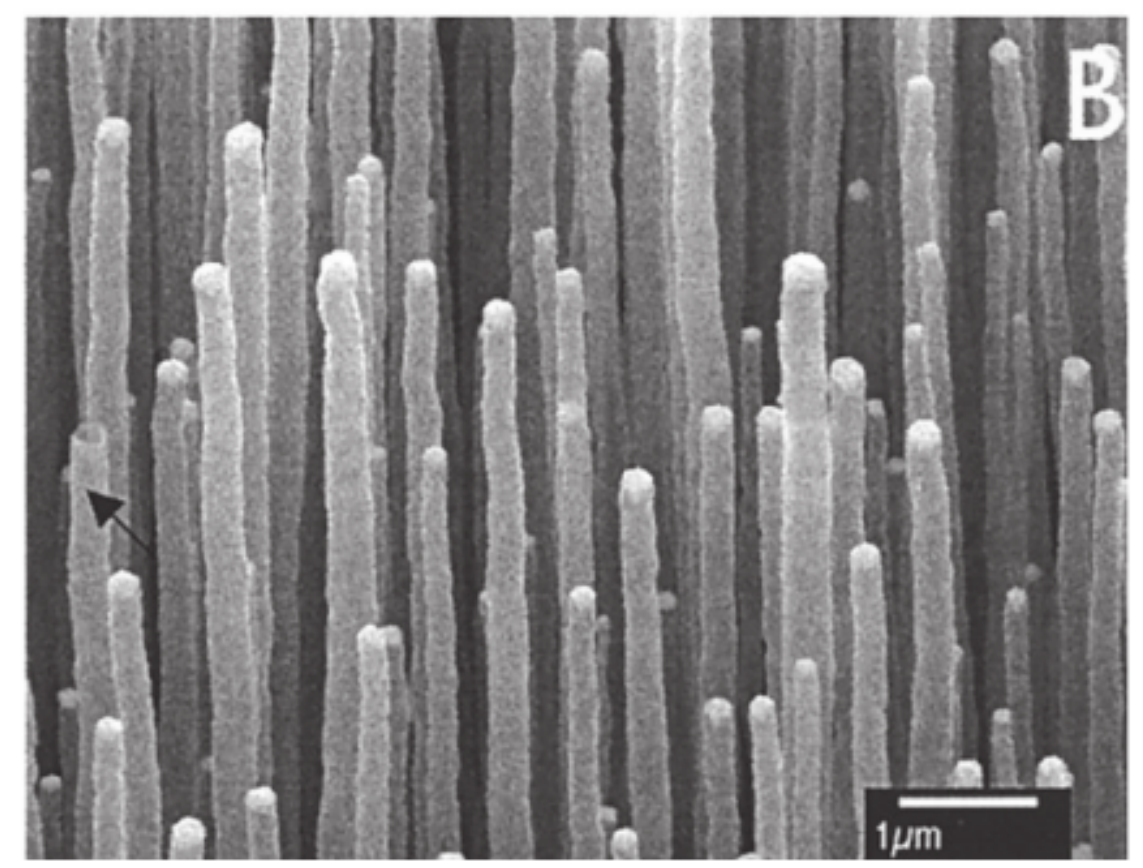

Figura 14 - Obtenção de nanotubos de carbono pelo método CVD

testes em sua estrutura através de tensões e deformações que são aplicados a este material (31). Isto necessariamente envolve uma compreensão das relações entre a microestrutura (isto é, características internas) de materiais e as suas propriedades mecânicas. Os materiais que são frequentemente escolhidos para aplicações estruturais, necessitam destes testes, justamente para se conhecer onde o material será aplicado, porque eles têm combinações desejáveis e características que podem ser utilizadas em diversas áreas. Há atualmente técnicas que são utilizadas em todo o mundo para se conhecer as propriedades mecânicas como rigidez, resistência, elasticidade e ductibilidade. O comportamento mecânico reflete a resposta de um material quando submetido a uma carga ou força aplicada. Existem quatro maneiras principais para se aplicar uma carga a um determinado material: a tensão, compressão, cisalhamento e a torção.

A tensão-deformação (45) é um dos testes mais comuns utilizados e serve para determinar várias propriedades mecânicas. Geralmente se usa uma amostra de 60 $\mathrm{mm}$ de comprimento por $12 \mathrm{~mm}$ de diâmetro, na qual se aplica uma carga ou força $\mathrm{F}$ gradualmente crescente ao longo do seu eixo longitudinal, levando vários minutos para ser executado, esticando ou comprimindo o material. Quando a amostra é tensionada, normalmente ela é deformada até à fratura, sendo totalmente destruída após o teste. A Figura 15 mostra a direção em que a força $F$ é aplicada quando a amostra é esticada ou comprimida e a Figura 16 mostra o desenho de uma máquina aplicando o teste de tensão-deformação. Neste caso, os dados são transmitidos a um computador e 
os resultados são registrados como a força ou carga em função de deformação. É importante considerar que a força aplicada é proporcional à área seção transversal da amostra ou corpo de prova. Neste caso a tensão de engenharia $T_{e}$ e a deformação de engenharia $\epsilon$ é dada por:

$$
\begin{gathered}
T_{e}=\frac{F}{A_{0}} \\
\epsilon=\frac{L-L_{0}}{L}
\end{gathered}
$$

Quando desejamos comprimir a amostra, usamos as mesmas equações 3.7 e 3.8 e, por convenção, considerando a força $\mathrm{F}$ e a deformação $\epsilon$ negativas. As unidades da tensão de engenharia são dadas em MPa e a deformação é adimensional.
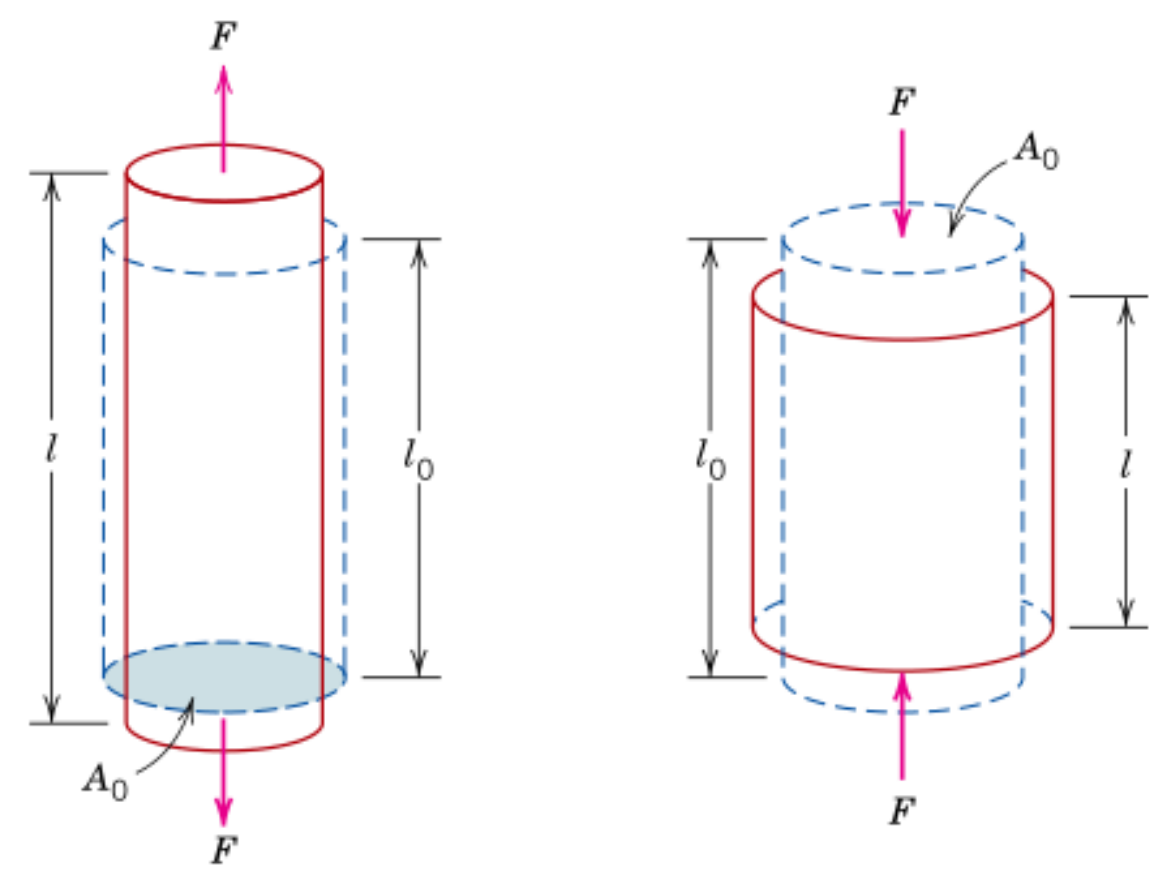

Figura 15 - À esquerda o material está sendo alongado e à direita está sendo comprimido. As linhas pontilhadas mostram o material antes da deformaçãofonte Callister

Onde $A_{0}$ é a área da seção transversal da amostra, L é o comprimento e $L_{0}$ é o comprimento inicial.

Quando desejamos fazer um ensaio de cisalhamento, conforme ilustrado na Figura 17, aplicamos uma força $\mathrm{F}$ paralela às seções de áreas superior e inferior da amostra, produzindo um ângulo $\theta$, onde a tensão $\tau$ e a deformação $\gamma$ de cisalhamento 


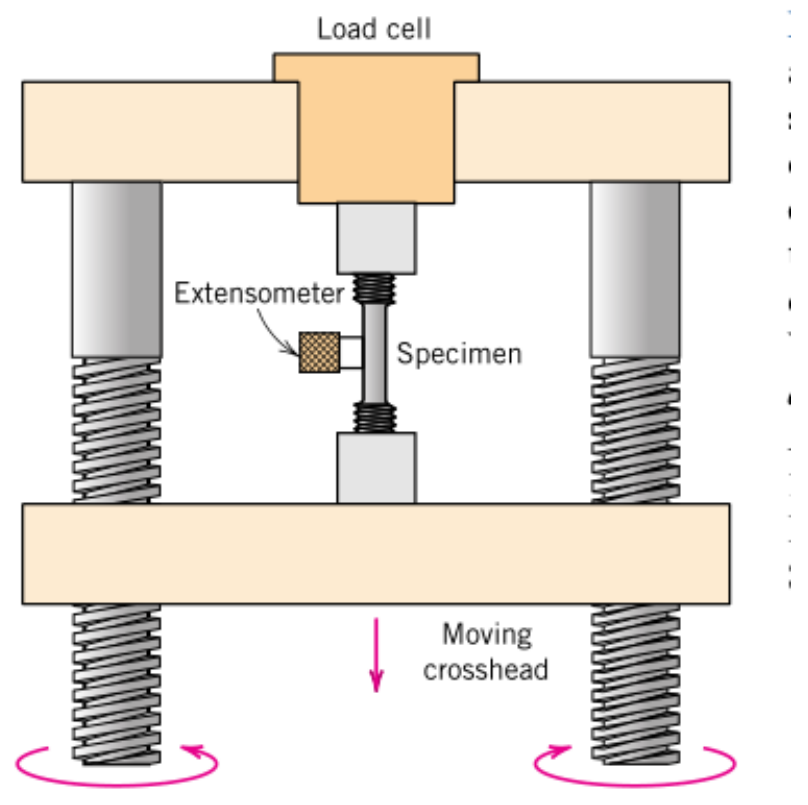

Figura 16 - Representação esquemática do aparelho usado para conduzir testes elásticos de tensão-deformação. A amostra de material é alongada pela cruzeta em movimento; uma célula de carga mede força F aplicada e o extensômetro mede o alongamento da amostra- fonte Callister.

é dado por:

$$
\begin{gathered}
\tau=\frac{F}{A_{0}} \\
\gamma=\tan \theta
\end{gathered}
$$

Onde $\tan \theta$ é a tangente do ângulo de deformação $\theta$ conforme mostrado na Figura 17.

A torção é uma variação do cisalhamento, onde existe um torque T (46) aplicado à amostra, enquanto a deformação de cisalhamento $\gamma$ está relacionado ao ângulo de torção $\phi$.

Quando um material e alongado na direção z, formando uma deformação $\epsilon_{z}$, há também deformaçôes $\epsilon_{x}$ e $\epsilon_{y}$, ambas na direção x e y, respectivamente. Neste caso podemos calcular o coeficiente de Poisson que é a razão entre as deformações lateral e axial, conforme é mostrado na Figura 18:

$$
v=-\frac{\epsilon_{x}}{\epsilon_{z}}=-\frac{\epsilon_{y}}{\epsilon_{z}}
$$



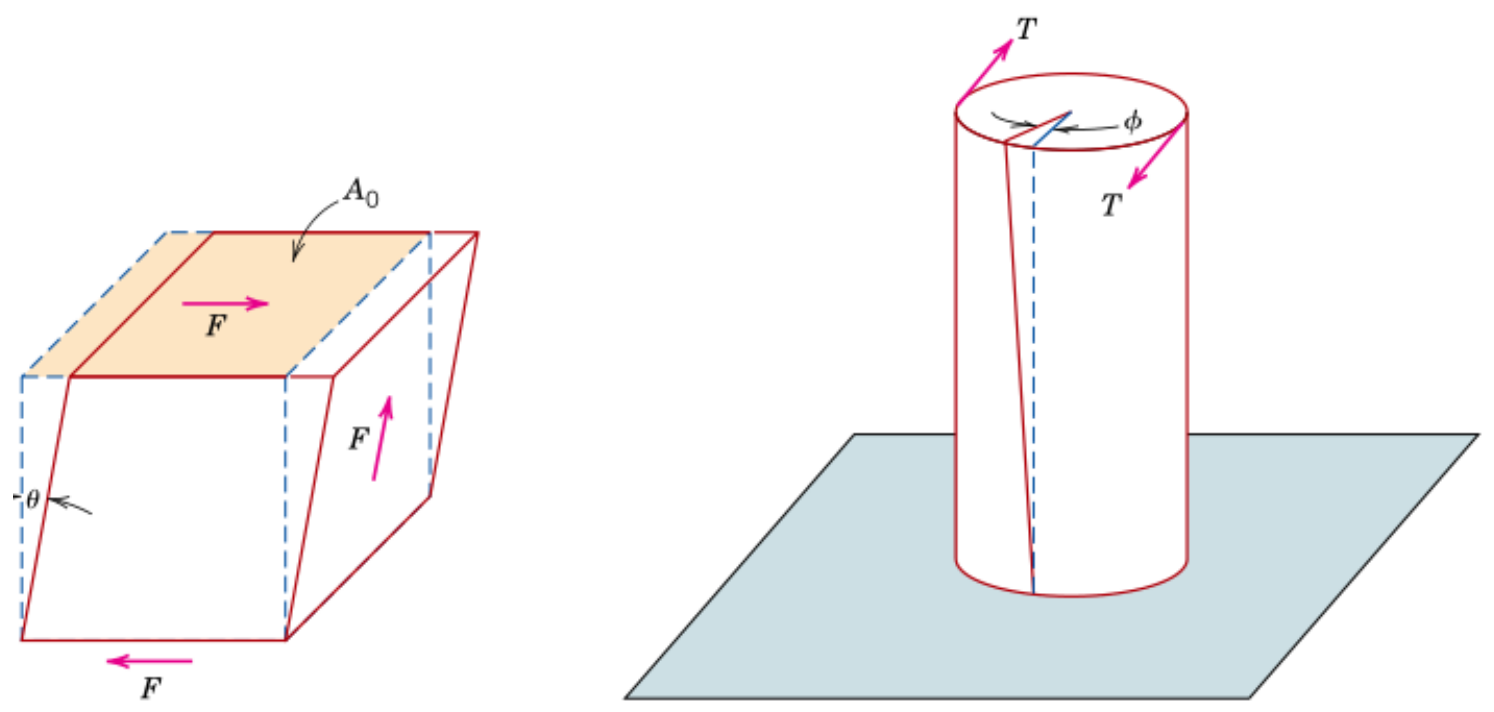

Figura 17 - À esquerda o material está sob deformação de cisalhamento e à direita está sob torção quando é aplicado um torque T. E $\phi$ é o ângulo de torção. As linhas pontilhadas mostram o material antes da deformação- fonte Callister.

Considerando o material isotrópico, $\epsilon_{x}=\epsilon_{y}$.

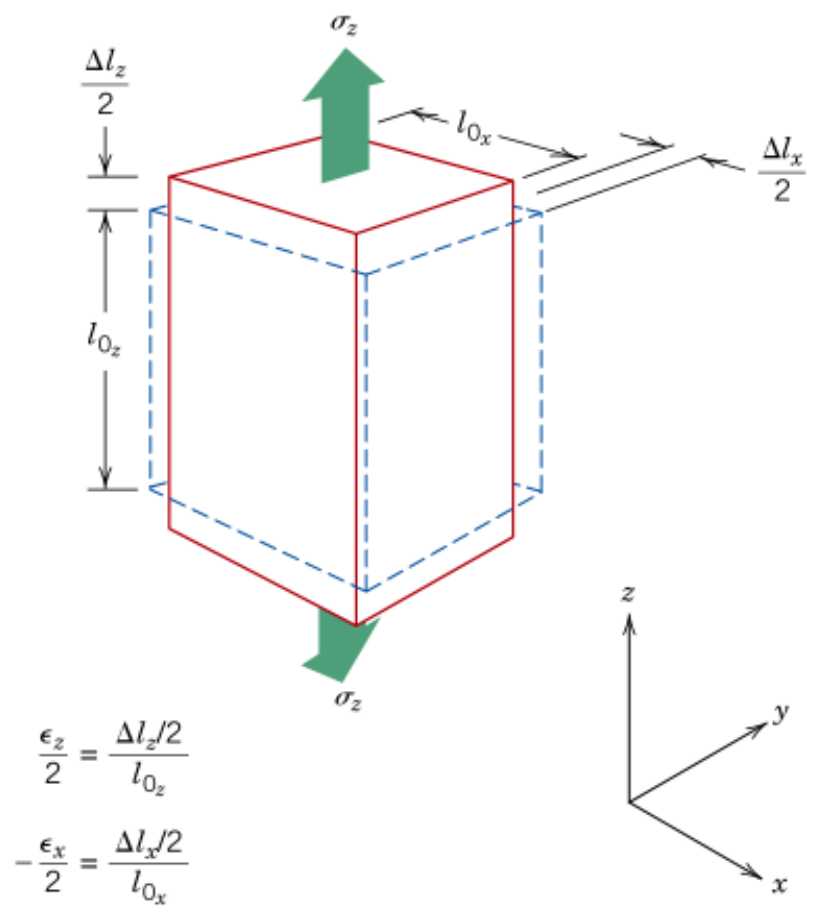

Figura 18 - Alongamento axial(z) (deformação positiva) e contrações laterais (x e y) (deformação negativa) na direção $\mathrm{z}$ em resposta a uma tensão de tração imposta. As linhas contínuas representam dimensões depois da aplicação tensão; as linhas tracejadas representam as dimensões antes da aplicação da tensão- fonte: Callister. 
Como o nosso trabalho tem como objetivo principal calcular o módulo de elasticidade na direção do comprimento do nanotubo, ou seja, na direção z, não trabalharemos com a tensão de cisalhamento.

Para a maioria dos metais o módulo de Young Y ou módulo de elasticidade na direção z é dado por:

$$
Y=\frac{T_{e}}{\epsilon}
$$

\subsubsection{O MÓDULO DE YOUNG EM NANOTUBOS DE CARBONO}

Para se calcular o módulo de Young em nanonotubos de carbono, necessitamos de uma outra abordagem (diferente daquela usada para materiais macroscópicos) que já foi alvo de estudo de vários autores, alguns usando métodos semelhantes, outros inovando e aperfeiçoando-os. Abaixo, descriminaremos, de uma forma sucinta, seus trabalhos e os seus métodos.

Robertson et al (47), em 1992, usando métodos de energia total com potenciais empíricos e de primeiros princípios, examinaram a energia e as propriedades elásticas de tubos de grafite com raios inferiores a 9 A. Encontrando que a energia de deformação por átomo de carbono em relação a uma folha de grafite não forçada varia em a 1 / R (em que $\mathrm{R}$ é o raio do tubo) e é insensível aos outros aspectos da estrutura de rede, indicando que as relação deriváveis da teoria elástica contínua persiste até o limite de pequenos raios. Os potenciais empíricos prevem ainda que as constantes elásticas ao longo do eixo do túbulo geralmente amolecem com a diminuição do raio do tubo, embora com uma dependência distinta na conformação helicoidal. Este autor e sua equipe usa um modelo elástico contínuo, utilizado por Tibbetts (48), em 1983, para derivar a energia de deformação da seguinte forma:

$$
\sigma=\frac{\pi L Y a^{3}}{12 R}
$$

Onde L é o comprimento, Y o módulo de Young, $a$ a espessura da parede e R é o raio do tubo. Dividindo esta equação pela número de átomos dado por $N=\frac{2 \pi R L}{\Omega}$, sendo $\Omega=3.02$ a área por carbono, nós encontramos a energia de deformação por átomo:

$$
\frac{\sigma}{N}=\frac{Y a^{2} \Omega}{24 R^{2}}
$$

Com isto foi calculado energias totais para uma série de tubos usando métodos de primeiros princípios, Densidade Funcional Local (LDF). Esses tubos são da forma $(n, m)$ e , foram encontrado as estruturas de menor energia por minimização direta da energia total. $\mathrm{O}$ mínimo da estrutura de energia foi encontrada para ter um raio de 
3.47 , com as ligações carbono-carbono sendo de $1,44 \AA$. Usando estruturas tubulares não otimizadas geradas a partir de um conformal mapeamento de uma folha de grafite , foram calculadas as energias totais dos tubos $(3,3),(4,4),(5,5),(6,6),(7,7)$, e $(9,9)$. Foi examinado a energética de alongamento e compressão de um tubo. A Figura. 19 mostra o total de energia versus a tensão ao longo do eixo dos tubos $(5,5)$, na qual foi comparado os resultados de estruturas totalmente otimizadas para um comprimento fixo ao longo do eixo do tubo, utilizando tanto os potenciais empíricos e do método LDF. Depois foi estendidos os cálculos potenciais empíricos sobre o mesmo conjunto de tubos usados acima para as segundas derivadas numéricas do total de energias com respeito à tensão ao longo do eixo tubular. Estes resultados (em termos de energia de deformação por átomo de carbono) estão representados na Figura 20. Observa-se que, com o aumento dos raios, estes valores se aproximam de um valor limite. $\mathrm{E}$ também relatam um pequeno enfraquecimento da rigidez do nanotubos à medida que o diâmetro diminui, e, por conseguinte, um módulo de Young menor para os nanotubos comparados com o grafeno. Eles encontram uma dependência sistemática com a quiralidade que, apesar de ser pequena, aumenta com a diminuição do raio do tubo.

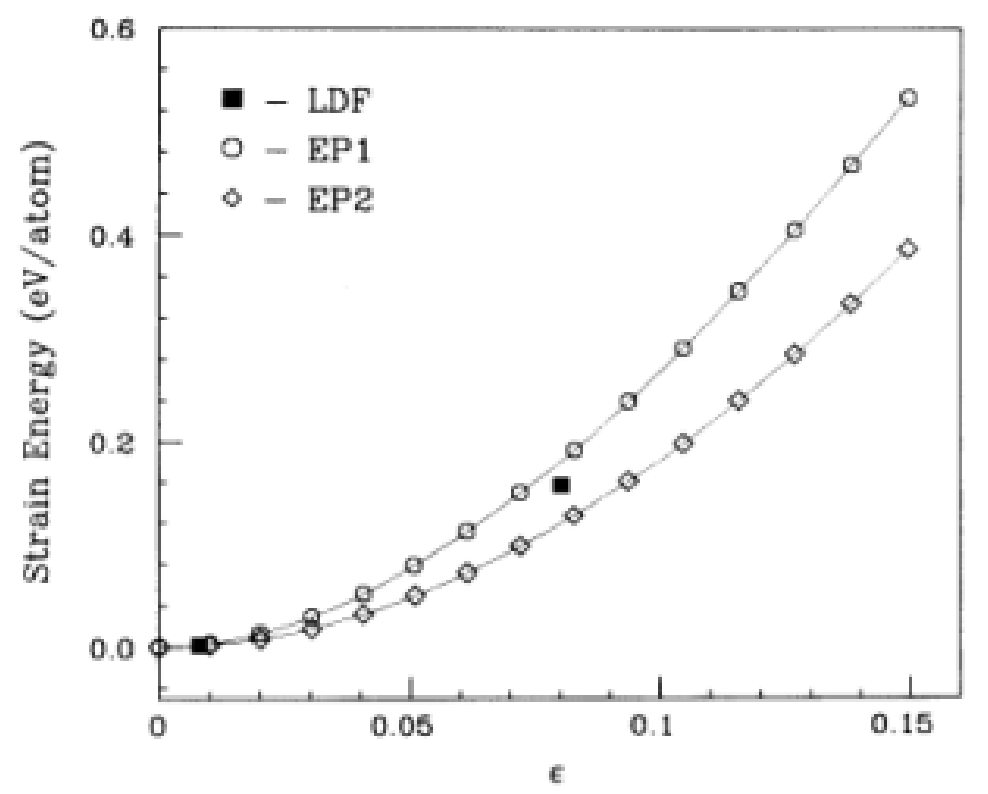

Figura 19 - Energia de deformação (eV por átomo de carbono) vs uniforme esforço de tensão na direção do eixo tubular para o tubo [5,5] usando potenciais empíricos EP1 (círculos abertos), EP2 (losangos abertos), e o método LDF (quadrados a cheio) calculados por Robertson et al .

Treacy et al (49), em 1996, estimou o módulo de Young de nanotubos medindo num microscópio eletrônico de transmissão a amplitude de suas vibrações termais intrínsecas. A partir destas observações, ele concluiu que os nanotubos de carbono 


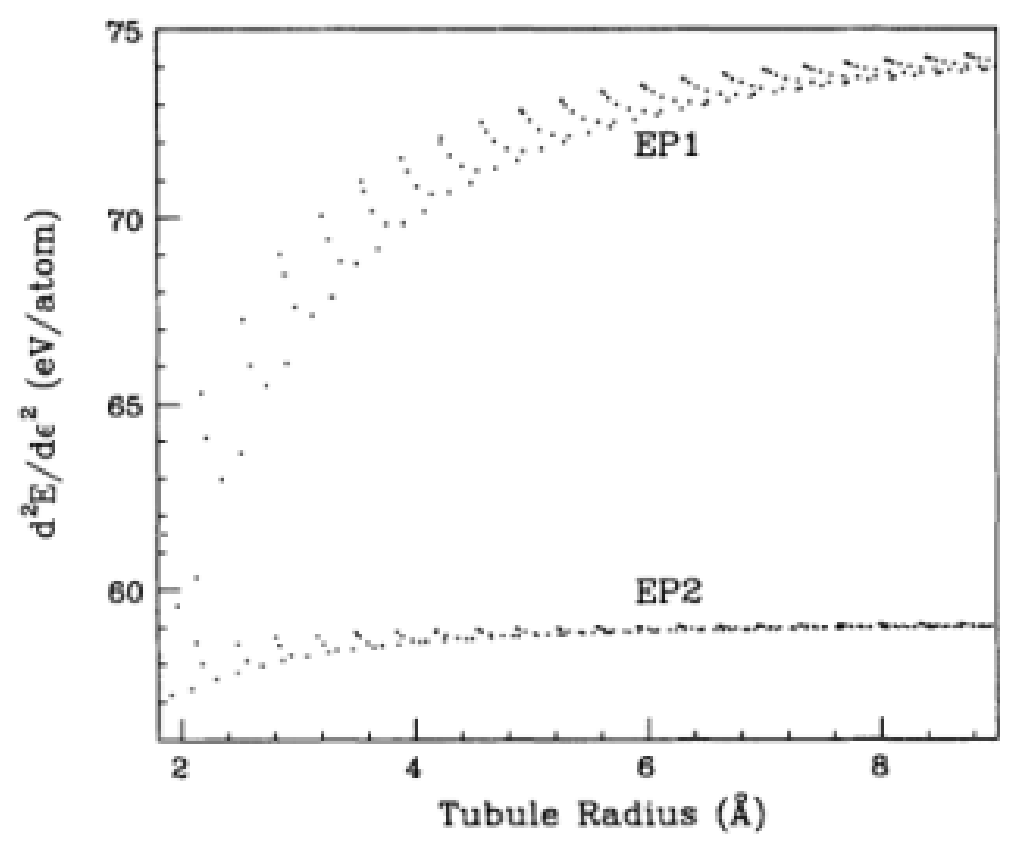

Figura 20 - Segunda derivadas numéricas de energia por carbono no que diz respeito à deformação uniforme ao longo da direção do eixo do tubo para potenciais EP1 e EP2 calculados por Robertson et al .

tem uma grande resistência, em 1TPa, e que sua resistência, associada com sua baixa densidade, implica que os nanotubos serão úteis na fabricação de materiais leves, compostos com fibras fortes. Nesta formulação Treacy considerou o nanotubo como uma barra de comprimento $\mathrm{L}$, com raio externo $a$ e raio interno $b$, onde foi medido a amplitude de vibração da barra, com desvio padrão dado pela soma das variâncias, chegando numa expressão onde se pode obter o módulo de Young:

$$
\sigma^{2}=0.4243 \frac{L^{3} K_{b} T}{Y\left(a^{4}-b^{4}\right)}
$$

Onde Y é o módulo de Young, $K_{b}=1,38.10^{-23} \mathrm{~m}^{2} \mathrm{kgs}^{-2} \mathrm{~K}^{-1}$ é a constante de Boltzmann e $\mathrm{T}$ é a temperatura. Abaixo, segue a Tabela1 mostrando os valores do módulo de Young obtidos por Treacy et al:

Jian Ping Lu (50), em 1997, investigou as propriedades dos nanotubos de carbono usando o modelo de força constante empírica, usando a segunda derivada da densidade da energia de deformação, fixando o coeficiente de poisson, com a espessura da parede do tubo $h=3.4 \AA$, concluindo que:

1. Os módulos elásticos são insensíveis para o tamanho e a helicidade.

2. Os módulos Young dos nanotubos são comparáveis à do diamante(1.06 TPa) e 
Tabela 1 - Valores do módulo de Young obtidos por Treacy et al.

\begin{tabular}{|c|c|c|c|c|}
\hline \hline$N^{o}$ Nanotubo & Comp. $(\AA)$ & Diam.Ext. $(\AA)$ & Diam.Int. $(\AA)$ & Mod.Young(TPa) \\
\hline 1 & 11700 & 56 & 23 & 1.06 \\
2 & 31100 & 73 & 20 & 0.91 \\
3 & 58100 & 248 & 66 & 0.59 \\
4 & 26500 & 119 & 20 & 1.06 \\
5 & 17300 & 70 & 23 & 2.58 \\
6 & 15300 & 66 & 23 & 3.11 \\
7 & 20400 & 70 & 30 & 1.91 \\
8 & 14300 & 66 & 33 & 4.15 \\
9 & 6600 & 70 & 33 & 0.42 \\
10 & 13200 & 99 & 30 & 0.4 \\
11 & 51000 & 84 & 10 & 3.7 \\
\hline \hline
\end{tabular}

do grafite(1.02 TPa) ao longo do plano basal.

3. Os nanotubos de parede simples são resistentes tanto na direção axial quanto no plano basal.

Na Tabela 2 podemos encontrar os valores do módulo de Young e cisalhamento obtidos por Jian Ping Lu:

Tabela 2 - Módulos de Young e cisalhamento de nanotubos de parede simples.

\begin{tabular}{|c|c|c|c|}
\hline \hline Tubo $\left(n_{1}, n_{2}\right)$ & Raio(nm) & Mod.Young(TPa) & Mod.Cis.(TPa) \\
\hline$(5,5)$ & 0.34 & 0.97 & 0.44 \\
$(6,4)$ & 0.34 & 0.97 & 0.44 \\
$(7,3)$ & 0.35 & 0.97 & 0.45 \\
$(8,2)$ & 0.36 & 0.97 & 0.45 \\
$(9,1)$ & 0.37 & 0.97 & 0.47 \\
$(10,0)$ & 0.39 & 0.97 & 0.45 \\
$(10,10)$ & 0.68 & 0.97 & 0.46 \\
$(50,50)$ & 3.39 & 0.97 & 0.46 \\
$(100,100)$ & 6.78 & 0.97 & 0.46 \\
\hline \hline
\end{tabular}

Outro grupo, E. Hernández et al (51) , em 1998, usando um método Tightbinding (TB) não ortogonal, estudou as propriedades energéticas, estruturais e elásticas dos nanotubos de carbono, incluindo nanotubos de $B N, B C_{3}$ e $B C_{2} N$ usando a equação 3.16, sendo que:

$$
Y_{S}=\frac{1}{S} \frac{\partial^{2} E}{\partial \epsilon^{2}}
$$


E

$$
Y=\frac{Y_{s}}{h}
$$

Onde $S=2 \pi R L$, com $\mathrm{R}$ sendo o raio, $\mathrm{L}$ o comprimento do tubo, $\mathrm{S}$ a superfície do tubo e $h=3.4 \AA$. A Tabela. 3 mostra os valores do módulo de Young obtidos por este autor, além do coeficiente de Poisson $v$. E a Figura 21 mostra o gráfico da energia de deformação que decresce com o raio do tubo, concluindo que os valores do módulo de Young para os nanotubos simples dão valores da ordem de 1TPa, bastante insensível à quiralidade do nanotubo, e principalmente determinada pelo diâmetro do tubo, se aproximando do limite de grafite para diâmetros de $1.2 \mathrm{~nm}$.

Tabela 3 - Módulos de Young e Coeficiente de Poisson de SWNT obtidos por Hernándes et al.

\begin{tabular}{|c|c|c|c|c|}
\hline \hline Tubo(n,m) & Diam. $(\mathrm{nm})$ & C.Poisson & $Y_{S}(\mathrm{TPa} . \mathrm{nm})$ & Mod. Young(TPa) \\
\hline$(10,0)$ & 0.80 & 0.28 & 0.42 & 1,22 \\
$(6,6)$ & 0.82 & 0.25 & 0.42 & 1.22 \\
$(10,5)$ & 1.03 & 0.27 & 0.43 & 1.25 \\
$(10,7)$ & 1.17 & 0.27 & 0.42 & 1.24 \\
$(10,10)$ & 1.36 & 0.26 & 0.42 & 1.24 \\
$(20,0)$ & 1.57 & 0.27 & 0.43 & 1.26 \\
$(15,15)$ & 2.03 & 0.26 & 0.43 & 1.25 \\
\hline
\end{tabular}

Já outra equipe, A. Krishnan et al (52), em 1998, aplicou a técnica de Treacy et al medindo o módulo de Young de muitos tubos isolados de paredes simples. Foi descrito um procedimento de otimização de mínimos quadrados para extrair com precisão as dimensões dos nanotubos e amplitudes de vibrações diretamente a partir de imagens digitais. Este processo assume apenas que o perfil de vibração é de uma viga presa. Eles encontraram um valor médio de $Y=1.25-0.35 /+0.45 T P a$, o que é consistente com os resultados para tubos de paredes múltiplas.

A relação entre o módulo de Young Y, comprimento $\mathrm{L}$, raio interior $b$ e exterior $a$ do tubo duplo e o desvio padrão $\sigma$ da amplitude de vibração na ponta de um nanotubo a uma temperatura T proposta por Krishnan é dado por:

$$
\sigma^{2}=0,4243 \frac{L^{3} K_{b} T}{Y\left(a^{4}-b^{4}\right)}
$$

E para um tubo de parede simples:

$$
\sigma^{2}=0,8486 \frac{L^{3} K_{b} T}{Y W G\left(W^{2}+G^{2}\right)}
$$




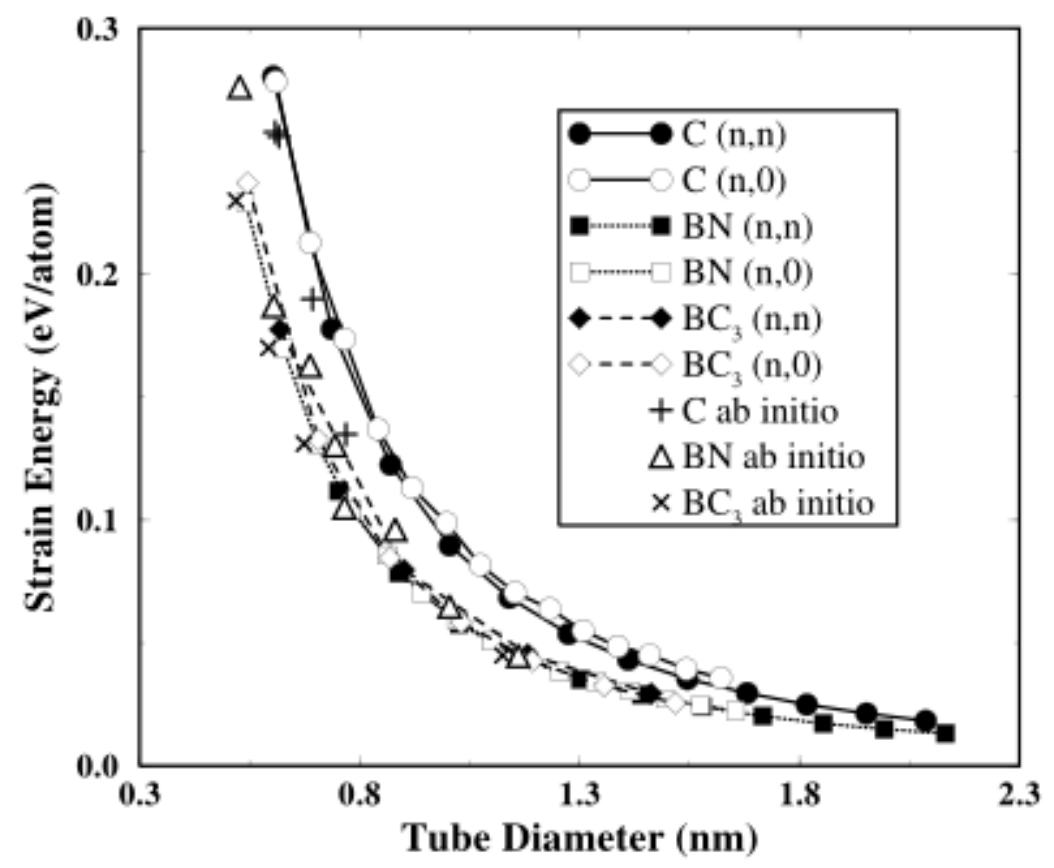

Figura 21 - Energia de deformação de curvatura em função do diâmetro do tubo de equilíbrio, tal como obtida a partir de cálculos tight-binding para nanotubos, para $\mathrm{C}, \mathrm{BN}$ e $B C_{3}$-E. Hernández et al.

Onde $\mathrm{W}$ é o diâmetro do tubo e $G=3.4 \AA ̊$ é a espessura da parede do tubo.

Os parâmetros dos nanotubos mostrados na Figura 22 ,incluindo nanotubos de diâmetro W, com correspondente estimativa do Y módulo de Young, são:

1. $L=36.8 \mathrm{~nm}, \sigma=0.33 \mathrm{~nm}, W=1.50 \mathrm{~nm}, Y=1.336 \pm 0.2 \mathrm{TPa}$;

2. $L=24.3 n m, \sigma=0.18 n m, W=1.52 n m, Y=1.206 \pm 0.2 \mathrm{TPa}$;

3. $L=23.4 n m, \sigma=0.30 n m, W=1.12 n m, Y=1.026 \pm 0.3 T P a$;

Daniel Sánchez-Portal (34), em 1998, nos diz que os cálculos realizados até agora para se encontrar o módulo de Young mostram uma grande dispersão em suas previsões, com alguns relatando valores da ordem de 5 TPa com base num empírico modelo Keating de força constante para o nanotubo $(5,5)$ finito e tampado. Outros, em um estudo sobre a estrutura instabilidades de SWNT para grandes deformações, e usando potenciais Tersoff-Brenner, obter uma estimativa para os módulo de Youngs de cerca de $5.5 \mathrm{TPa}$. E tantos encontrando valores para o nanotubos entre 0.8 à 1.2 TPa. Ele esclarece que valores exageradamente altos do módulo de Young pode ser devido ao pequeno tamanho dos agregados utilizados para descrever o tubo, como a 

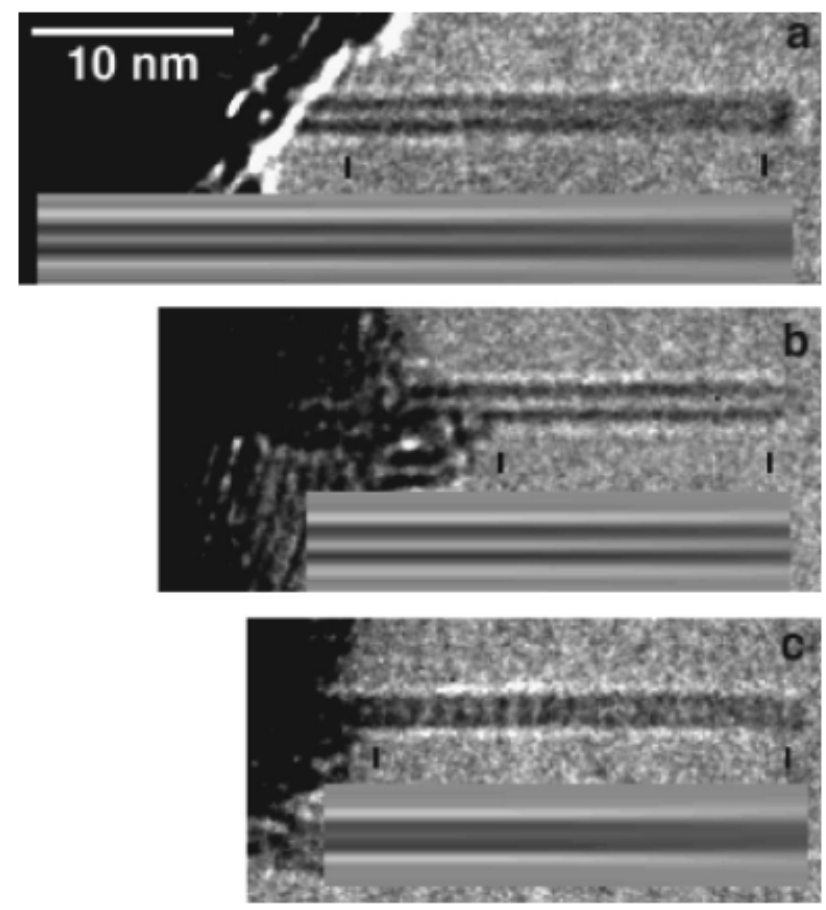

Figura 22 - Micrografias de vibração de nanotubos simples no campo de vibração TEM . Inserido em cada micrografia é a imagem simulada que corresponde aos melhores mínimos quadrados após o ajuste para o comprimento L nanotubo livre L e ponta amplitude de vibração $\sigma$. As marcas em cada micrografia indicar a secção da haste nanotubo que foi montado-A. Krishnan et al.

quantidade de átomos ou devido a uma definição diferente do módulo de Young nestes sistemas, como exemplo o espaçamento do plano do grafeno usado por Yakobson et al de $h=0.6 \AA$, quando muitos autores usam o valor de $3.4 \AA$.

Este autor nos esclarece que os resultados experimentais dão um módulo de Young em torno de um 1TPa, semelhante ao do grafite, mas a incerteza experimentais é bastante elevada. Há também um desacordo dos valores teóricos na literatura correspondente a diferentes aproximações, mas também há diferentes definições eficazes da área seccional para os cálculos dos módulos de Young .

No trabalho de Daniel Sánches foi utilizando a Teoria Funcional da Densidade com Pseudopotencial e foi analisado resultados sobre a rigidez elástica dos nanotubos utilizando a segunda derivada da energia de deformação com respeito à tensão axial: $\frac{\partial^{2} E}{\partial \epsilon^{2}}$. O valores encontrados estão listados na Tabela 4.

Os resultados mostram claramente que não há diferença apreciável entre os resultados obtidos para os nanotubos e aqueles obtidos na folha de grafeno, sendo as diferenças dentro da incerteza do cálculo. Estes dados confirmam que o efeito de curvatura sobre o módulo de Young do SWNT é pequeno para raios da ordem de, 
Tabela 4 - Cálculo da $\frac{\partial^{2} E}{\partial \epsilon^{2}}$ para diferentes SWNT e folhas de grafeno com diferentes células.

\begin{tabular}{|c|c|c|}
\hline \hline Tubo $(n, m)$ & Raio $(\AA)$ & $\frac{\partial^{2} E}{\partial \epsilon^{2}}(E v)$ \\
\hline$(4,4)$ & 2.794 & 56 \\
$(5,5)$ & 3.463 & 55 \\
$(6,6)$ & 4.140 & 56 \\
$(8,8)$ & 5.498 & 59 \\
$(10,10)$ & 6.864 & 52 \\
$(8,4)$ & 4.211 & 54 \\
$(10,0)$ & 3.979 & 60 \\
Grafeno (4,4) & & 50 \\
Grafeno (10,10) & & 54 \\
\hline \hline
\end{tabular}

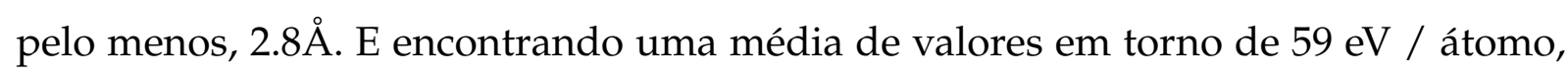
com muito pouca dependência do raio e / ou quiralidade. Usando a constante elástica $C_{11}=1.06$ TPA do grafite em volume foi obtido a $\frac{\partial^{2} E}{\partial \epsilon^{2}}=C_{11} V a=58.2 \mathrm{eV} /$ átomo ( onde Va é o volume atômico do grafite), encontrando valores parecidos com Robertson et al(fig. 20)

Boris I. Yakobson et al (36), em 2001, nos esclarece que uma definição de módulos de elasticidade de um sólido implica uma uniformidade espacial do material, pelo menos num sentido médio, estatístico. Isto é necessário para uma definição precisa de qualquer característica, e geralmente não em escala nanométrica. Um único nanotubo possui variância translacional em direção radial, uma vez que um centro oco e uma sequência de camadas coaxiais são bem distintas, com o espaço entre as camadas, c, comparável com a raio do nanotubo, R. E uma definição de quaisquer características do material, deve ser sempre acompanhada com os pressupostos adicionais específicos envolvidos (por exemplo, a definição de uma área de secção transversal). Sem eles confusões podem facilmente prejudicar os resultados ou comparações.

O padrão inicial para se definir o módulo elástico como $\frac{1}{V} \frac{\partial^{2} E}{\partial \epsilon^{2}}$ não é uma posição segura para estruturas moleculares, funcionando para $\epsilon$ na direção axial; sendo que qualquer outra deformação, em outras direções, induz tensões não uniformes das camadas constituintes, o que torna a expressão anterior enganosa. Além disso, para os nanotubos ocos, o volume $\mathrm{V}$ é não é bem definido. Para um determinado comprimento $\mathrm{L}$ de um nanotubo, a área de secção transversal A pode ser escolhida de várias maneiras relativamente arbitrárias, tornando assim tanto o volume $V=L A$ errôneo. Para eliminar este problema, a energia elástica do nanotubo é melhor caracterizada pela mudança da energia não pelo volume, mas por área $S$ da camada de grafite constituinte (ou camadas), $C=\frac{1}{S} \frac{\partial^{2} E}{\partial \epsilon^{2}}$. A uniformidade espacial bidimensional da 
camada de grafite assegura que $S=l L$, e, assim, o valor de $C$ se torna correto. Aqui lé o comprimento da circunferência total das camadas do grafite na seção transversal do nanotubo. Ao contrário de módulos materiais mais comuns, $\mathrm{C}$ tem dimensão de tensão superficial, N / m, e pode ser definido em termos de mensurável características dos nanotubos,e pode ser definido em termos de mensurável características dos nanotubos.

Assim o Módulo de Young pode ser escrito:

$$
Y=\frac{1}{L l h} \frac{\partial^{2} E}{\partial \epsilon^{2}}
$$

onde $h=3,4 \AA$ é a espessura da parede do tubo.

Por exemplo, para um volume de grafite $h=c=0.335 \mathrm{~nm}, \mathrm{C}=342 \mathrm{~N} / \mathrm{meY}=$ $1.02 \mathrm{GPa}$, respectivamente. Este cálculo funciona razoavelmente bem para tubos de grandes diâmetros com multicamadas (macro-limite), mas pode causar erros significativos na avaliação axial e especialmente rigidez à flexão para estreitos e, em particular, nanotubos de parede simples. 


\section{METODOLOGIA}

\subsection{MODELAGEM MOLECULAR}

O interesse em modelagem molecular utilizando recursos computacionais vem aumentando em função do melhor desempenho apresentado pelos computadores nas últimas duas décadas (53). A modelagem molecular atualmente está sendo amplamente aplicada na interpretação de resultados experimentais e na construção de novos materiais com propriedades específicas. A base da modelagem molecular está em relacionar todas as propriedades moleculares importantes, ou seja, estabilidade, reatividade e propriedades eletrônicas com a estrutura molecular. Desta forma é possível desenvolver algoritmos capazes de calcular uma estrutura molecular com uma estereoquímica específica e correlacioná-la com as propriedades moleculares apresentadas pela substância.

Existem três principais categorias de cálculos teóricos: método de orbital molecular ab initio, método de orbital molecular semi-empírico e cálculos de campo de força empírico também conhecido como mecânica molecular. Dos três métodos, os dois primeiros usam a mecânica quântica (54) e para efeito deste trabalho, nos concentraremos neste último, que utiliza o conhecimentos da mecânica clássica por ser mais simples e rápido. Abaixo segue os pontos principais deste assunto encontrados com maior profundidade na referência (55).

\subsection{MECÂNICA MOLECULAR}

A geometria de uma molécula é especificada em termos de suas coordenadas atômicas. Assim, a partir de um conjunto de dados de entrada, uma geometria inicial é especificada e sua energia estérica é calculada (56). Todos os parâmetros que definem a geometria do sistema são modificados em incrementos pequenos e, através do uso de métodos de abaixamento de gradiente, a geometria é otimizada ( ou seja, a E é minimizada). É importante lembrar que a minimização é um método interativo de otimização geométrica que depende da geometria de partida. A minimização usualmente leva ao mínimo local mais próximo e não ao mínimo global. A varredura completa da superfície de energia potencial (SEP) de uma molécula é chamada de análise conformacional.

Na análise conformacional (57) por busca sistemática são feitos incrementos nos valores dos ângulos diedro de todas ligações passíveis de rotação para explorar o 
espaço conformacional da molécula.

Os cálculos de dinâmica molecular (DM) simulam o movimento baseado em cálculos de energia potencial usando o campo de força e as equações de Newton para o movimento (46), assumindo cada átomo como uma partícula. As equações do movimento de Newton são usadas para calcular a posição e a velocidade de todos os átomos a cada intervalo de tempo.

A simulação de DM pode ser descrita para um sistema atômico simples pela Equação 4.1:

$$
\begin{gathered}
F_{i}(t)=m_{i} a_{i} \\
F_{i}(t)=-\frac{\partial V\left(r_{i}\right)}{\partial \vec{r}_{i}},
\end{gathered}
$$

onde $F_{i}$ é a força que atua sobre cada partícula do sistema em um instante de tempo $\mathrm{t}$, e $a_{i}$ é a aceleração do átomo i de massa $m_{i}$. Uma vez definido o campo de força, é possível calcular as forças que atuam sobre cada átomo, calculando-se a primeira derivada da energia potencial em relação às posições desses átomos (Equação 4.3). Conhecendo-se a massa da partícula, esta equação gera diretamente a aceleração da partícula. Integrando-se a aceleração, pode-se obter a velocidade, cuja integral, por sua vez, proporciona a mudança de posição do átomo. Com as novas posições e velocidades de cada partícula, obtêm-se as energias potencial e cinética do sistema. Aplicando-se sucessivamente esse procedimento, obtém-se o que se denomina de "trajetória", que nada mais é do que o conjunto de posições e velocidades de cada partícula ao longo do tempo (58).

Um dos métodos mais utilizados em dinâmica molecular para integrar as equações de movimento é o algoritmo de Verlet (59), obtido através da expansão em série de Taylor, que utiliza as posições e acelerações dos átomos no tempo $t$ e as posições do passo anterior, $\mathrm{r}(\mathrm{t}-\Delta t)$, para determinar as novas posições no tempo $\mathrm{t}+\Delta t$, de acordo com a Equação 9:

$$
r(t+\Delta t)=2 r(t)-r(t-\Delta t)+a(t) \Delta t^{2}
$$

onde $\Delta t$ é o passo de integração.

A mecânica molecular é um dos métodos que, principalmente por razões de simplicidade computacional e eficiência, tem sido o mais utilizado para modelar estruturas moleculares e energias conformacionais na elucidação de problemas experimentais em vários ramos das ciências. 
Historicamente, os cálculos de mecânica molecular tiveram início em compostos orgânicos. Os primeiros cálculos foram realizados por Bartell et al (60) e Boyd et al (61). Allinger (62) analisando as deficiências do que denominou "primeira geração" dos campos de força, onde estão incluídos os campos $M M 1, E A S, M u b-2$, desenvolveu o campo de força $M M 2$ para hidrocarbonetos, no qual incluiu os termos de torção e o aprimorou gerando os campos de força $M M 3$ para compostos orgânicos oxigenados. Posteriormente foram desenvolvidos campos de força para compostos inorgânicos. Desde então a mecânica molecular vem sendo utilizada no estudo de diferentes sistemas moleculares.

Na Mecânica Molecular, usamos o campo de força para calcular todas as forças intra e intermoleculares, contendo termos que descrevem as partes ligadas e não ligadas que estão atuando no sistema estudado, sendo que no caso ignoramos os elétrons devido a sua massa ser aproximadamente 1360 menor que a do núcleo e com uma função, calculamos a mínima energia do sistema somente com os movimentos dos núcleos a fim de encontrar a melhor geometria do sistema. No entanto, se quiséssemos fazer os cálculos pela mecânica quântica, teríamos que levar em conta todos os elétrons do sistema e como isso o cálculo seria muito demorado (63).

A Mecânica Molecular dá resultados próximos da Mecânica quântica em pouco tempo nos cálculos computacionais. Contudo não dá propriedades eletrônicas das moléculas. É baseada num simples modelo que calcula as interações dentro do sistema como ligações entre os núcleos, o abrir e fechar das ligações, como também a rotação existente neste conjunto. No caso é usada, de uma maneira bem aceitável, a lei de Hooke para expressar tais situações (55).

Os campos de forças podem conter muitos termos, mas existem quatro principais que trabalham com quatro componentes que descrevem as forças intra e intermoleculares dentro do sistema. Os vários termos podem ser descritos como cargas em específicas coordenadas levando em consideração os comprimentos das ligações, ângulos, rotações das ligações e movimentos de átomos uns com os outros, onde energias são associadas com o desvio das ligações e ângulos das ligações, predizendo certas propriedades, sendo que para isso terá que ser parametrizado. Este campo de força é uma forma funcional que pode ser usada para modelar uma simples molécula como um conjunto de átomos. Assim, existe uma função que descreve como a energia das cargas das ligações são rotacionadas e contem termos que descrevem as partes ligadas e não ligadas do sistema (64): 


$$
\begin{array}{r}
V\left(r^{N}\right)=\sum \frac{k_{i}}{2}\left(l_{i}-l_{i, 0}\right)^{2}+\sum \frac{k_{i}}{2}\left(\theta_{i}-\theta i, 0\right)^{2}+\sum \frac{V_{n}}{2}(1+\cos (n \omega-\gamma))+ \\
\sum_{i=1}^{N} \sum_{j=i+1}^{N}\left\{4 \epsilon_{i j}\left[\left(\frac{\sigma_{i j}}{r_{i j}}\right)^{12}-\left(\frac{\sigma_{i j}}{r_{i j}}\right)^{6}\right]+\frac{q_{i} q_{j}}{4 \pi \epsilon_{0} r_{i j}}\right\}
\end{array}
$$

Partindo-se da esquerda para a direita: $V\left(r^{N}\right)$ é o potencial de energia, dada pelas posições $r$ das $N$ partículas; o primeiro termo da equação após a igualdade representa a interação entre dois pares de átomos ligados, representado por um potencial harmônico, dando um acréscimo da energia quando o comprimento da ligação passa de $l_{i, 0}$ para $l_{i}$; o segundo termo representa o somatório de todas as valências angulares da molécula, usando um potencial harmônico em que os átomos $\mathrm{A}$ e B estão ligados com o átomo C; o terceiro termo é o potencial de torção, que modela como a energia muda rotacionando as ligações; o quarto termo são as ligações nãoligadas, calculadas entre os pares $i$ e $j$ de todas as moléculas do sistema considerado.

Agora, vamos discutir cada um destes componentes que formam o potencial de energia dado pelo campo de força.

\subsubsection{FORMAS LIGADAS}

\subsubsection{ALONGAMENTO DE LIGAÇÃO}

A curva de energia potencial de uma ligação normal tem a forma mostrada na Figura 23.

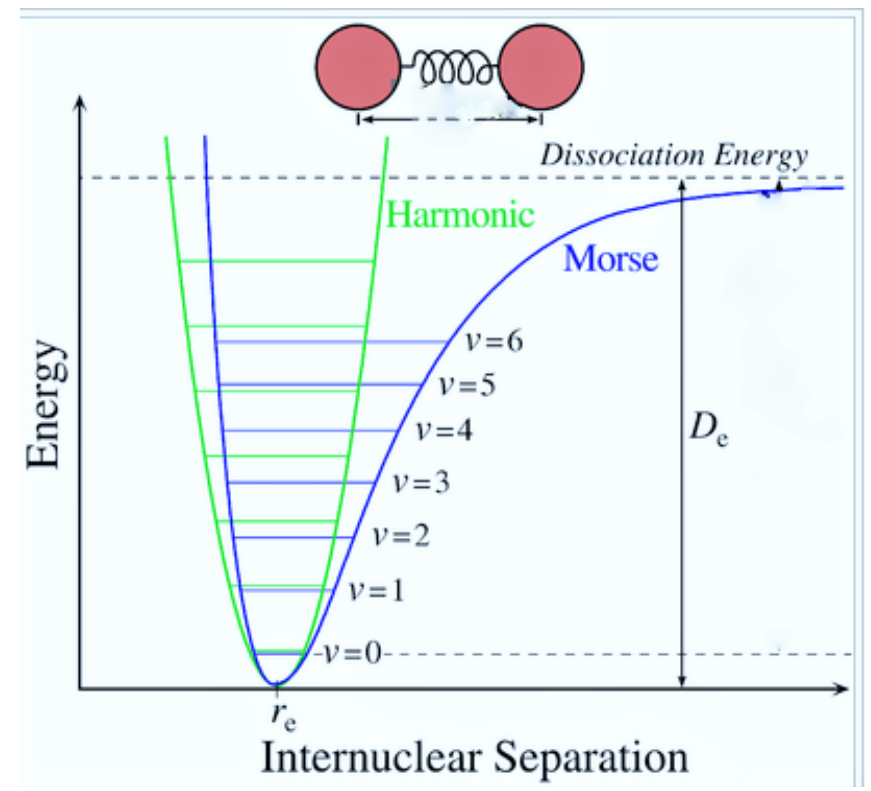

Figura 23 - Curva do Potencial Morse 
Das muitas formas funcionais usadas para modelar a curva de energia potencial, o sugerido por Morse (65) é o mais utilizado. O potencial de Morse tem a forma:

$$
v(l)=D_{e}\left\{1-\exp \left[-a\left(l-l_{0}\right)\right]\right\}^{2}
$$

$D_{e}$ representa a profundidade do potencial mínimo de energia e

$$
a=\omega \sqrt{\mu / 2 D_{e}}
$$

onde $\mu$ é a massa reduzida e $\omega$ é a frequência da vibração da ligação, $\omega$ é relacionada com a constante de alongamento da ligação, $k$, por

$$
\omega=\sqrt{k / \mu}
$$

$l_{0}$ é o valor de referência da ligação, que é o valor que a ligação adota quando todos os outros termos no campo de força são ajustados para zero. O equilíbrio do comprimento da ligação, pelo contrário, é o valor que é adotado em um mínimo de energia da estrutura, quando todos os outros termos no campo de força estão contribuindo.

Na complexa interação entre os diferentes componentes do campo de força, há desvios do valor de referência, a fim de compensar as outras contribuições para a energia, devido a movimento vibracionais. Um alongamento $(l)$ da ligação em uma molécula vai desviar-se do valor de equilíbrio para o estado imóvel hipotético. Os efeitos são geralmente pequenos, mas são significativos quando se deseja prever comprimentos de ligação a um milésimo de angstrom.

O potencial de Morse (66) não é normalmente utilizados em campos de força da mecânica molecular porque o custo computacional seria muito alto, utilizando uma série de potências de infinitos termos (67). Além disso, é raro em mecânica, cálculos moleculares para ligações fora de seus valores de equilíbrio; a curva de Morse descreve um ampla gama de comportamentos a partir do forte comportamento de equilíbrio da dissociação. Consequentemente, expressões mais simples são muitas vezes utilizadas, especificamente a lei de Hooke (potencial harmônico), em que a energia varia com o quadrado do deslocamento do comprimento da ligação de referência:

$$
v(l)=k / 2\left(l-l_{0}\right)^{2}
$$

A forma funcional da lei de Hooke é uma aproximação razoável para a forma da curva de energia potencial (45) na parte inferior do poço de potencial, a distâncias que correspondem à ligação em moléculas do estado fundamental. A precisão não é possível afastando-se do equilíbrio, ver Figura 23. Para modelar a curva de Morse com 
mais precisão, termos superiores cúbicos podem ser incluídos e o elo- potencial de alongamento pode ser escrito da seguinte forma (64):

$$
v(l)=k / 2\left(l-l_{0}\right)^{2}\left[1-k^{\prime \prime}\left(l-l_{0}\right)^{2}-K^{\prime \prime \prime}\left(l-l_{0}\right)^{3} \ldots\right]
$$

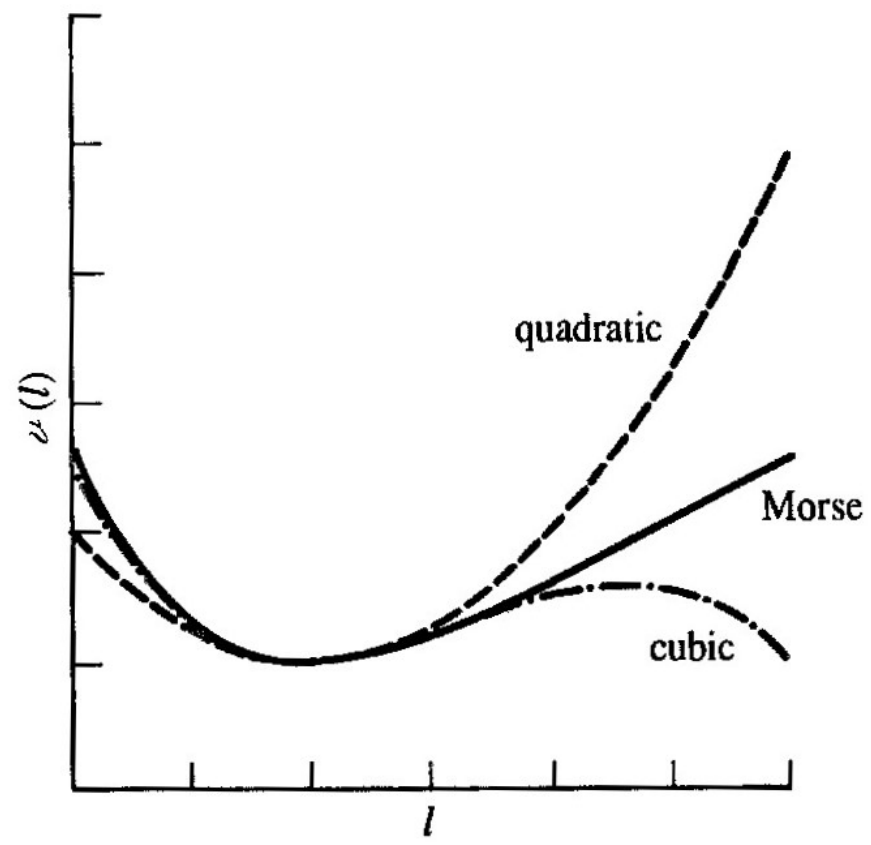

Figura 24 - Comparação da curva da Lei de Hooke com as Curvas quadrática e cúbica

\subsubsection{2 ÂNGULO DE FLEXÃO}

O desvio de ângulos de seus valores de referência também é descrito com frequência usando a lei de Hooke ou potencial harmônico:

$$
v(\theta)=k / 2\left(\theta-\theta_{0}\right)^{2}
$$

A contribuição de cada ângulo é caracterizada por uma constante de força e um valor de referência. Em vez disso, menos energia é necessária para deformar um ângulo de afastamento do equilíbrio do que para esticar ou comprimir uma ligação (55).

Tal como acontece com os termos de alongamento de ligações, a precisão do campo de força pode ser melhorado pela incorporação de termos de ordem superior. A forma geral do termo do ângulo de flexão torna-se:

$$
v(\theta)=k / 2\left(\theta-\theta_{0}\right)^{2}\left[1-k^{\prime \prime}\left(\theta-\theta_{0}\right)^{2}-K^{\prime \prime \prime}\left(\theta-\theta_{0}\right)^{3} \cdots\right]
$$




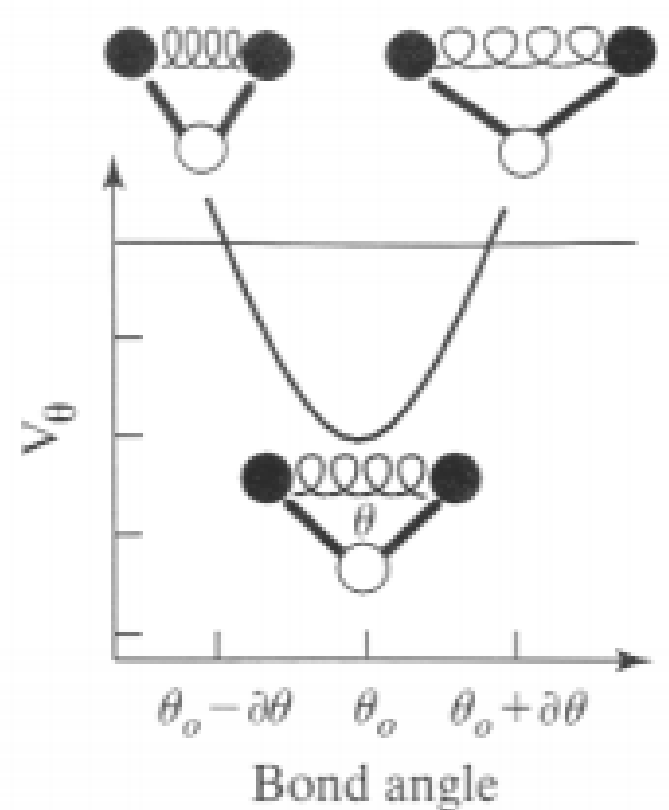

Figura 25 - Ângulos de Flexão

\subsubsection{TERMOS DE TORÇÃO}

Os termos de flexão-angulares (68) são muitas vezes consideradas como graus "duro"de liberdade, em que as energias substanciais são necessárias para causar deformações significativas de seus valores de referência. A maior parte da variação na estrutura e energias relativas é devido a uma interação complexa entre a torção e as contribuições não ligadas. A existência de barreiras à rotação sobre ligações químicas é fundamental para a compreensão das propriedades estruturais de moléculas e análise conformacional. Muitos campos de força são utilizados para a modelagem de moléculas flexíveis, onde as grandes mudanças na conformação são devido a rotações em torno das ligações; a fim de simular esta, é essencial que o campo de força representa adequadamente os perfis de energia de tais alterações.

Nem todos os campos de força da mecânica molecular usam potenciais de torção que são quase sempre expressos como uma expansão em série de cosseno. Uma forma funcional é:

$$
v(\omega)=\sum_{n=0}^{N} \frac{V_{n}}{2}[1+\cos (n \omega-\gamma)]
$$

$\omega$ é o ângulo de torção.

$\mathrm{O}$ valor de $V_{n}$ dá uma indicação qualitativa das barreiras em relação à rotação; por exemplo, $V_{n}$ para uma ligação de amida será maior do que para uma ligação 
entre dois átomos de carbono $s p^{3}$. Na equação, $\mathrm{n}$, é a multiplicidade e seu valor indica o número de pontos mínimos na função que a ligação é girada em 360. $\gamma$ é o fator de fase que determina onde o ângulo de torção passa no seu mínimo valor. Por exemplo, o perfil de energia para rotação em torno da ligação simples entre dois átomos de carbono $s p^{3}$ poderia ser representado por um único termo de torção, com $n=3$ e $\gamma=0$. Isto daria um perfil de rotação tripla com os mínimos em ângulos de torção de +60 ,-60 e 180 e máximos a 120 e 0 . A ligação dupla entre dois átomos de carbono $s p^{2}$ teria $n=2$ e $\gamma=180$, dando mínimos a 0 e 180 . O valor de $V_{n}$ também seria significativamente maior do que a ligação dupla para a única ligação. Os efeitos da variação do $V_{n}$, n e $\gamma$ estão ilustrados na figura 26 para potenciais torcionais que normalmente ocorrem em moléculas.

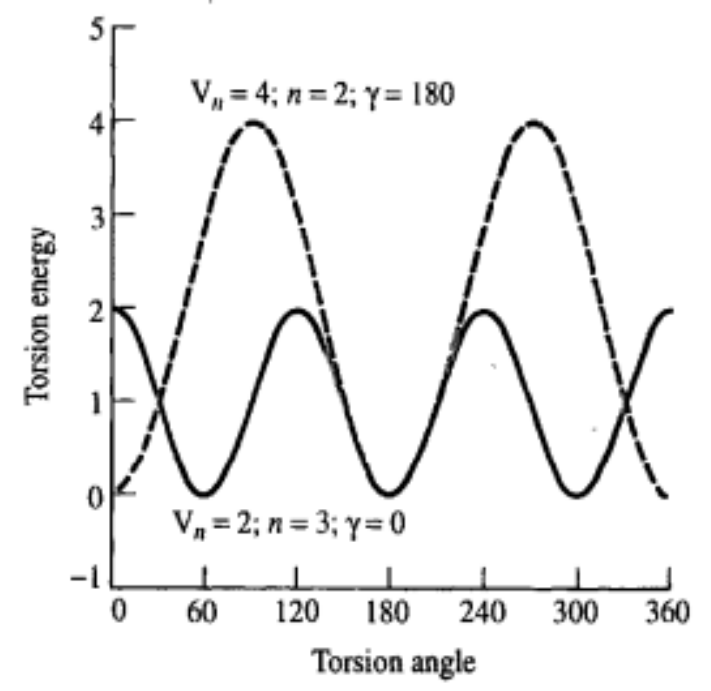

Figura 26 - Potenciais torcionais mostrados para valores diferentes de $V_{n}, \mathrm{n}$ e $\gamma$

Nem todos os campos de força da mecânica molecular usam potenciais de torção. Podem haver interações não-ligados entre os átomos no final de cada ângulo de torção para alcançar o perfil de energia desejado. No entanto, a maioria dos campos de força para moléculas "orgânicas" fazem uso dos potenciais de torção explícitas com uma contribuição de cada quarteto ligado de átomos ABCD no sistema. Assim, haveria 9 termos de torção individuais para o etano e 24 para o benzeno (6 x CCCC, 12 x $\mathrm{CCCH}$ e $6 \times \mathrm{HCCH})$.

\subsubsection{TORÇÕES IMPRÓPRIAS e MOVIMENTOS DE LIGAÇÕES FORA DO PLANO}

Para alcançar a desejada geometria em um determinado campo de força, às vezes, é necessário incorporar um termo adicional chamado termo fora do plano de dobragem. Existem várias maneiras em que termos fora do plano podem ser incorporados em um campo de força. Como exemplo, é tratar os quatro átomos do 
cyclobutano como um ângulo de torção imprópria (ou seja, uma torção ângulo em que os quatro átomos não estão ligadas na sequência $1-2-3-4)$. Uma maneira de definir uma torção imprópria para cyclobutano envolveria os átomos $1-5-3-2$ como mostrado na Figura 27.

Um potencial torsional da seguinte forma é então usado para manter a torção imprópria ângulo de $0^{\circ}$ ou $180^{\circ}$ :

$$
v(\omega)=k(1-\cos 2 \omega)
$$
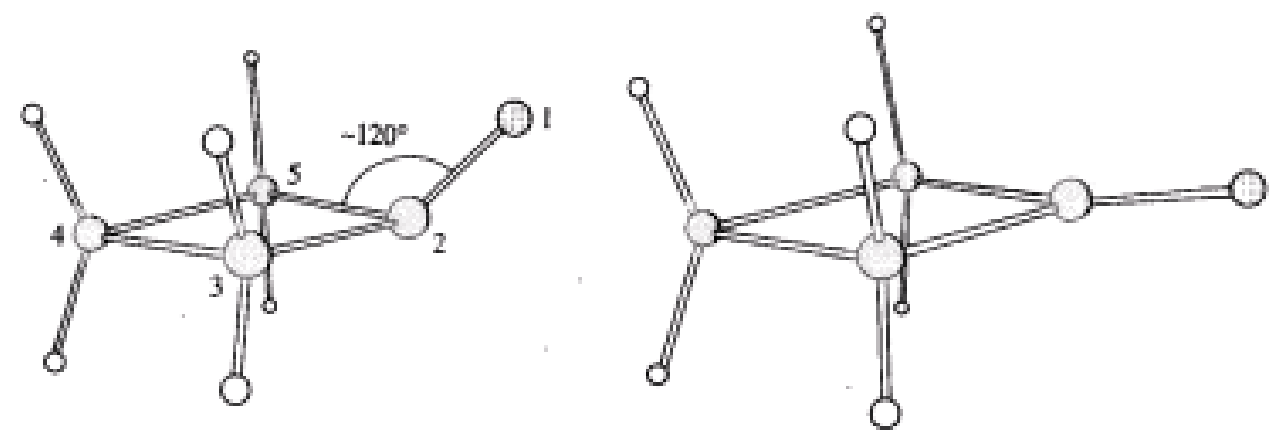

Figura 27 - Ângulos de Torção

\subsubsection{TERMOS CRUZADOS}

A presença de termos cruzados em um campo de força reflete acoplamento entre as coordenadas internas. Em princípio, devem-se incluir termos cruzados entre todas as contribuições para o campo de força. No entanto, apenas alguns termos cruzados são geralmente necessários para reproduzir com precisão as propriedades estruturais ou mais termos quando necessita-se reproduzir outras propriedades tais como as frequências de vibração.

A maioria dos termos cruzados são funções de duas coordenadas internas, tais como termos de esticar-esticar, esticar-dobrar e esticar-torcer (veja Figura 28), mas termos cruzados envolvendo mais de duas coordenadas internas, tais como a curva-curva-torção também têm sido utilizados. Várias formas funcionais são possíveis para os termos cruzados. Por exemplo, o termo cruz estica-estica entre duas ligações 1 e 2 pode ser modelada como:

$$
v_{l_{1}, l_{2}}=k_{l_{1}, l_{2}} / 2\left[\left(l_{1}-l_{1,0}\right)\left(l_{2}-l_{2,0}\right)\right]
$$


O alongamento de duas ligações adjacentes em um ângulo pode ser modelada utilizando uma equação da seguinte forma:

$$
\left.v\left(l_{1}, l_{2}, \theta\right)=k_{(} l_{1}, l_{2}\right), \theta / 2\left[\left(l_{1}-l_{1}, 0\right)\left(l_{2}-l_{2}, 0\right)\right]\left(\theta-\theta_{0}\right)
$$

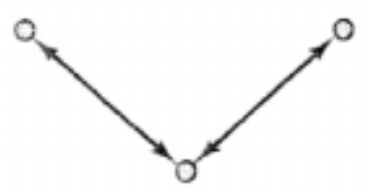

Stretch - stretch

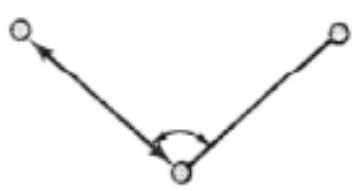

Stretch - bend
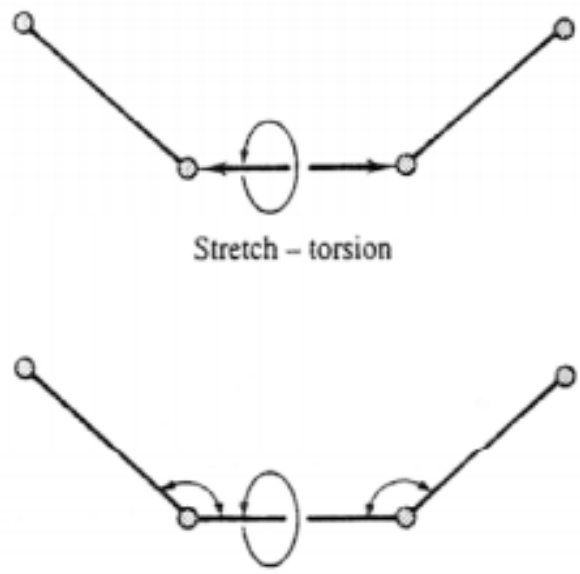

Bend - torsion

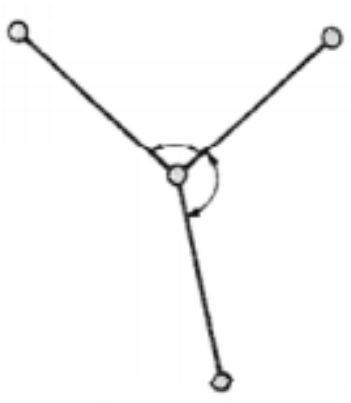

Bend - bend

Figura 28 - Termos Cruzados

\subsubsection{INTERAÇÕES NÃO-LIGADAS}

Moléculas independentes e os átomos interagem através de forças não ligadas, que também desempenham um papel importante na determinação da estrutura de espécies moleculares individuais. As interações não ligadas não dependem de uma relação de ligação específica entre átomos. Elas são interações "através do espaço" e são geralmente modeladas como uma função de alguma potência inversa da distância. Os termos não ligados em um campo de força são geralmente considerados em dois grupos, compreendendo um como interações eletrostáticas e o outro como van der Waals (69).

\subsubsection{INTERAÇÕES ELETROSTÁTICAS}

Elementos eletronegativos atraem mais elétrons do que elementos menos eletronegativos, dando uma distribuição desigual da carga em uma molécula. Esta distribuição de carga pode ser representada de várias maneiras, uma abordagem comum é de um arranjo de fracionadas cargas pontuais ao longo da molécula. As cargas são restritas para os centros nucleares que são muitas vezes referidas como cargas atômicas parciais ou cargas atômicas líquidas. Estas cargas são inseridas para reproduzir as propriedades eletrostáticas da molécula. 
Infelizmente, a carga atômica parcial não é uma quantidade experimentalmente observável e não podem ser calculada a partir da função de onda, usando a mecânica quântica. Isso explica por que inúmeras maneiras de determinar cargas atômicas parciais têm sido propostas, e por que ainda há um debate considerável sobre o melhor método para extraí-las. Comparações indiretas dos vários métodos são possíveis, normalmente calculando as quantidades apropriadas do modelo de carga e, em seguida, comparando os resultados com qualquer experiência ou mecânica quântica.

A interação eletrostática (70) entre duas moléculas (ou entre partes diferentes da mesma molécula) é então calculada como uma soma de interações entre pares de cargas pontuais, usando a lei de Coulomb:

$$
V=\sum_{i=1}^{N_{A}} \sum_{j=1}^{N_{B}} \frac{q_{i} q_{j}}{4 \pi \epsilon_{0} r_{i j}}
$$

$N_{A}$ e $N_{B}$ são os números de cargas pontuais; $q_{i} e q_{j}$ são as cargas pontuais das moléculas.

\subsubsection{INTERAÇÕES DE VAN DER WAALS}

Os desvios do comportamento do gás ideal foram quantificados por van der Waals, portanto, as forças que dam origem a esses desvios são muitas vezes referidas como de Van der Waals (71).

Os gases raros mostram um comportamento similar à curva descrita na Figura 29. As essenciais características desta curva são: A energia de interação é zero a distância infinita (e na verdade, é insignificante, mesmo a distâncias relativamente curtas). À medida que a separação é reduzida, a energia diminui, passando por um mínimo a uma distância de cerca de 3.8 Å. A energia, então, aumenta rapidamente à medida que a separação diminui ainda mais. A força entre os átomos, equivalente a menos a primeira derivada da energia potencial com relação à distância é também mostrada na figura 29.

A mais conhecida das funções potenciais de Van der Waals é a função de Lennard-Jones 12 - 6 que é usada para campos de forças que exigem uma maneira de modelar a curva do potencial interatômico com precisão, usando uma simples expressão empírica que pode ser rapidamente calculada e avaliada em consequência do grande número de interações de van der Waals entre os átomos de sistemas. Isto nos leva a seguinte formula para a interação entre dois átomos:

$$
v(r)=4 \epsilon\left[\left(\frac{\sigma}{r}\right)^{12}-\left(\frac{\sigma}{r}\right)^{6}\right]
$$




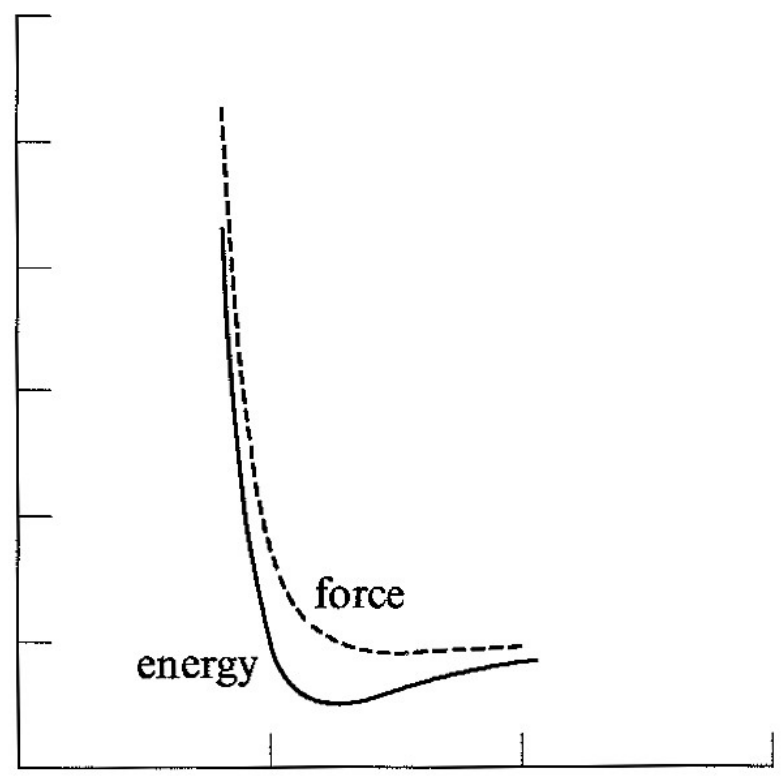

Interatomic separation

Figura 29 - Interação energética e a força entre dois átomos

O potencial de Lennard-Jones 12 - 6 contém apenas dois parâmetros ajustáveis: a colisão diâmetro $\sigma$ (a separação para as quais a energia é zero) e a profundidade do poço $\epsilon$. Estes parâmetros são graficamente ilustrados na Figura 30 .

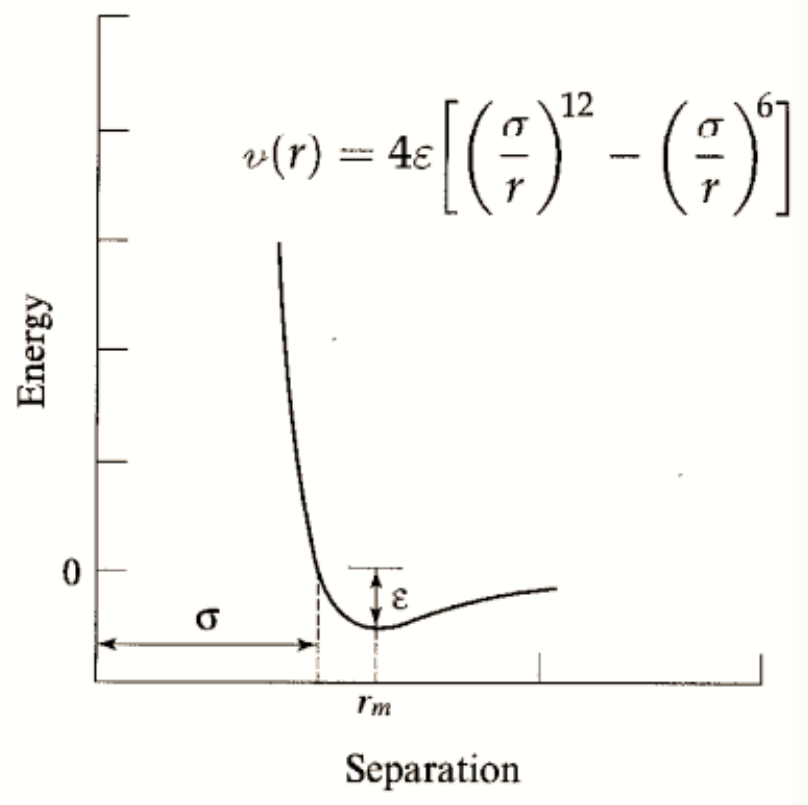

Figura 30 - O potencial de Lennard Jones

O potencial de Lennard-Jones (72) é caracterizada por uma parte atraente que varia como $r^{-6}$ e um parte repulsiva que varia em $r^{-12}$. 
Em sistemas poliatômicos, a energia de interação entre as moléculas depende não apenas da sua separação, mas também sobre as suas orientações relativas e, eventualmente, suas conformações. É usual calcular a energia de interação de van der Waals entre duas moléculas através de um modelo local em que a interação é determinada como a soma das interações entre todos os pares locais sobre as duas moléculas. Os locais são muitas vezes identificados com as posições nucleares, mas isso não precisa ser necessariamente o caso.

Sistemas poliatômicos invariavelmente envolvem o cálculo de interações de van der Waals entre diferentes tipos de átomos. A determinação de parâmetros van der Waals pode ser uma tarefa difícil e o tempo do processo moroso e por isso é comum assumir que os parâmetros para as interações transversais podem ser obtidos a partir dos parâmetros dos puros átomos usando regras de mistura. Nas comumente regras de mistura utilizada por Lorentz-Berthelot, o diâmetro de colisão $<\sigma_{A B}$ para a interação $\mathrm{AB}$ igual a média aritmética dos valores para as duas espécies puras, e a profundidade do poço $\epsilon_{A B}$ é dada como a média geométrica:

$$
\begin{gathered}
\sigma_{A B}=1 / 2\left(\sigma_{A A}+\sigma_{B B}\right) \\
\epsilon_{A B}=\sqrt{\epsilon_{A A} \epsilon_{B B}} \\
r *_{A B}=R *_{A A}+R *_{B B}
\end{gathered}
$$

Onde $r *_{A B}$ é a separação com a mínima energia e $R *_{A A}$ e $R *_{B B}$ são parâmetros atômicos, igual a metade de $r *_{A A}$ e $r *_{B} B$, respectivamente.

Felizmente, verifica-se que uma parte significativa dos efeitos de muitos corpos podem ser incorporadas a um modelo de pares, se devidamente parametrizado. Os potenciais pares mais comumente utilizados na modelagem molecular são, portanto, potenciais pares "eficazes"; eles não representam a verdadeira energia de interação entre duas partículas isoladas, mas são parametrizados para incluir efeitos de muitos corpos na energia dos pares. Da mesma forma, os efeitos de polarização pode ser implicitamente incluído em um campo de força pelo simples expediente de reforçar a interação eletrostática. Isto pode ser feito por meio de cargas parciais maiores do que aquelas que são usadas para uma molécula isolada.

\subsubsection{O PROGRAMA MATERIALS STUDIO}

Para o cálculo das propriedades mecânicas, energias potenciais e dinâmicas, em nosso trabalho, utilizamos o programa Materials Studio 6.1, com Campo de Força 
Compass-Modules Forcite.

Materials Studio é um software que permite realizar simulações e modelagem de materiais. Cria e estuda modelos de estruturas moleculares, explorando recursos gráficos. Integração com ferramentas de produtividade que facilita a comunicação desses dados. Trabalha com servidores Microsoft Windows e Linux para executar cálculos avançados. Nos seus cálculos combina mecânica quântica, mecânica molecular, modelagem de mesoescala, simulação de instrumento analítico e correlações estatísticas para um ambiente de modelagem com construção de estrutura, visualização e ferramentas para analisar e apresentar dados científicos. É um ambiente modular que fornece uma solução diferente para cada estrutura criada dependendo de suas propriedade ou método de simulação. Os cálculos podem ser executados localmente no computador ou através da rede em um servidor remoto.

No Materials Visualizer do Materials Studio é possível manipular modelos gráficos de moléculas, cristais orgânicos e inorgânicos, polímeros, materiais amorfos, superfícies e estruturas em camadas. Permite analisar dados em texto, gráfico, grade, e formatos de tabela de estudo, e possibilita a fácil transferência de tais dados dentro e fora do computador. 


\section{RESULTADOS E DISCUSSÕES}

\subsection{ENCAPSULAMENTO DE NANOTUBOS DE CARBONO}

No encapsulamento de nanotubos de carbono, estávamos interessados em saber qual distância mínima entre paredes dos nanotubos seria necessária para que houvesse um encapsulamento e se no caso também haveria uma regra na qual devêssemos seguir para alcançar este objetivo. Então fizemos vários testes entre os nanotubos armchair e zig-zag utilizando o programa Materials. Neste programa, no ambiente Visualizer, criamos os nanotubos sempre do mesmo tipo, mas com diâmetros diferentes. Aproximamos um tubo da extremidade do outro e fizemos várias dinâmicas até encontrarmos a distância que mais favorece o encapsulamento. Após verificarmos esta distância, nos preocupamos com o diâmetro que um nanotubo encapsula no outro. $\mathrm{E}$ através de várias dinâmicas, com nanotubos diferentes, verificamos o diâmetro ideal para que o encapsulamento ocorresse. E concluímos que é necessário uma distância entre paredes em torno de 3.5 para que haja seguramente tal encapsulamento, ou seja, a diferença entre o diâmetro do nanotubo externo e interno deve ser maior ou igual a 7 Å. Observamos que tal distância pode variar entre 3.2 à 3.55 dependendo do nanotubo estudado. A Tabela 5 nos mostra todos os nanotubos que foram testados.

Também notamos que existem duas regras fundamentais para que haja o encapsulamento:

a) para os nanotubos armchair:

A diferença entre os índices quirais do nanotubo externo $\left(n_{e}\right)$ e do nanotubo interno $\left(m_{i}\right)$ deve ser $\geq 5$;

b) para os nanotubos zig-zag:

A diferença entre os índices quirais do nanotubo externo $\left(n_{e}\right)$ e do nanotubo interno $\left(m_{i}\right)$ deve ser $\geq 9$;

Para demonstrarmos isto, utilizaremos as equações 3.4 e 3.5 (30):

Como o diâmetro do nanotubo SWNT(n,m) é dado por:

$$
d_{t}=\frac{a \sqrt{n^{2}+m^{2}+n m}}{\pi}
$$

E considerando dois nanotubos armchair, um $\operatorname{SWNT}\left(n_{e}, n_{e}\right)$ externo e $\operatorname{SWNT}\left(m_{i}, m_{i}\right)$ interno, $\operatorname{com} n_{e} \neq m_{i}$ então: 


$$
\begin{aligned}
d_{t_{e}}-d_{t_{i}} & =\frac{a \sqrt{n_{e}^{2}+n_{e}^{2}+n_{e} n_{e}}}{\pi}-\frac{a \sqrt{m_{i}^{2}+m_{i}^{2}+m_{i} m_{i}}}{\pi} \\
& =\frac{a \sqrt{3 n_{e}^{2}}}{\pi}-\frac{a \sqrt{3 m_{i}^{2}}}{\pi} \\
& =\frac{a \sqrt{3}}{\pi}\left(n_{e}-m_{i}\right)
\end{aligned}
$$

Como $a=2.49, \frac{a \sqrt{3}}{\pi} \cong 1.3728$ e a diferença entre os diâmetros externo e interno dos nanotubos deve ser um número maior ou igual a $7 \AA$ A. Assim:

$$
n_{e}-m_{i} \geq \frac{d_{2}-d_{1}}{1.3728} \cong \frac{7}{1.3728} \cong 5
$$

Por exemplo, para encapsularmos um nanotubo armchair, de $m_{i}=8$, de diâmetro $d_{i}=10.856$, devemos ter um nanotubo de $n_{e}=13$, de diâmetro $d_{e}=17.84$ e com distância entre paredes do nanotubo interno e externo $\left(r_{e}-r_{i}\right)$ de 3.492. Isto poderá ser verificado nas equações 5.4 e 5.5 :

$$
\begin{gathered}
\frac{d_{e}-d_{i}}{2}=r_{e}-r_{i} \\
n_{e}-m_{i} \geq \frac{d_{e}-d_{i}}{1.3728}=\frac{17.84-10.856}{1.3728} \cong 5
\end{gathered}
$$

Observando a tabela $5, n_{e}$ e $m_{i}$ são números inteiros, e a diferença entre eles também produzirá um número inteiro, então $n_{e}-m_{i} \geq 5$. Considerando $r_{e}$ e $r_{i}$ como raio externo e interno, respectivamente.

Na tabela 5 podemos verificar esta regra para todos os nanotubos armchair e zig-zag.

Para nanotubos zig-zag, um $\operatorname{SWNT}\left(n_{e}, 0\right)$ externo e $\operatorname{SWNT}\left(m_{i}, 0\right)$ interno , com $n_{e} \neq m_{i}$, e utilizando o mesmo procedimento anterior, chegamos a conclusão que:

$$
n_{e}-m_{i} \cong \frac{d_{e}-d_{i}}{0.79} \cong 9
$$

Caso $n_{e}-m_{i} \geq 5$ (no caso armchair) e $n_{e}-m_{i} \geq 9$ (no caso zig-zag) certamente haverá encapsulamento.

Após a demonstração acima, podemos concluir que para haver encapsulamento seguro entre um nanotubo armchair basta subtrairmos os índices quirais do nanotubo externo e interno, cujo resultado deve maior ou igual a 5; e para nanotubos zig-zag, 
Tabela 5 - Tabela de nanotubos de carbono armchair e zig-zag com respectivos diâmetros

\begin{tabular}{|c|c|c|c|}
\hline Tubo(m,n)-Armchair & Diâmetro(A) & Tubo(m,0)-Zig-Zag & Diâmetro (A) \\
\hline$(5,5)$ & 6.79 & $(5,0)$ & 3.92 \\
\hline$(6,6)$ & 8.14 & $(6,0)$ & 4.70 \\
\hline$(7,7)$ & 9.50 & $(7,0)$ & 5.48 \\
\hline$(8,8)$ & 10.86 & $(8,0)$ & 6.27 \\
\hline$(9,9)$ & 12.21 & $(9,0)$ & 7.05 \\
\hline$(10,10)$ & 13.57 & $(10,0)$ & 7.83 \\
\hline$(11,11)$ & 14.93 & $(11,0)$ & 8.62 \\
\hline$(12,12)$ & 16.28 & $(12,0)$ & 9.40 \\
\hline$(13,13)$ & 17.64 & $(13,0)$ & 10.19 \\
\hline$(14,14)$ & 19.00 & $(14,0)$ & 10.97 \\
\hline$(15,15)$ & 20.35 & $(15,0)$ & 11.75 \\
\hline$(16,16)$ & 21.71 & $(16,0)$ & 12.54 \\
\hline$(17,17)$ & 23.07 & $(17,0)$ & 13.32 \\
\hline$(18,18)$ & 24.43 & $(18,0)$ & 14.10 \\
\hline$(19,19)$ & 25.78 & $(19,0)$ & 14.89 \\
\hline$(20,20)$ & 27.14 & $(20,0)$ & 15.67 \\
\hline$(21,21)$ & 28.50 & $(21,0)$ & 16.45 \\
\hline$(22,22)$ & 29.85 & $(22,0)$ & 17.24 \\
\hline$(23,23)$ & 31.21 & $(23,0)$ & 18.02 \\
\hline$(24,24)$ & 32.57 & $(24,0)$ & 18.80 \\
\hline$(25,25)$ & 33.92 & $(25,0)$ & 19.59 \\
\hline$(26,26)$ & 35.28 & $(26,0)$ & 20.37 \\
\hline$(27,27)$ & 36.64 & $(27,0)$ & 21.15 \\
\hline$(28,28)$ & 38.00 & $(28,0)$ & 21.94 \\
\hline$(29,29)$ & 39.35 & $(29,0)$ & 22.72 \\
\hline$(30,30)$ & 40.71 & $(30,0)$ & 23.50 \\
\hline
\end{tabular}

devemos subtrair os índices quirais do nanotubo externo e interno e o resultado dever ser maior ou igual a 9. E tendo a certeza que os nanotubos de paredes simples (SWNT) podem encapsular em outros nanotubos de parede simples, e observando estas regras, podemos obter os nanotubos de parede dupla (DWNT).

Fizemos várias dinâmicas de encapsulamentos no programa Materials mostrando as forças de Van der Walls entre os átomos dos nanotubos, indicando que caso um nanotubo tenha o diâmetro adequado e esteja perto o suficiente, o encapsulamento ocorre de forma natural. Tais dinâmicas foram feitas com o tempo de 5ps, num total de 1001 quadros. Como exemplo, as Figuras 31, 32 e 33 mostram o encapsulamento do nanotubo $(8,8)$ no nanotubo $(13,13)$ nos quadros 01,84 e 113. 


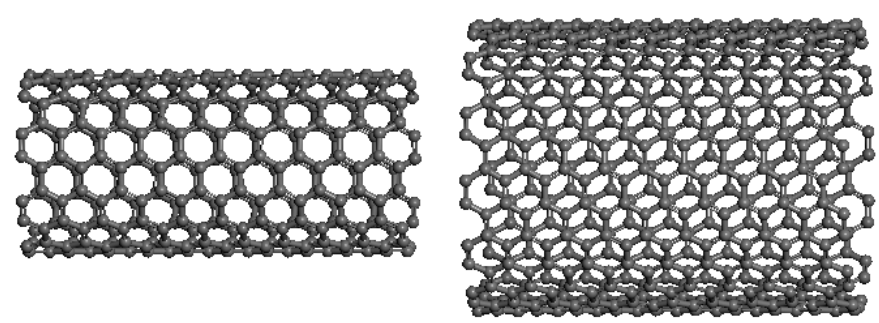

Figura 31 - Encapsulamento do $\operatorname{SWNT}(8,8)$ no $\operatorname{SWNT}(13,13)$-quadro 01

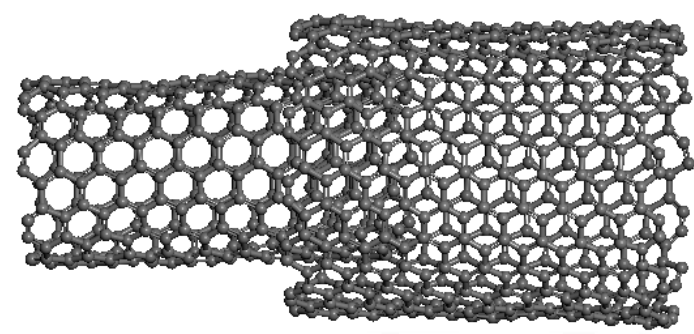

Figura 32 - Encapsulamento do SWNT(8,8) no SWNT(13,13)-quadro 84

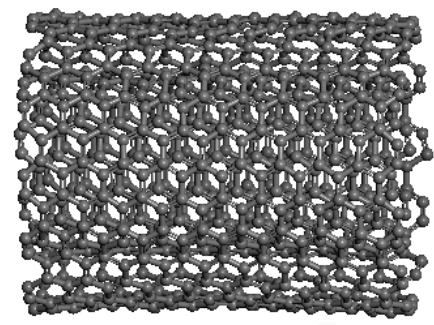

Figura 33 - Encapsulamento do SWNT(8,8) no SWNT(13,13)-quadro 113

\subsection{ENCAPSULAMENTO DE FULERENOS EM NANOTUBOS DE CARBONO DE PAREDE SIMPLES-SWNT}

Inicialmente, estávamos interessados em confirmar o encapsulamento de fulerenos $C_{60}$ em nanotubos de carbono de parede simples. Karla et al (9) nos relata o estudo de dinâmica molecular totalmente atomística detalhada do encapsulamento de fulerenos simétricos $\left(C_{60}\right)$ e fulerenos assimétricos $\left(C_{70}\right.$ e $\left.C_{78}\right)$ dentro de nanotubos de carbono de parede única de diferentes diâmetros. Diferentes fases ordenadas foram 
encontrados e mostraram-se dependente do diâmetro do tubo e que o $C_{60}$ se ordena de forma helicoidal dentro do nanotubo de carbono (veja Figura 42). Devido a isso, fizemos várias dinâmicas no programa Materials para visualizarmos como isto ocorreria. Sendo que neste caso, estávamos interessados no menor diâmetro para que o fulereno $C_{60}$ encapsulasse no SWNT. E como o fulereno $C_{60}$ possui aproximadamente $7 \AA$ Å diâmetro, imaginamos que seria necessário uma pequena folga entre ele e o nanotubo. Começamos o encapsulamento com nanotubos $(7,7)$, com diâmetros de 9,5 $\AA ̊$ e verificamos que o fulereno era atraído, porém não encapsulava. Assim, fomos aumentando os diâmetros dos nanotubos até encontrarmos o nanotubo ideal para que o encapsulamento ocorresse. Também, ao mesmo tempo, verificamos a distância mínima para que o fulereno fosse atraído pelo nanotubo. E concluímos que se os fulereno estiverem a uma distância de aproximadamente $3 \AA$ da borda do nanotubo, haveria uma atração para o interior deste, ocorrendo com sucesso o encapsulamento.

Posteriormente, estávamos interessados se vários fulerenos seriam atraídos pelo nanotubo e quais seriam as suas posições uns em relação aos outros. Notamos que todos ficaram separados por uma distância de $3.5 \AA$, aproximadamente, um do outro, isto após a minimização da energia de interação atômica do sistema.

Concluímos que para ocorrer tal encapsulamento, o diâmetro do nanotubo externo deve ter aproximadamente $14 \AA$, ou seja, o diâmentro do fulereno, $7 \AA$, mais as distâncias entre paredes do fulereno e do nanotubo, aproximadamente $3.5 \AA$, devem dar o diâmetro do nanotubo.

No encapsulamento de fulerenos $C_{60}$ em SWNT, fizemos os testes e concluímos que a partir dos $\operatorname{SWNT}(10,10)$, cujo diâmetro é de $13.57 \AA$ este encapsulamento ocorreria, ficando uma folga de $3.28 \AA$ entre o fulereno e a parede do nanotubo. Quando fizemos a dinâmica de encapsulamento no programa Materials, módulo forcite e campo de força universal, observamos que o nanotubo funciona como um aspirador de pó, sugando a maioria dos fulerenos que estão próximos às bordas. As Figuras 34, 35 e 36 mostram o encapsulamento de dois fulerenos, um em cada ponta do nanotubo $(10,10)$ nos quadros 01,320 e 495.

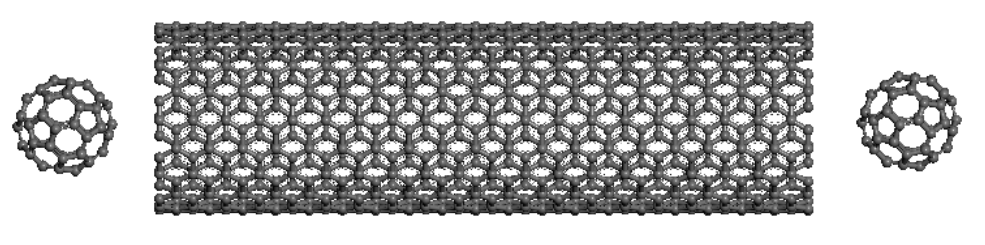

Figura 34 - Encapsulamento de fulereno $C_{60}$ em SWNT-quadro 01 


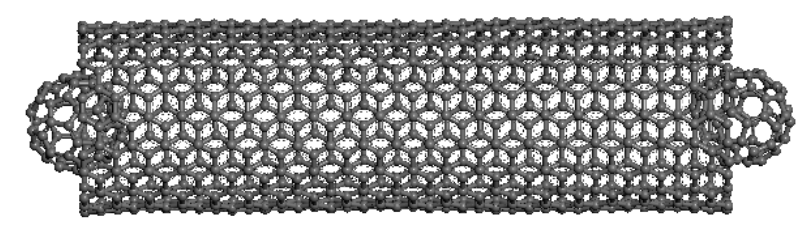

Figura 35 - Encapsulamento de fulereno $C_{60}$ em SWNT-quadro 320

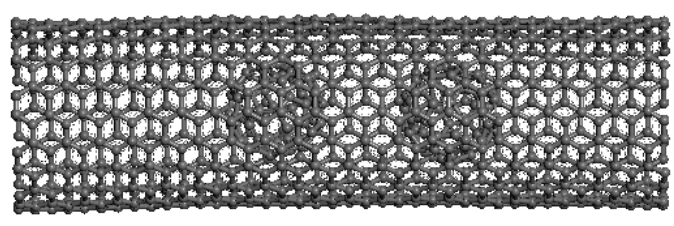

Figura 36 - Encapsulamento de fulereno $C_{60}$ em SWNT-quadro 495

A Figura 37 mostra que no caso de um nanotubo $(10,10)$, de 20 células, diâmetro de $13.56 \AA$ A e de $49.19 \AA$ de comprimento, o nanotubo suporta, no máximo, 4 fulerenos, ou seja, 1 fulerenos para cada $12.29 \AA$ de comprimento.

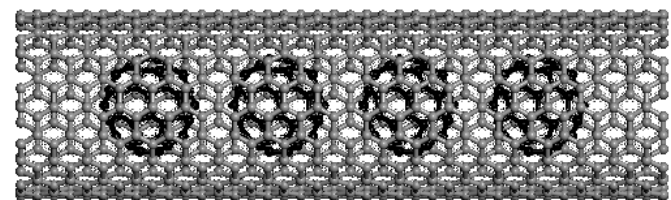

Figura 37 - 4 fulereno $C_{60}$ encapsulados em $\operatorname{SWNT}(10,10)$, distanciados $3.5 \AA$ um do outro

\subsection{ENCAPSULAMENTO DE FULERENOS EM NANOTUBOS DE CARBONO DE PAREDE DUPLA-DWNT}

No encapsulamento de fulerenos $C_{60}$ em nanotubos de carbono de parede dupla (DWNT), a mesma regra da distância à parede que ocorre em SWNT deve ser respeitada, ou seja, quando o fulereno encapsular, deve haver uma folga entre ele e a parede do nanotubo de aproximadamente $3.5 \AA$, isto é, a cavidade de encapsulamento entre o nanotubo interno e externo deve ter, aproximadamente, $14 \AA$ A. E observando a Tabela 5 , notamos que os nanotubo interno e externo devem ser $(10,10)$, com diâmetro 
de $13.57 \AA$ e o $(30,30)$, com diâmetro de $40.68 \AA$, respectivamente. Isto para se falar em diâmetros mínimos necessários ao encapsulamento, porque à medida que os diâmetros aumentam, não haverá interação entre os átomos do fulereno e o nanotubo, não havendo sentido neste tipo de dinâmica. Portanto, o diâmetro do nanotubo externo deve ser, no mínimo, 3 vezes o diâmetro do nanotubo interno $(10,10)$. Com isto garantimos o encapsulamento do fulereno tanto no nanotubo interno quanto na cavidade entre paredes, ficando o fulereno a uma distância mínima de aproximadamente $3.28 \AA$ da parede do nanotubo.

Fizemos os cálculo do potencial de energia na aproximação do fulereno $C_{60}$, em trajetória retilínea, passando à $2 \AA$ do centro do nanotubo duplo e a Figura 38 mostra o gráfico das barreiras potenciais (picos) que impedem o encapsulamento do fulereno, como também as regiões onde são mais propícios os encapsulamentos (vales). Na figura 39 nos é mostrado o fulereno em trajetória horizontal, onde se percebe que a medida que o fulereno avança em sua trajetória, ele encontra as bordas das paredes (picos da figura 38) dos nanotubos $(10,10)$ e $(30,30)$, onde as barreiras potenciais são maiores, como também as regiões de encapsulamentos entre as paredes dos nanotubos (vales). Notamos que as regiões dos vales tem o mesmo comprimento do diâmetro do fulereno mais as distâncias entre paredes que somadas dão $14 \AA$ aproximadamente.

Na figura 40 mostramos o gráfico do potencial de interação entre o fulereno $C_{60}$ e o DWNT $(10,10) @(20,20)$ quando o fulereno está em movimento retilíneo passando pelo centro da extremidade do DWNT. Tal gráfico mostra que pode haver encapsulamento do fulereno no nanotubo interno, pois a região de vale tem comprimento de aproximadamente $14 \AA$. Porém entre as paredes isto é impossível devido ao comprimento da região do vale ser de aproximadamente $8 \AA$, bem menor que os aproximadamente $14 \AA$ necessários ao encapsulamento.

Concluímos, então que, embora haja encapsulamento de um nanotubo dentro do outro, isto não indica onde o fulereno irá encapsular, seja no nanotubo interno ou externo. Mas sim as distâncias entre as paredes dos nanotubos, que devem estar em torno dos $14 \AA$, respeitando, é claro, a proximidade que o fulereno deve estar da extremidade do nanotubo, que é próximo de $3 \AA$.

No caso de nanotubos de paredes duplas (DWNT), que é formado após o encapsulamento de nanotubos simples um dentro do outro, há a região entre as paredes dos nanotubos interno e externo onde realizamos encapsulamentos de vários fulerenos, sendo que a dinâmica foi feita colocando-se um fulereno em cada extremidade do nanotubo, à aproximadamente $3 \AA$. E repetindo este procedimento, notamos que caso colocássemos mais fulerenos nas extremidades do DWNT, este atraía muitos dos fulerenos, embora alguns escapavam à atração. Após uma dinâmica em que os fulerenos encapsulavam, fazíamos uma nova, colocando mais fulerenos nas extremi- 


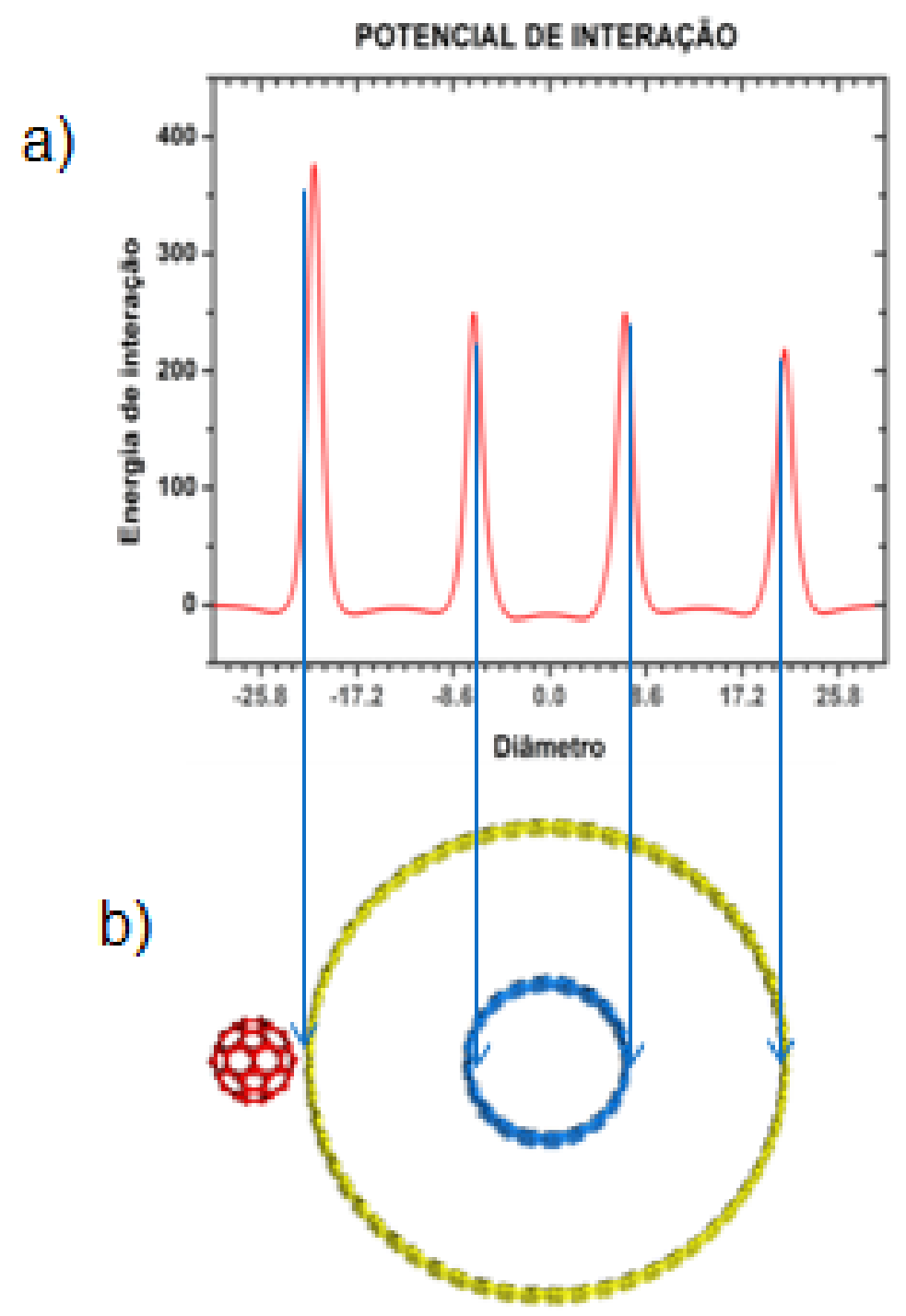

Figura 38 -a) Gráfico do Potencial da borda da parede percebido pelo fulereno $C_{60}$ à distância de aproximadamente $2 \AA$ da extremidade de um DWNT $(10,10) @(30,30)$. Os picos correspondem às extremidades das paredes dos nanotubos onde há expulsão dos fulerenos $C_{60}$. Os vales correspondem regiões propícias ao encapsulamento. b) Fulereno $C_{60}$ em trajetória horizontal passando pela extremidade do DWNT.

dades e assim sucessivamente, até se atingir o limite de empacotamento. O nosso objetivo nesta dinâmica seria averiguar se haveria mudança no módulo de Young, porém acabamos descobrindo que os fulerenos ao encapsular em nanotubos de paredes duplas se dispõem em círculos, com estes círculos paralelos uns aos outros. Então podemos perceber as diferenças das posições dos fulerenos quando encapsulados entre as paredes do DWNT e quando encapsulados em SWNT, pois Karla et al (9) nos mostra em seu artigo de que os fulerenos formam uma trajetória helicoidal quando encapsulado em SWNT, como nos mostra a Figura 42. A Figura 41 mostra a disposição 


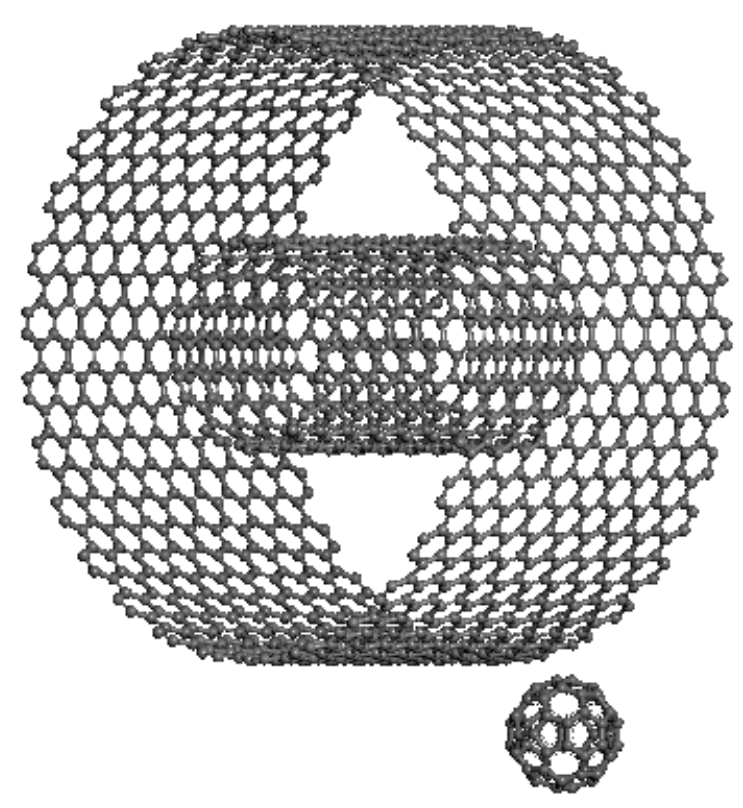

Figura 39 - Fulereno $C_{60}$ em trajetória vertical, no qual passará à $2 \AA$ da ponta de um DWNT(10,10)@(30,30))

dos fulerenos em círculos paralelos e a Figura 43 mostra a mesma Figura 41 sem o nanotubo externo.

\subsection{OBTENÇÃO DO MÓDULO DE YOUNG EM NANOTUBOS DE CARBONO POR METODOLOGIAS CLÁSSICAS}

Em nossa pesquisa, algo que queríamos descobrir seria como se obter o módulo de Young em nanotubos de carbono. No capítulo 3 descrevemos várias metodologias de alguns autores, sendo que muitos usaram metodologias quânticas que, neste caso, não estaríamos interessados devido a demora nos cálculos, dependendo da quantidade de átomos que estivéssemos utilizando no nosso sistema. Então, gostaríamos de encontrar uma metodologia que possibilitasse a obtenção do módulo de elasticidade não de uma forma quântica, mas sim de uma maneira clássica. Com este objetivo, fizemos muitos testes e selecionamos aquelas que melhor possibilitavam obter os módulos de Young compatível com valores experimentais e quânticos. Portanto, resolvemos utilizar a segunda derivada da energia de deformação E (strain energy) pela deformação $\epsilon$ (strain), $\frac{\partial^{2} E}{\partial \epsilon^{2}}$, e a do desvio padrão das vibrações das amplitudes, $\sigma$. Das várias metodologias citadas no capítulo 3, selecionamos duas delas que deram resultados compatíveis com a de outros autores e com resultados experimentais: as de E. Hernández et al e de A.Krishnan et al, respectivamente. 


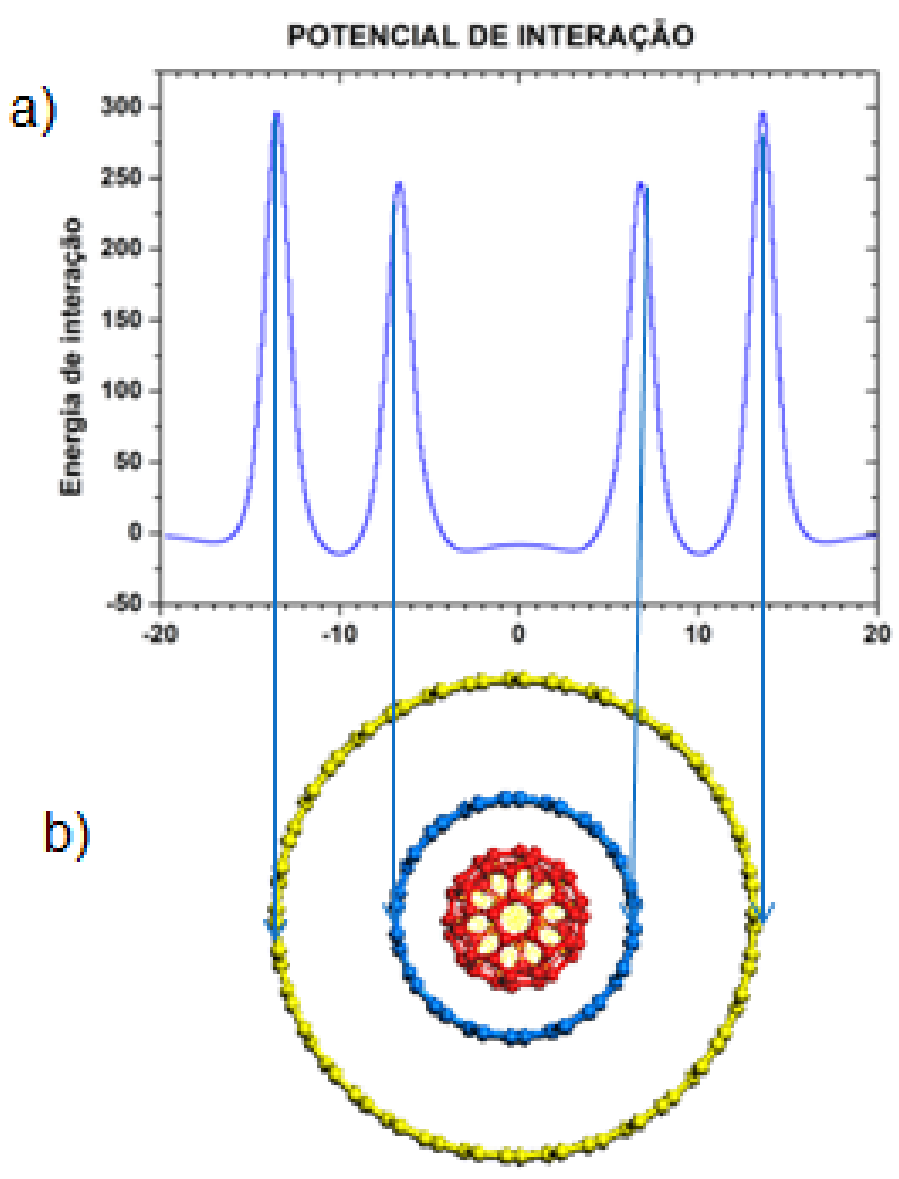

Figura 40 - a) Gráfico do Potencial da borda da parede percebido pelo fulereno $C_{60}$ à distância de aproximadamente $2 \AA$ da ponta de um $\operatorname{DWNT}(10,10) @(20,20))$. Os picos correspondem às extremidades das paredes dos nanotubos. Os vales correspondem regiões onde não ocorrem o encapsulamento devido à largura ser menor que $14 \AA$. b) Fulereno $C_{60}$ em trajetória horizontal passando pela extremidade da parede do DWNT.
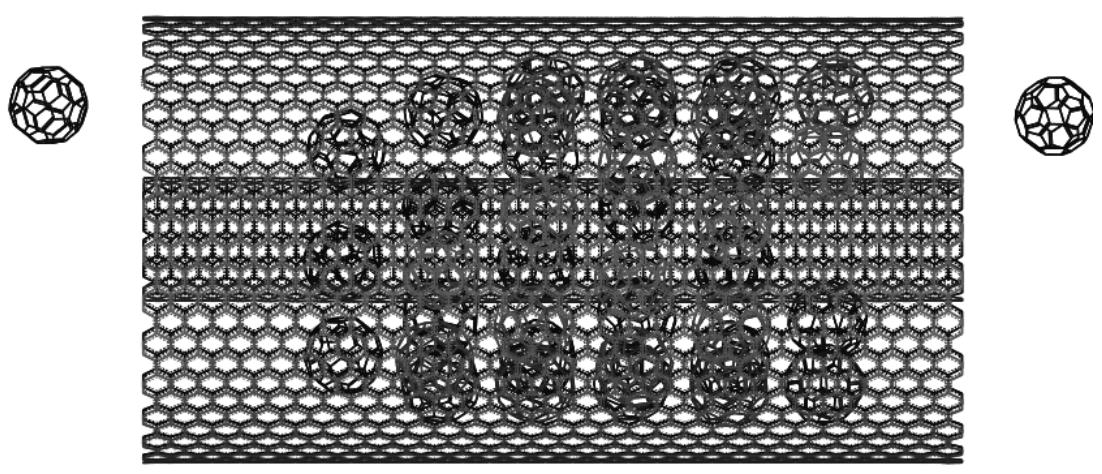

Figura 41 - Emcapsulamento de fulerenos em DWNT- Disposição quase paralela.

Na metodologia que se obtém a segunda derivada da energia de deformação em relação à deformação, simulamos um nanotubo sendo esticado com, no máximo dez por cento de seu comprimento, calculando a energia potencial de todos átomos 


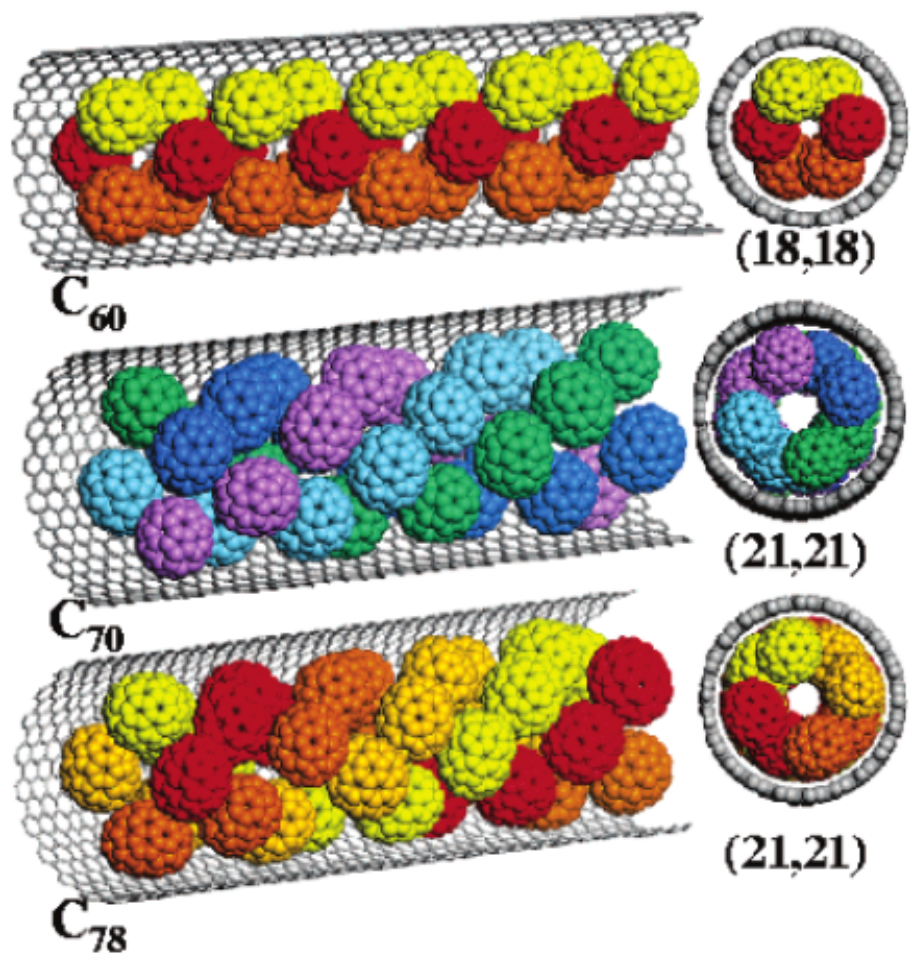

Figura 42 - Fulerenos $C_{60}$ no interior $\operatorname{SWNT}(18,18)$ (Camada de três molécula) e fulerenos $C_{70}$ e $C_{78}$ dentro SWNT $(21,21)$ (quatro cadeias de simples hélices) obtidas por simulações de dinâmica molecular-fonte Karla et al

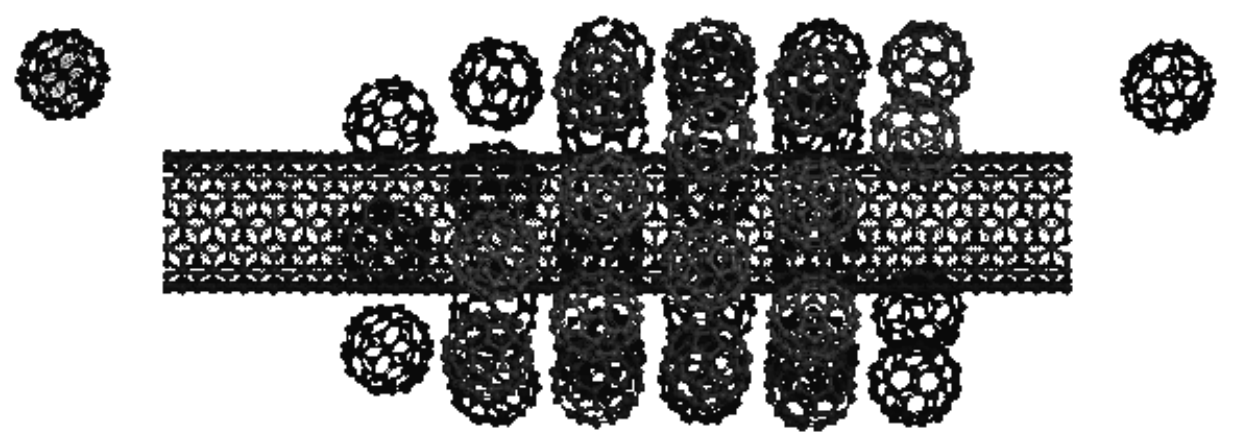

Figura 43 - Emcapsulamento de fulerenos em DWNT- Disposição quase paralela, sem o nanotubo exterior.

a cada estiramento e posteriormente otimizando a estrutura. Neste caso, usamos a equação 5.7 para calcularmos a deformação. Com estes resultados, plotamos a curva da energia potencial pela deformação, conforme Figura 46 e calculamos a segunda 
derivada da energia pela deformação, $\frac{\partial^{2} E}{\partial \epsilon^{2}}$. Neste caso a deformação é dada por:

$$
\epsilon=\frac{\epsilon_{i}-\epsilon_{0}}{\epsilon_{0}}
$$

Onde $\epsilon_{i}$ é o comprimento instantâneo do nanotubo e $\epsilon_{0}$ é o comprimento inicial.

Para obtermos o módulo de Young, dividimos $C=\frac{\partial^{2} E}{\partial \epsilon^{2}}$ pela área da superfície do nanotubo (35), dada pela equação 5.8 e dividimos pela espessura da parede do nanotubo $h=3.4 \AA$.

$$
A=2 \pi R L
$$

Onde $\mathrm{R}$ é o raio do nanotubo e L o seu comprimento. Assim, o módulo de Young Y e dado por:

$$
Y=\frac{C}{A h^{\prime}}
$$

Utilizamos os seguintes procedimentos para obtermos os resultados na aproximação quase-estática:

1) No ambiente Visualizer do programa Materials criamos o nanotubo, fixando uma das suas extremidades;

2) Selecionamos o módulo Forcite Calculation com os parâmetros descritos na Figura 44 e realizamos uma dinâmica molecular.

3) Um programa em linguagem Perl produz deformações sistemáticas numa das extremidades do nanotubo. A deformação total(que representa $10 \%$ do comprimento total do nanotubo) foi subdividida em 50 partes, para cada passo de deformação otimiza-se completamente a geometria do nanotubo e calcula-se a energia potencial neste estado.

4) Com base nos resultados da deformação e do potencial, produz-se um gráfico que apresenta forma parabólica. Daí em diante, estima-se o coeficiente do termo quadrático da parábola, isto equivale a segunda derivada da energia de deformação (E) pela deformação $(\epsilon), C=\frac{\partial^{2} E}{\partial \epsilon^{2}}$;

5) Calcula-se o módulo de elasticidade pela Equação 5.9 .

Para estimarmos o módulo de Young, trabalhamos com nanotubos armchair $(5,5),(6,6),(7,7),(8,8),(9,9),(10,10),(11,11),(12,12)$ e $(50,50)$; com nanotubos mistos $(6,4)$, 


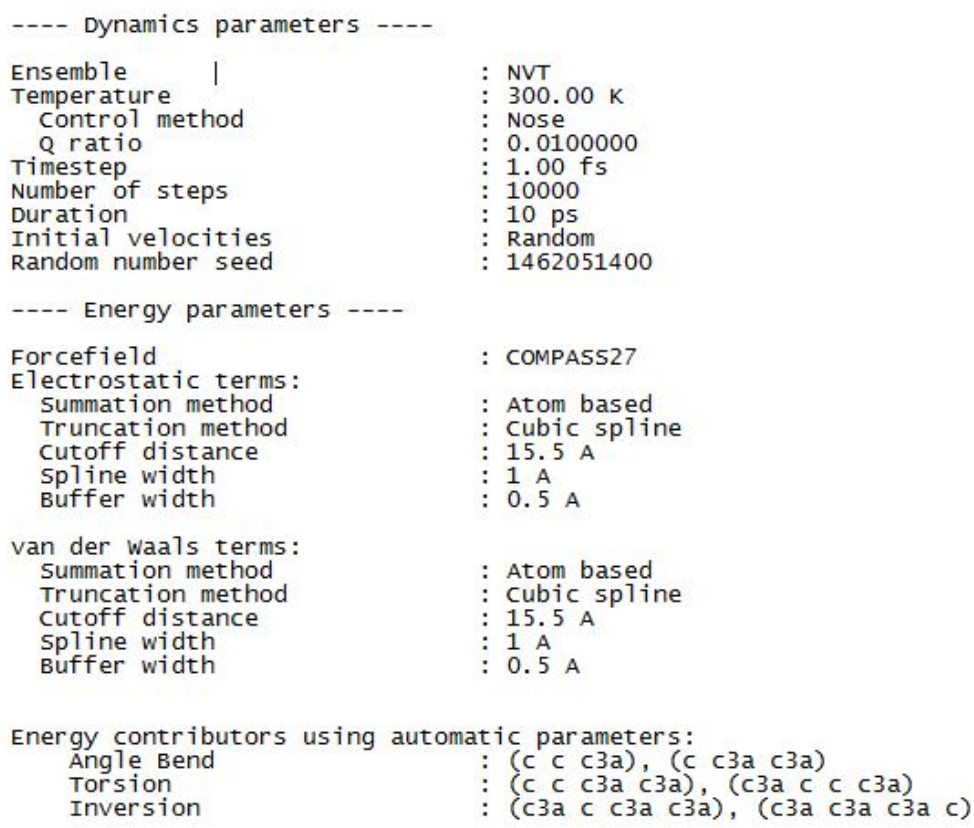

Figura 44 - Parâmetros utilizados pelo programa Materials para realização da dinâmica para o cálculo do módulo de elasticidade em nanotubos curtos e longos.

$(7,3),(8,2),(9,1)$; e um zig-zag $(10,0)$. Procuramos trabalhar com os mesmos nanotubos utilizados por vário autores, com o objetivo de fazermos comparações. A Tabela 6 além de mostrar os valores dos módulos de Young, também informam os valores obtidos para a energia de deformação por átomo.

Tabela 6 - Valores da energia de deformação por átomo e Módulo de Young

\begin{tabular}{|c|c|c|c|c|c|}
\hline \hline Tubo $(n, m)$ & Compr. $(L)$ & $N^{o}$ de át. & Raio & $\frac{\partial^{2} E}{\partial \epsilon^{2}}($ Ev) & Mód.Young(TPa) \\
\hline$(5,5)$ & 49.19 & 400 & 3.39 & 57 & 1.03 \\
$(6,6)$ & 49.19 & 480 & 4.07 & 64 & 1.16 \\
$(7,7)$ & 49.19 & 560 & 4.75 & 64 & 1.16 \\
$(8,8)$ & 49.19 & 640 & 5.43 & 64 & 1.16 \\
$(9,9)$ & 49.19 & 720 & 6.10 & 64 & 1.16 \\
$(10,10)$ & 49.19 & 800 & 6.8 & 65 & 1.16 \\
$(11,11)$ & 49.19 & 880 & 7.5 & 65 & 1.16 \\
$(12,12)$ & 49.19 & 960 & 8.1 & 65 & 1.17 \\
$(50,50)$ & 49.19 & 4000 & 33.9 & 62 & 1.10 \\
$(6,4)$ & 55.17 & 456 & 3.4 & 58 & 1.05 \\
$(7,3)$ & 75.73 & 632 & 3.5 & 53 & 0.95 \\
$(8,2)$ & 58.57 & 504 & 3.6 & 55 & 0.98 \\
$(9,1)$ & 81.28 & 728 & 3.7 & 53 & 0.95 \\
$(10,0)$ & 51.12 & 480 & 3.9 & 59 & 1.06 \\
\hline \hline
\end{tabular}

A Figura 45 mostra o gráfico da energia de deformação por átomo usando 
esta metodologia no nanotubo(10,10), com 20 células, de comprimento $49.9 \AA$ e raio $6.78 \AA$ que é semelhante ao encontrado por Robertson et al. E caso queiramos não dividir a energia de deformação pela quantidade de átomos teremos um gráfico, como mostrado na Figura 46. Observamos que a Tabela 6 tem valores semelhantes à energia de deformação encontrados por Sánches Portal el al, inclusive com valores praticamente idênticos encontrados por E. Hernándes et al e valores próximos dos encontrados por Jian Ping Lu. Com todos estes autores citados no capítulo 03. As Tabelas 7, 8 e 9 mostram comparações dos nossos resultados com os obtidos por este autores, sendo que as diferenças médias são 7 \% e $10 \%$.

Tabela 7 - Comparação entre os nossos resultados e os de Jim Ping Lu.

\begin{tabular}{|c|c|c|r|}
\hline \hline Tubo $(n, m)$ & Nossos Resultados & Jim Ping Lu & Diferença \\
\hline$(5,5)$ & 1.03 & 0.97 & $6 \%$ \\
$(6,4)$ & 1.05 & 0.97 & $8 \%$ \\
$(7,3)$ & 0.95 & 0.97 & $2 \%$ \\
$(8,2)$ & 0.98 & 0.97 & $1 \%$ \\
$(9,1)$ & 0.95 & 0.97 & $2 \%$ \\
$(10,0)$ & 1.06 & 0.97 & $8 \%$ \\
$(10,10)$ & 1.16 & 0.97 & $19 \%$ \\
\hline \hline
\end{tabular}

Tabela 8 - Comparação entre os nossos resultados e os de E. Hernándes et al.

\begin{tabular}{|c|c|c|r|}
\hline \hline Tubo $(n, m)$ & Nossos Resultados & E. Hernándes et al & Diferença \\
\hline$(6,6)$ & 1.16 & 1.22 & $5 \%$ \\
$(10,0)$ & 1.03 & 1.22 & $18 \%$ \\
$(10,10)$ & 1.16 & 1.24 & $7 \%$ \\
\hline \hline
\end{tabular}

Tabela 9 - Comparação entre os nossos resultados e os de Sánches Portal.

\begin{tabular}{|c|c|c|r|}
\hline \hline Tubo $(n, m)$ & Nossos Resultados & Sánches Portal & Diferença \\
\hline$(5,5)$ & 57 & 55 & $4 \%$ \\
$(6,6)$ & 64 & 56 & $14 \%$ \\
$(8,8)$ & 64 & 59 & $8 \%$ \\
$(10,10)$ & 65 & 52 & $25 \%$ \\
$(10,0)$ & 59 & 60 & $2 \%$ \\
\hline \hline
\end{tabular}

Na metodologia utilizada por A. Krishnan et al, submetemos os nanotubos a uma dinâmica em temperatura ambiente e calculamos o módulo de elasticidade pelo desvio padrão $(\sigma)$ das amplitudes de vibrações dos átomos da extremidade do nanotubo, usando a mesma equação $3.19, \sigma^{2}=0,8486 \frac{L^{3} K_{b} T}{Y W G\left(W^{2}+G^{2}\right)}$.

Conseguimos calcular os módulos de elasticidade dos nanotubos levando em consideração as direções $x, y$ e $z$, diferentemente da metodologia anterior na qual foram calculados os módulos de Young somente na direção z. 


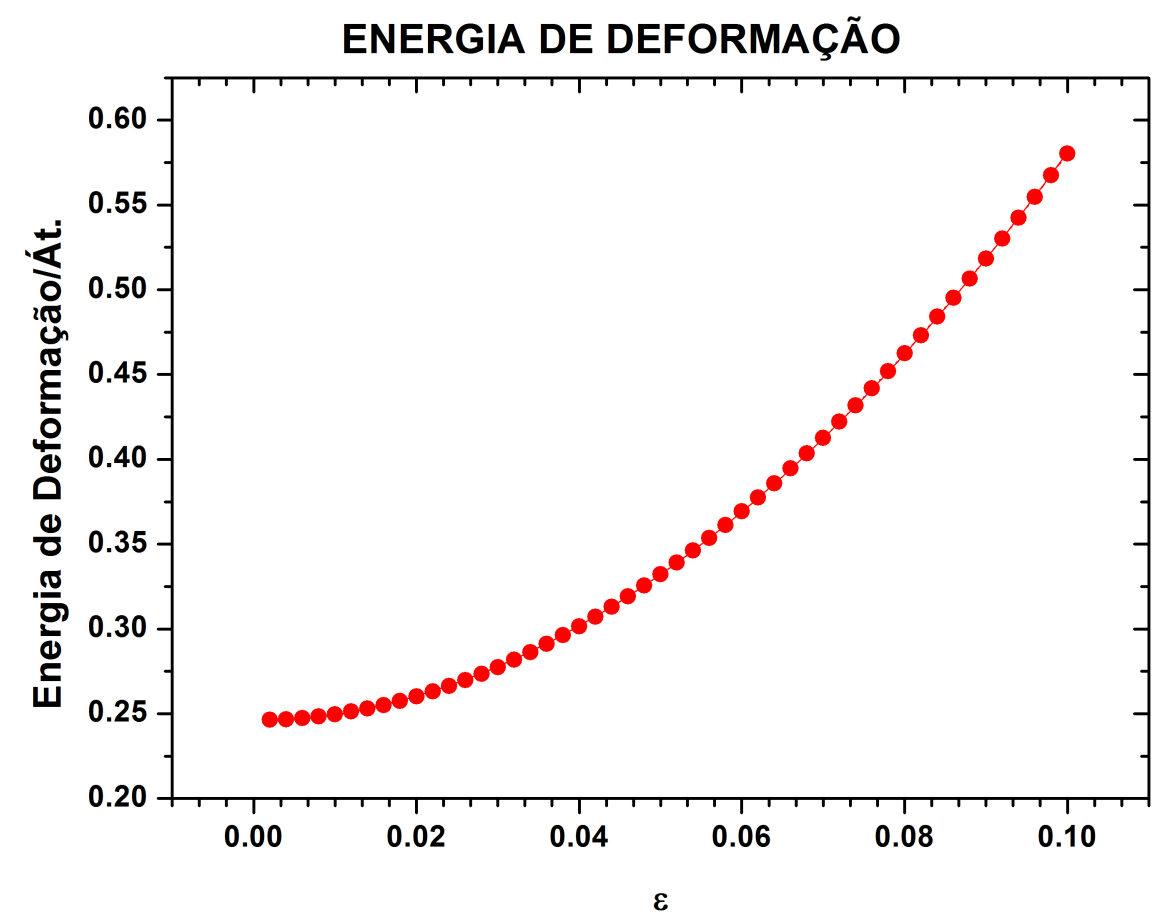

Figura 45 - Gráfico da energia de deformação/átomo pela deformação $(\epsilon)$ do nanotubo $(10,10)$.

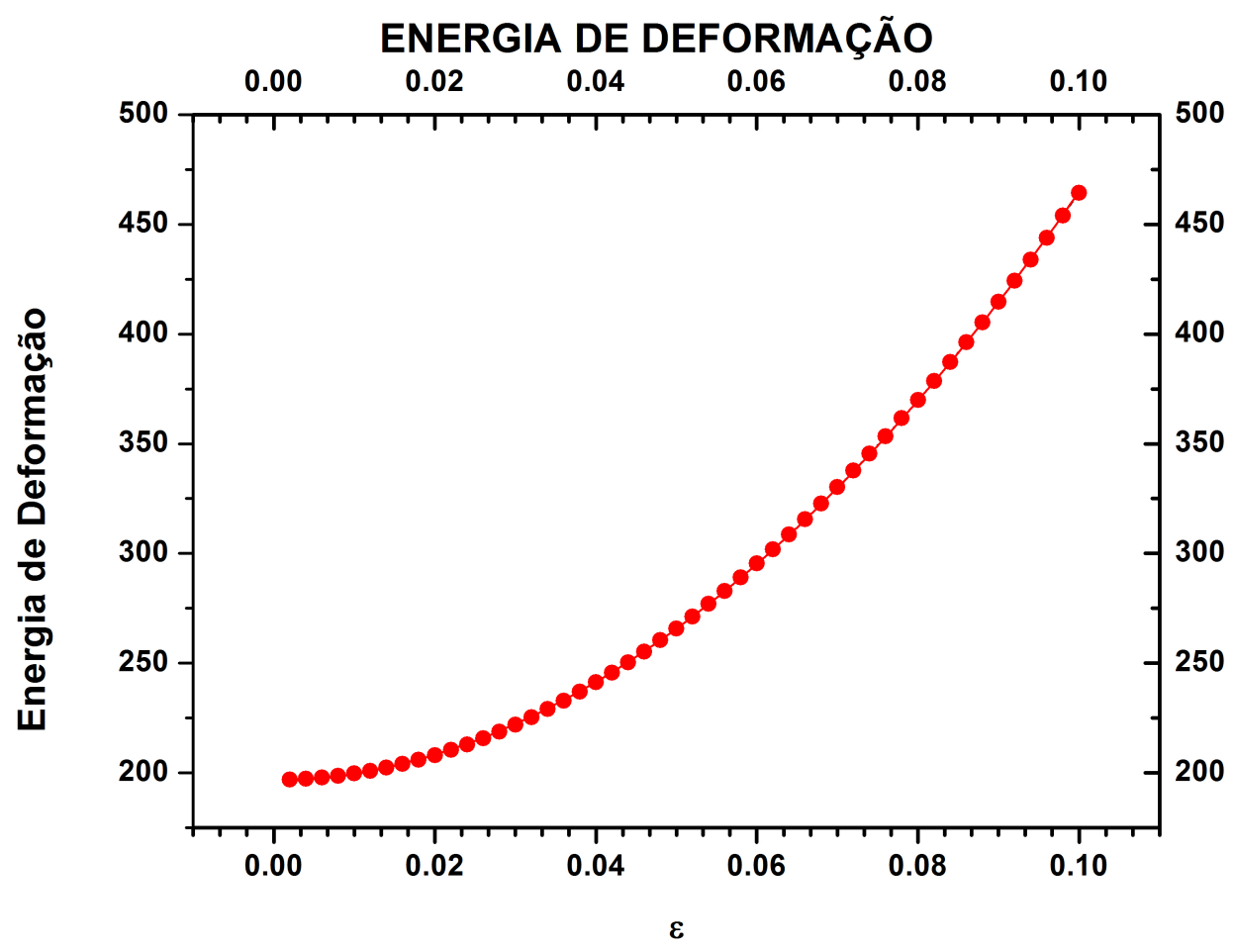

Figura 46 - Gráfico da energia de deformação pela deformação( $\epsilon)$ do nanotubo(10,10). 
Executamos as seguintes etapas para obtermos os resultados utilizando dinâmica molecular:

1) No ambiente Visualizer do programa Materials criamos o nanotubo com $245.95 \AA$ de comprimento: (semelhante aos utilizados em medidas experimentais), fixando uma das suas extremidades;

2) Selecionamos o módulo Forcite Calculation com os parâmetros descritos na Figura 44 e realizamos uma dinâmica molecular.

3) A partir da trajetória descrita pela dinâmica, um programa em linguagem Perl extrai os dados fornecidos pelo programa Materials do deslocamento dos átomos da borda do nanotubo nas direções $x, y$ e $z$ e calcula os desvios padrões das amplitudes de vibrações destes átomos nestas direções;

4) Fazendo-se todas as substituições necessárias na equação 3.19, calcula-se os módulos de Young nas direções $x, y$, z. Também calculamos o módulo de elasticidade global quando consideramos as direções $\mathrm{x}, \mathrm{y}$ e $\mathrm{z}$.

Observamos que esta metodologia de Krishnan não é apropriada para nanotubos curtos, com $49.19 \AA$, pois analisando os dados da Tabela 10, que considera as direções $\mathrm{x}, \mathrm{y}$ e $\mathrm{z}$, concluímos que os valores, em média, estão bem abaixo dos encontrados pela técnica da segunda derivada da energia em relação à deformação. E mesmo que consideremos estes módulos somente na direção z, veja Tabela 11, é perceptível a diminuição destes valores.

Tabela 10 - Módulos de Young calculados pela metodologia do desvio padrão das amplitudes de vibrações nas direções x,y e z.

\begin{tabular}{|c|c|c|c|c|}
\hline \hline Tubo $(n, m)$ & Diâmetro $(\AA)$ & Comprimento $(\AA)$ & D.Padrão( $\sigma)$ & Mód.Young $(T P a)$ \\
\hline$(5,5)$ & 6.78 & 49.19 & 0.53 & 1.1 \\
$(6,6)$ & 8.14 & 49.19 & 0.62 & 0.51 \\
$(7,7)$ & 9.49 & 49.19 & 0.54 & 0.44 \\
$(8,8)$ & 10.85 & 49.19 & 0.72 & 0.17 \\
$(9,9)$ & 12.2 & 49.19 & 0.42 & 0.36 \\
$(10,10)$ & 13.56 & 49.19 & 0.58 & 0.14 \\
$(11,11)$ & 14.92 & 49.19 & 0.35 & 0.28 \\
$(12,12)$ & 16.27 & 49.19 & 0.41 & 0.17 \\
$(13,13)$ & 17.63 & 49.19 & 0.31 & 0.23 \\
$(14,14)$ & 18.98 & 49.19 & 0.33 & 0.16 \\
$(15,15)$ & 20.34 & 49.19 & 0.27 & 0.19 \\
\hline \hline
\end{tabular}

Neste trabalho, fizemos simulações com nanotubos com comprimentos e diâmetros próximos aos mesmos utilizados por A.Krishnan et al, com 96, 99 e 150 células, 
Tabela 11 - Módulos de Young calculados pela metodologia do desvio padrão das amplitudes de vibrações na direções $z$.

\begin{tabular}{|c|c|c|c|c|}
\hline \hline Tubo $(n, m)$ & Diâmetro $(\AA)$ & Comprimento $(\AA)$ & D.Padrão $(\sigma)$ & Mód.Young $(\mathrm{TPa})$ \\
\hline$(5,5)$ & 6.78 & 49.19 & 0.50 & 1.3 \\
$(6,6)$ & 8.14 & 49.19 & 0.46 & 0.93 \\
$(7,7)$ & 9.49 & 49.19 & 0.42 & 0.71 \\
$(8,8)$ & 10.85 & 49.19 & 0.39 & 0.57 \\
$(9,9)$ & 12.2 & 49.19 & 0.39 & 0.42 \\
$(10,10)$ & 13.56 & 49.19 & 0.35 & 0.38 \\
$(11,11)$ & 14.92 & 49.19 & 0.32 & 0.35 \\
$(12,12)$ & 16.27 & 49.19 & 0.30 & 0.30 \\
$(13,13)$ & 17.63 & 49.19 & 0.26 & 0.32 \\
$(14,14)$ & 18.98 & 49.19 & 0.27 & 0.25 \\
$(15,15)$ & 20.34 & 49.19 & 0.24 & 0.25 \\
\hline \hline
\end{tabular}

porque o sistema Materials não possibilitou o mesmos valores de comprimentos e diâmetros. No entanto, chegamos a resultados semelhantes (Tabela 12) nesta simulação computacional, esclarecendo que este autor chegou ao resultado dos módulos de elasticidade com medidas experimentais!

Tabela 12 - Comparações entre os Módulos de Young calculados pelo programa Materials e o calculado por A.Krishnan et al nas direções $x, y$ e $z$

\begin{tabular}{|c|c|l|c|c|c|c|}
\hline \hline Tubo $(n, m)$ & Células & Fonte & Diâm. $(\AA)$ & Comp. $(\AA)$ & $(\sigma)$ & Mód.Young $(\mathrm{TPa})$ \\
\hline$(8,8)$ & 96 & Presente & 10.85 & 236.11 & 2.57 & 1.50 \\
- & - & Krishnan & 11.20 & 234.00 & 3.00 & 1.02 \\
$(11,11)$ & 99 & Presente & 14.92 & 243.49 & 2.30 & 0.81 \\
- & - & Krishnan & 15.20 & 243.00 & 1.80 & 1.20 \\
$(11,11)$ & 150 & Presente & 14.92 & 367.69 & 3.01 & 1.60 \\
- & - & Krishnan & 15.00 & 368.00 & 3.30 & 1.33 \\
\hline \hline
\end{tabular}

Ao analisarmos a Tabela 12 concluímos que os valores calculados pelo programa Materials (Presente) diferem dos resultados experimentais de A.Krishnan et al em média de 33\% TPa. Embora Yakobson et al nos esclarece que os nanotubos de carbono, na realidade, possuem presença de luxações, falta de empilhamento, limites de grãos, vazios, defeitos pontuais, impurezas e má formação de redes. Sendo que os nanotubos utilizados no programa Materials são livres de todas esses problemas, ou seja, os nanotubos são ideais. Por tudo isso, chegamos a conclusão que os valores encontrados estão de acordo com os artigos já citados anteriormente, com o módulo de Young em torno de $1 \mathrm{TPa}$.

Procuramos, também, verificar se esta metodologia é condizente com os valores encontrados na literatura para nanotubos maiores, com 245,95 A. Para isto, simulamos 15 nanotubos (n,n), com 100 células, variando o seu diâmetro e calculando os valores 
para o módulo de Young nas direções x,y e z. A Tabela 13 e 14 nos mostra que os valores do módulo de Young, levando em consideração tanto a direção $\mathrm{z}$ quanto nas direções $x, y$ e $z$, dependem do raio do tubo, decrescendo à medida que o raio diminui e que os valores estão entre 5.0 TPa e 0,5 TPa, com média de valores de $1.08 \mathrm{TPa}$ (direção z) e $1.33 \mathrm{TPa}$ (direções x,y e z).

Tabela 13 - Módulos de Young calculados pela metodologia do desvio padrão das amplitudes de vibrações na direção z em SWNT(n,n) de 100 células.

\begin{tabular}{|c|c|c|c|c|}
\hline \hline Tubo $(n, n)$ & Diâmetro $(\AA)$ & Comprimento $(\AA)$ & D.Padrão( $\sigma)$ & Mód.Young $(\mathrm{TPa})$ \\
\hline$(5,5)$ & 6.78 & 245.95 & 2.73 & 5.30 \\
$(6,6)$ & 8.14 & 245.95 & 2.61 & 3.56 \\
$(7,7)$ & 9.49 & 245.95 & 2.49 & 2.56 \\
$(8,8)$ & 10.85 & 245.95 & 2.35 & 1.98 \\
$(9,9)$ & 12.20 & 245.95 & 2.29 & 1.50 \\
$(10,10)$ & 13.56 & 245.95 & 2.20 & 1.20 \\
$(11,11)$ & 14.92 & 245.95 & 2.01 & 1.09 \\
$(12,12)$ & 16.27 & 245.95 & 2.01 & 0.84 \\
$(13,13)$ & 17.63 & 245.95 & 1.91 & 0.74 \\
$(14,14)$ & 18.98 & 245.95 & 1.78 & 0.68 \\
$(15,15)$ & 20.34 & 245.95 & 1.74 & 0.58 \\
\hline \hline
\end{tabular}

Tabela 14 - Módulos de Young calculados pela metodologia do desvio padrão das amplitudes de vibrações nas direções x,y e z em SWNT(n,n) de 100 células.

\begin{tabular}{|c|c|c|c|c|}
\hline \hline Tubo(n,n) & Diâmetro $(\AA)$ & Comprimento $(\AA)$ & D.Padrão( $\sigma)$ & Mód.Young $(T P a)$ \\
\hline$(5,5)$ & 6.78 & 245.95 & 2.99 & 4.41 \\
$(6,6)$ & 8.14 & 245.95 & 3.10 & 2.53 \\
$(7,7)$ & 9.49 & 245.95 & 3.12 & 1.64 \\
$(8,8)$ & 10.85 & 245.95 & 2.46 & 1.81 \\
$(9,9)$ & 12.20 & 245.95 & 2.50 & 1.26 \\
$(10,10)$ & 13.56 & 245.95 & 2.27 & 1.13 \\
$(11,11)$ & 14.92 & 245.95 & 2.16 & 0.94 \\
$(12,12)$ & 16.27 & 245.95 & 2.10 & 0.77 \\
$(13,13)$ & 17.63 & 245.95 & 1.96 & 0.70 \\
$(14,14)$ & 18.98 & 245.95 & 1.95 & 0.57 \\
$(15,15)$ & 20.34 & 245.95 & 1.89 & 0.49 \\
\hline \hline
\end{tabular}

Acreditamos que os valores altos encontrados para os módulos de elasticidade para nanotubos com raios pequenos seja devido à maior aproximação das paredes e com isso havendo maior interação entre os átomos. Isso é explicável acha vista a espessura das paredes do nanotubo de aproximadamente $h=3.4 \AA$ (35). Então, ao considerarmos o diâmetro de um nanotubo $(5,5)$, por exemplo, concluímos que aproximadamente $7 \AA$ são usados somente para as espessuras das paredes. E de acordo com a Tabela 5 o diâmetro deste nanotubo é aproximadamente $7 \AA$ ! 
A Figura 47 nos mostra o decrescimento do módulo de elasticidade dos nanotubos descritos na Tabela 14 em função do raio e após o ajuste da curva descrita pelos pontos vermelhos, podemos notar que o módulo de elasticidade dos nanotubos de carbono é uma função dependente de $\frac{1}{R^{-2}}$, onde $\mathrm{R}$ é o raio do nanotubo. Tal comportamento também pode ser percebido no trabalho de Treacy (49), conforme é mostrado na Tabela 1, do Capítulo 1 e na Figura 48. Apesar dos nanotubos terem tamanhos diferentes na Tabela de Treacy et al, percebe-se que nos nanotubos que possuem tamanhos próximos há um decréscimo do módulo de elasticidade à medida que se aumenta o diâmetro. Além do que, nesta figura, podemos fazer várias combinações entre os pontos que mostram o decréscimo do módulo de Young em função do raio, caso desprezemos o comprimento do nanotubo.

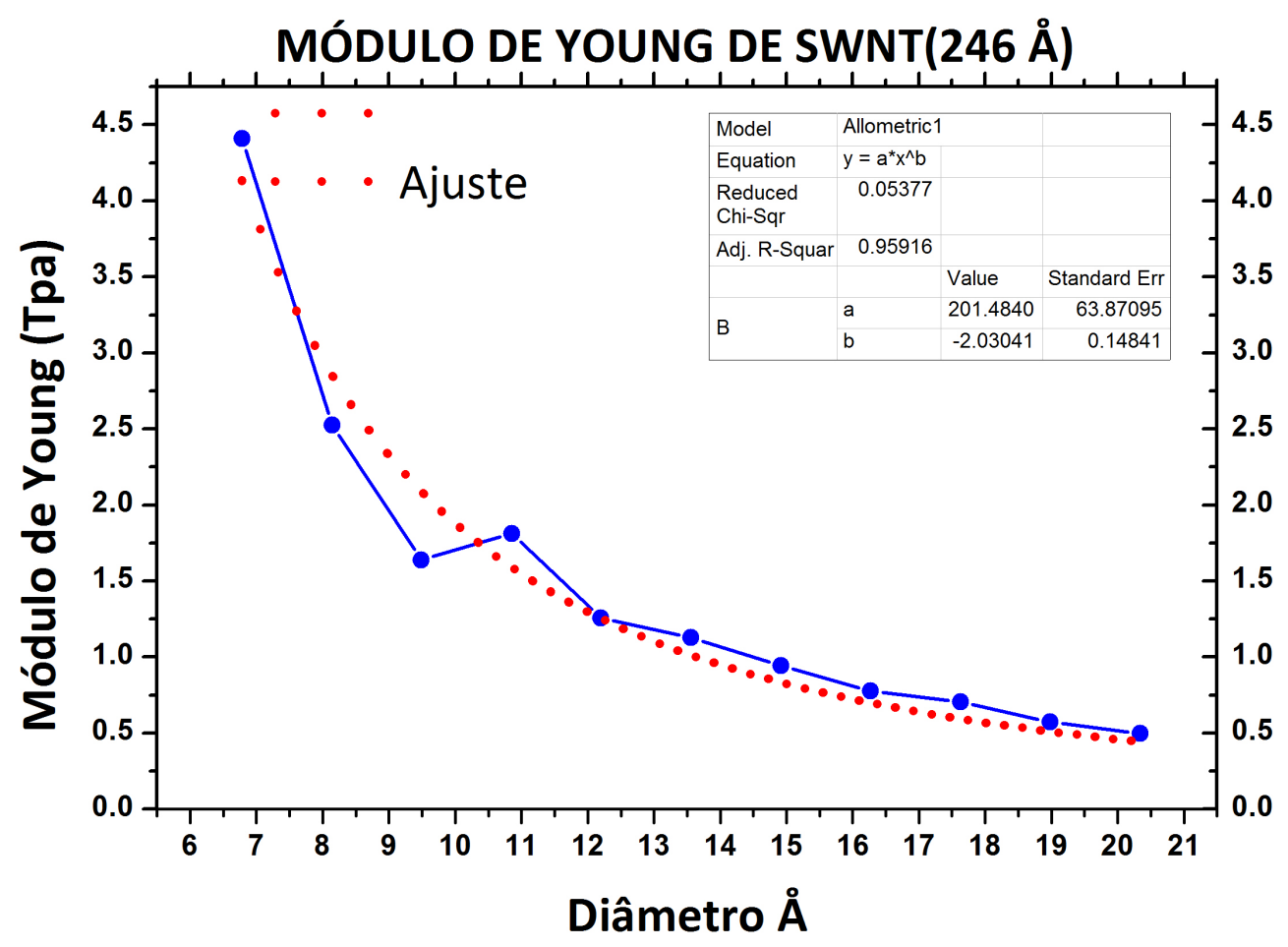

Figura 47 - Gráfico do módulo de Young dos nanotubos de carbono descritos na Tabela14. Os pontos em vermelho descrevem a curva $y=\frac{a}{x^{2}}$. 


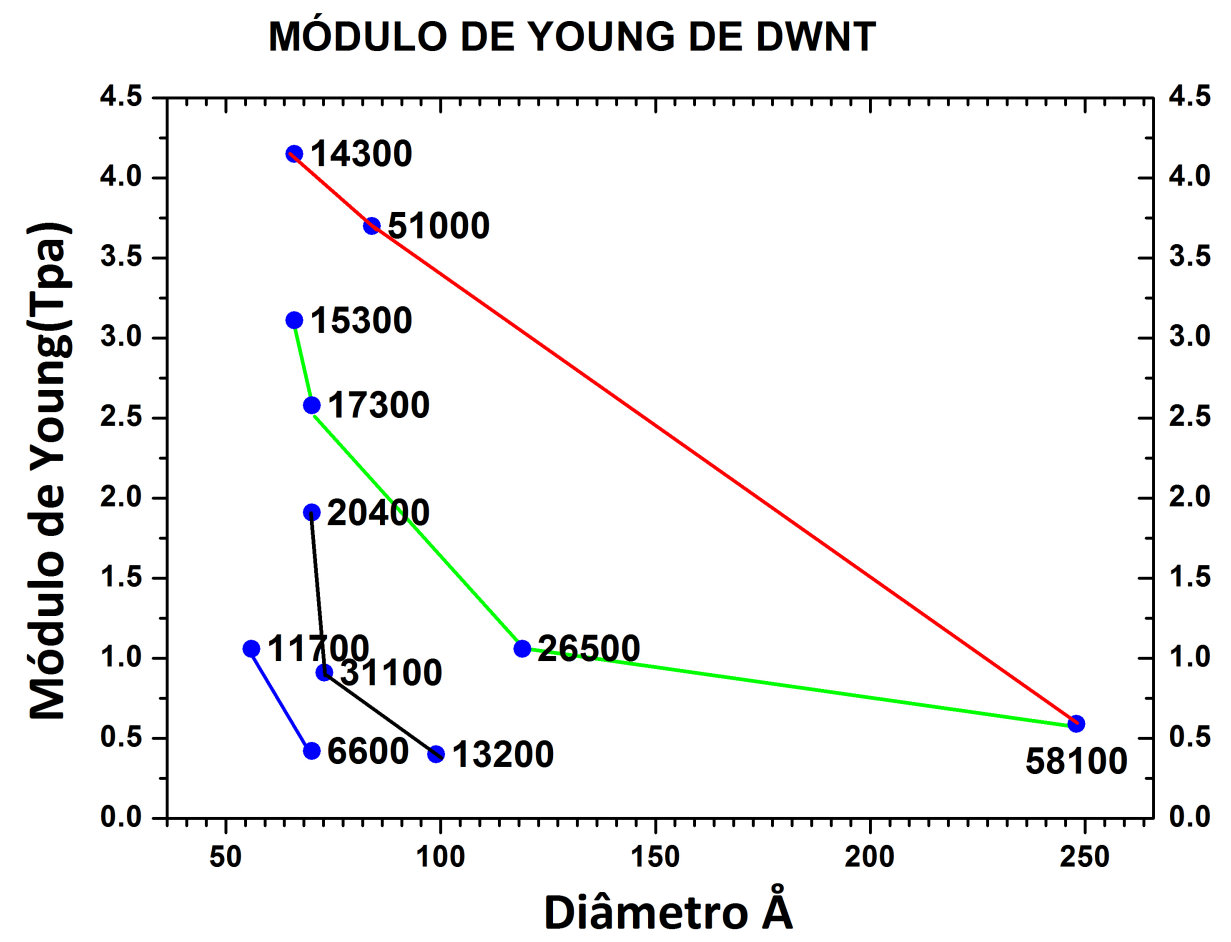

Figura 48 - Gráfico do módulo de Young dos nanotubos de carbono descritos na Tabela1. Módulo de Young decrescente em função do raio. Os números ao lado dos pontos representam os tamanhos dos nanotubos, em $\AA$.

\subsection{O MÓDULO DE ELASTICIDADE EM NANOTUBOS DE CAR- BONO PREENCHIDOS COM FULERENOS}

Agora que possuímos duas metodologias clássicas que nos dão os módulos de elasticidade tanto para nanotubos pequenos quanto para maiores, resolvemos calcular estes módulos em nanotubos armchair preenchidos com fulerenos. E como o diâmetro do fulereno é em torno de $7 \AA$, teríamos que utilizar nanotubos $(10,10),(11,11)$ e $(12,12)$, nos quais o diâmetros são $13.56 \AA$, $14.92 \AA$ e $16.27 \AA$, respectivamente.

Como já sabemos que o nanotubo encapsula naturalmente, simplesmente introduzimos os fulerenos dentro destes nanotubos, com espaçamento entre eles em torno de 3,0 A, otimizamos a estrutura e calculamos o módulo de Young. A Tabela 15 mostra estes cálculos tanto para os nanotubos de 20 células, como para os de 96, 99 e 150 células.

A Tabela 15 nos mostra que tanto o método da segunda derivada da energia da deformação pela deformação quanto o método das vibrações das amplitudes dão resultados próximos ou semelhantes e apenas o que devemos considerar quando queiramos usá-los é o tamanho dos nanotubos considerados no cálculo. E que o módulo de Young não se altera quando utilizamos o método da segunda derivada 
Tabela 15 - Comparações entre os valores dos Módulos de Young dos nanotubos armchair com e sem fulerenos na direção $\mathrm{z}$.

\begin{tabular}{|c|c|c|c|c|}
\hline \hline Tubo $(n, m)$ & Células & Diâm. $(\AA)$ & Comp. $(\AA)$ & Mód.Young(TPa) \\
\hline$(10,10)$ & 20 & 13.56 & 49.19 & 1.2 \\
C60@(10,10) & 20 & 13.56 & 49.19 & 1.2 \\
$(11,11)$ & 20 & 14.92 & 49.19 & 1.2 \\
C60@(11,11) & 20 & 14.92 & 49.19 & 1.2 \\
$(12,12)$ & 20 & 16.27 & 49.19 & 1.2 \\
C60@(12,12) & 20 & 16.28 & 49.19 & 1.2 \\
$(11,11)$ & 150 & 14.92 & 367.70 & 1.7 \\
C60@(11,11) & 150 & 14.92 & 367.70 & 1.3 \\
$(12,12)$ & 150 & 16.27 & 368.90 & 1.3 \\
C60@(12,12) & 150 & 16.27 & 368.90 & 0.9 \\
\hline \hline
\end{tabular}

para calcularmos os nanotubos encapsulados. Porém, quando utilizamos o método do desvio padrão há uma diferença para menos de em média 27\%.

Devido ao parágrafo anterior, acreditamos que esta metodologia para o cálculo do módulo de elasticidade em $C_{60}$ encapsulados em nanotubos de carbono de parede simples $\left(C_{60} @ S W N T\right)$ necessita de ajustes. É intuitivo pensar que ao encapsularmos o fulerenos em um nanotubo oco, deveria haver aumento de resistência e não nenhuma alteração ou mesmo diminuição. Embora saibamos que em nanotubos de paredes múltiplas, que possuem muitas camadas de grafeno enroladas (ver Figura 49), o módulo de elasticidade é em torno de 1 Tpa e que independe do números de camadas (36). Então poderíamos pensar que os $C_{60} @ S W N T$ (que estão entre as paredes dos nanotubos) teriam as mesmas resistências das folhas de grafeno. Sabemos que isto não é verdade porque ao mudar a geometria de uma molécula, alteraríamos suas características e propriedades. E a geometria do fulereno é parecida com um bola de futebol e não como uma folha de grafeno enrolada. Portanto, não podemos pensar que os $C_{60} S W N T$ tenham os módulos de elasticidade próximos a $1 \mathrm{TPa}$. Devido a isto, precisamos realizar um estudo mais apurado desta metodologia para podermos afirmar que os módulos de Young possam aumentar, diminuir ou mesmo se conservarem constantes. 


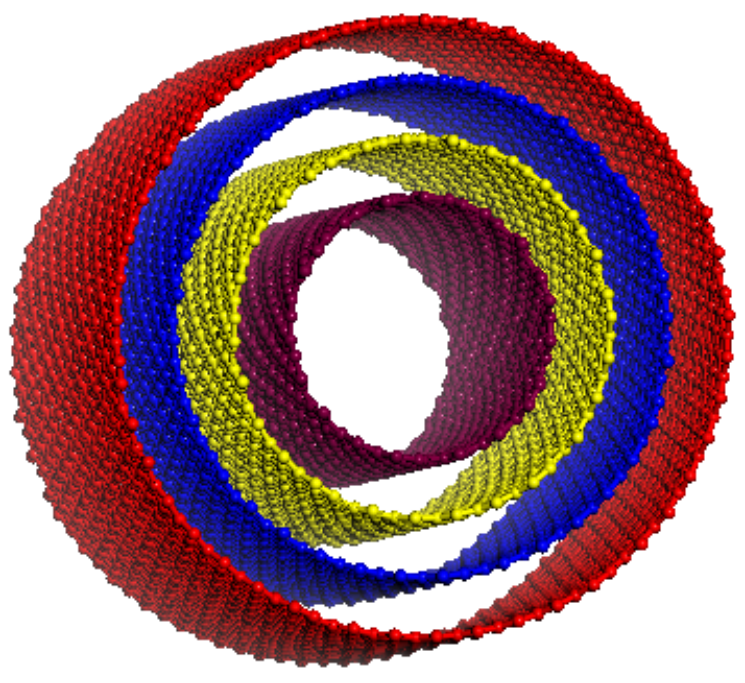

Figura 49 - Nanotubo de parede múltipla. 


\section{Conclusão}

Neste trabalho, chegamos a algumas conclusões relativas ao processo de encapsulamento e a obtenção de propriedades elásticas utilizando mecânica clássica e dinâmica clássica:

1) As forças de van der Walls, em nanotubos de carbono, quando estes se encontram próximos às bordas um do outro, atuam facilitando que um nanotubo encapsule no outro. Isso de forma natural, em temperatura ambiente. Encontramos uma regra simples que garante que o encapsulamento entre nanotubos:

a. Caso sejam armchair, o encapsulamento ocorre quando a diferença entre o índice quiral do nanotubo externo e interno for maior ou igual 5.

b. Caso sejam zig-zag, o encapsulamento ocorre quando a diferença entre o índice quiral do nanotubo externo e interno for maior ou igual 9.

2) Constatamos que fulerenos também encapsulam em nanotubos de carbono de forma natural e em temperatura ambiente. Sendo que o nanotubo funciona como um vaso capilar sugando a maioria dos fulerenos que se aproxima da borda. Já a magnitude do módulo de elasticidade do nanotubo é pouco afetado quando ocorre estes encapsulamentos em nanotubos pequenos, porém em nanotubos maiores há um decréscimo do módulo de Young em média de 27 \%.

3) Os nanotubos de paredes dupla (DWNT) também atraem os fulerenos, mostrando que estes não tem preferências em encapsular no nanotubo interno ou entre as paredes dos nanotubos. Mas, o mais importante é que haja espaço suficiente para que encapsulamento ocorra tanto no nanotubo interno, quanto entre as paredes dos nanotubos. Além do que, a disposição destes fulerenos no interior dos nanotubos (entre as paredes) é em formação circular em círculos paralelos.

4) Aplicamos de forma sistemática duas metodologias inteiramente clássicas para se calcular o módulo de elasticidade: a primeira, utilizamos o cálculo da segunda derivada da energia de deformação pela deformação para nanotubos pequenos; e a segunda, o cálculo do desvio padrão das amplitudes de vibração para nanotubos maiores. Com base nestas propriedades, foi possível determinar o módulo de elasticidade das diversas estruturas. Desta forma, pudemos comparar com os resultados experimentais e teóricos encontrados por diversos autores e concluímos a viabilidade, eficiência e confiabilidade destes métodos na obtenção do módulo de elasticidade em SWNT. 
5) O uso destas duas metodologias para o cálculo de $C_{60} @ S W N T$ ainda necessita de ajustes, haja vista que em $C_{60} @ S W N T$ de comprimentos pequenos, com poucas células, o módulo de Young é constante; e em $C_{60} @ S W N T$ de comprimentos grandes, com muitas células, há uma diminuição do módulo de Young em média de $27 \%$. Notamos que precisamos realizar um estudo mais apurado destas metodologias para podermos afirmar que os módulos de Young de $C_{60} @ S W N T$ possam aumentar, diminuir ou mesmo se conservarem constantes. 


\section{Referências}

1 VALCáRCEL, M. Analytical nanoscience and nanotechnology today and tomorrow. Springer, Springer Berlin Heidelberg, v. 374, n. 5, p. 1881-1887, 2008.

2 HOLM, B. A. Nanotechnology in biomedical applications. Taylor Francis, Taylor Francis, v. 391, n. 1, p. 589-598, 2002.

3 MCGEOUGH, J. Micromachining Engineering Materials. [S.l.: s.n.], 2002.

4 DZENIS, Y. Spinning continuous fibers for nanotechnology. Science, AAAS, v. 304, n. 5679, p. 1917-1919, 2004.

5 DRESSELHAUS, M. Science of Fullerenes e Carbon Nanotubes. [S.1.: s.n.], 1995.

6 CHEM101-6.1. 2016. Chem101. Disponível em: <http://www.saylor.org/courses / chem102-6.1>. Acesso em: 04 jan. 2016.

7 FRIEDEN. The Chemical Elements of Life. [S.1.]: Scientific American, 1972.

8 CARBONO. 2016. Wikipedia. Disponível em: <https://pt.wikipedia.org/wiki/ Carbono>. Acesso em: 07 jun. 2016.

9 KARLA. Prediction of ordered phases of encapsulated c 60 , c 70 , and c 78 inside carbon nanotubes. Nano Letters, American Chemical Society, v. 05, n. 2, p. 349-355, 2005.

10 KROTO. C60: Buckminsterfullerene. Nature, Nature, v. 318, p. 162, 1985.

11 MARTINS, J. L. Fulerenos: Uma Nova Família de Compostos de Carbono. [S.l.], 1993.

12 TAYLOR. Isolation, separation and characterisation of the fullerenes c60 and c70: the third form of carbon. Journal of the Chemical Society, Chemical Communications, Journal of the Chemical Society, Chemical Communications, v. 20, p. 1423-1425, 1990.

13 FILHO, R. R. Os Fulerenos. [S.1.], 1996.

14 KUMAR. X-ray raman scattering studies on c60 fullerenes and multi-walled carbon nanotubes under pressure. Diamond and Related Materials, Diamond and Related Materials, v. 16, p. 1250-1253, 2007.

15 XIE. vibrational and magnetic properties of a novel c48n12 aza-fullerene. Chemical Physics Letters, Chemical Physics Letters, v. 368, p. 486-494, 2003.

16 SMALLEY. Discovery of Fullerenes. [S.1.], 2010.

17 BING-SHE. Prospects and research progress in nanoonion-like fullerenes. New Carbon Materials, Elsevier, v. 23, p. 289-301, 2008.

18 SOUSA. Nano-osciladores formados por fulerenos e nanotubos: uma investigação teórica. Tese (Mestrado) — Universidade Federal da Bahia, 2006. 
19 CHADLI. Raman active modes in carbon peapods. Physica A, Physica A, v. 358, p. 226-236, 2005.

20 HAWKINS. Crystal structure of osmylated c60: confirmation of the soccer ball framework. Science, Sciense, v. 252, p. 312, 1991.

21 LIU. Fullerene. [S.1.]: Sci. and Tech, 1994.

22 KROTO. Buckminsterfullerene. Chemical reviews, Chemical reviews, v. 19, p. 1213, 1991.

23 ECHEGOYEN. Electrochemistry of fullerenes and their derivatives. Accounts of chemical research, ACS Publications, v. 31, p. 593-601, 1998.

24 HOLCZER. Alkali-fulleride superconductors: Synthesis,composition, and diamagnetic shielding. sciense, sciense, v. 252, p. 1154-1157, 1991.

25 TUTT. Optical limiting performance of c60 and c70 solutions. letters to nature, letters to nature, v. 356, p. 225-226, 1992.

26 ARBOGAST. Photophysical properties of sixty atom carbon molecule (c60). The journal of physicalchemistry, American Chemical Society, v. 95, p. 11-12, 1991.

27 ROUFF. The bulk modulus of c6,, molecules and crystals: A molecular mechanics approach. Appl. Physics Letters, American Institute of Physics, v. 59, n. 13, p. 1553-1557, 1991.

28 IIJIMA. S. Helical Microtubules of Graphitic Carbon. [S.l.: s.n.], 1991.

29 BETHUME. Cobalt-catalysed growth of carbon nanotubes with singleatomiclayer. [S.1.: s.n.], 1993.

30 SAITO. Physical Properties of Carbon Nanotubes. [S.1.: s.n.], 1998.

31 CALLISTER, W. D. Ciência e Engenharia de Materiais uma Introdução. Rio de Janeiro: LTC, 2012.

32 DRESSELHAUS, M. S. Carbon Nanotubes. [S.l.: s.n.], 2000.

33 TOMáNEK. Science and Application of Nanotubes. New York: Springer-Verlag, 2002.

34 PORTAL, S. Ab initio structural, elastic, and vibrational properties of carbon nanotubes. Physical Review, The American Physical Society, v. 59, n. 19, p. 12678-12687, 1998.

35 YAKOBSON. Fullerene nanotubes: C1000000 and beyond. American Scientist, Sigma Xi, The Scientific Research Society, v. 85, p. 324-337, 1997.

36 YAKOBSON. Mechanical properties of carbon nanotubes. Springer Link, Springer Berlin Heidelberg, v. 80, p. 287-327, 2001.

37 SAITO. Growth and structure of graphitic tubules and polyhedral particles in arc-discharge. Chemical Physics Letters, Elsevier, v. 204, p. 277-282, 1993.

38 AYALA. Efeitos de fonte precursora no controle da dopagem e ambiente químico em nanotubos decarbono dopados com nitrogênio. Tese (Doutorado) - PUC, 2007. 
39 NOSSOL. Novos eletrodos construídos a partir de diferentes nanoestruturas de carbono. Tese (Mestrado) — Universidade Federal do Paraná, 2009.

40 HERBEST. Tecnologia dos nanotubos de carbono: tendências e perspectivas de uma área multidisciplinar. Química Nova, Química Nova, v. 27, n. 6, p. 986-992, 2004.

41 GUO. Self-assembly of tubular fullerenes. NANO LETTERS, Journal Physical Chemistry, v. 99, p. 10694-10697, 1995.

42 PIEDIGROSSO. Production of different sharped multi-wall carbonnanotubes using various cobalt supported catalysts. Physical Chemistry Chemical, PCCP, v. 2, p. 163-169, 2000.

43 ROHMUND. A simple method for the production of large arrays of aligned carbon nanotubes. Chemical Physical letter, Chemical Physical letter, v. 328, n. 6, p. 369-373, 2000.

44 PUC. Sintetizando nanotubos. [S.1.].

45 YOUNG, H. D. Física I. São Paulo: Pearson, 2008.

46 HALLIDAY, D. Física I. Rio de Janeiro: LTC, 2009.

47 ROBERTSON, D. H. Energetics of nanoscale graphitic tubules. Physical Review B, The American Physical Society, v. 45, n. 21, p. 12592-12595, 1992.

48 TIBBETTS, G. G. Why are carbon filaments tubular? Journal of Crystal Growth, North-Holland Physics Publishing Division, v. 66, n. 1984, p. 632-638, 1983.

49 TREACY. Exceptionally high young's modulos observed for individual carbon nanotubes. NATURE, Nature, v. 381, n. 20, p. 678-680, 1996.

50 LU, J. P. Elastic Properties of Carbon Nanotubes and Nanoropes. [S.1.], 2008.

51 HERNáNDEZ, E. Elastic Properties of $C$ and $B_{x} C_{y} N_{z}$ composite nanotubes. [S.1.], 1998.

52 KRISHNAN, A. Young's modulus of single-walled nanotubes. Physical Review B, The American Physical Society, v. 58, n. 20, p. 14013-14019, 1998.

53 SCHLICK, T. Molecular Modeling and Simulation. [S.l.: s.n.], 2010.

54 ATTILA. Modern Quantum Chemistry. New York-EUA: Dover Publications, 1996.

55 ANDREW. Molecular Modelling-PRINCIPLES AND APPLICATIONS. [S.l.: s.n.], 2001.

56 CARVALHO, I. Introdução à modelagem de fármacos no curso experimental de química farmacêutica. Quim. Nova, Quim. Nova, v. 26, n. 03, p. 428-438, 2003.

57 BRUCKNER, R. Organic Mechanism. Columbia-EUA: Springer, 2010.

58 NAMBA, A. M. Dinâmica molecular: teoria e aplicações em planejamento de fármacos. Eclética Química, Ecl. Química, v. 33, n. 4, p. 208, 2008. 
59 VERLET, L. Computer "experiments" on classical fluids. ii. equilibrium correlation functions. APS journals Archive, American Physical Society, v. 165, n. 1, p. 201, 1965.

60 BARTELL, L. Chem.Phys. [S.l.: s.n.], 1967.

61 BOYD, H. The Sciense of Polymer Molecule. New york: University of Cambridge, 1996.

62 ALLINGER, N. L. Conformational analysis. 130. $\mathrm{mm} 2$. a hydrocarbon force field utilizing v1 and v2 torsional terms. Journal of the American Chemical Society, ACS Publications, v. 99, n. 25, p. 8127-8134, 1977.

63 EISBERG, R. Atomos, Moléculâs, Sólidos. Santa Bárbara-Instituto Politécnico Rensselaer-23a: Universidade da Califórnia, 2013.

64 L., C. APLICAÇÃO DE MECÂNICA MOLECULAR EM QUÍMICA INORGÂNICA. [S.1.], 1998.

65 BARTEL. Representations of molecular force fields. v. on the equilibrium structure of methane. J.Quim. Phis, American Institute of Physics, v. 68, n. 3, p. 1213-1215, 1977.

66 MORSE. Diatomic molecules according to the wave mechanics. ii. vibrational levels. APS Journals Archieve, American Physical Society, v. 34, n. 57, p. 1, 1929.

67 BURDEN, R. Numerical Analysis. Boston-EUA: Brooks/Cole, 2010.

68 JUARISTI, E. Introdução à Estereoquímica e à Análise Conformacional. [S.1.: s.n.], 2012.

69 ATKINS, P. Princípios de Química. Porto Alegre-RS: Bookman, 2005.

70 VOET, D. The Molecules of Life. New York-EUA: Garland Sciense, 2013.

71 VOET, D. Bioquímica. Porto Alegre-RS: Artmed, 2006.

72 LENNARD-JONES, J. Young's modulus of single-walled nanotubes. IOP Sciense, Physical Society, v. 43, n. 5, p. 461, 1931. 